DUCE, MAURICIO. "El Derecho a un Juzgamiento Especializado de los Jóvenes Infractores en el Nuevo Proceso Penal Juvenil Chileno". Polit. crim. Vol. 5, No 10 (Diciembre 2010), Art. 1, pp. 280-340. [http://www.politicacriminal.cl/Vol_05/n_10/Vol5N10A1.pdf]

\title{
El Derecho a un Juzgamiento Especializado de los Jóvenes Infractores en el Nuevo Proceso Penal Juvenil Chileno ${ }^{1}$
}

\author{
Mauricio Duce Julio \\ Magíster en Ciencias Jurídicas Universidad de Stanford, Profesor Titular Facultad de \\ Derecho Universidad Diego Portales \\ mauricio.duce@udp.c1
}

\section{Resumen}

El presente trabajo corresponde a la tercera parte de una investigación realizada con el propósito de revisar los alcances del derecho a un juzgamiento especializado de los jóvenes que cometen delitos. El proyecto ha identificado la existencia de estándares especiales para el juzgamiento de niños y adolescentes por infracciones penales y luego ha pretendido establecer la manera en que ellos son recogidos por las legislaciones nacionales. En este contexto, el objetivo específico del presente trabajo es analizar la forma en que dicho derecho ha sido regulado en la normativa nacional $\mathrm{y}$, especialmente, como ha sido desarrollado en la práctica de los actores del sistema, principalmente a nivel jurisprudencial. Este derecho es analizado en tres ejes centrales: reforzamiento del debido proceso; aspectos de estructura procesal; y, necesidad de contar una política amplia de diversificación de respuestas y desestimación de casos.

\section{Palabras claves}

Proceso Penal Juvenil, Juzgamiento Especializado, Jurisprudencia Tribunales Superiores.

\begin{abstract}
This paper is the third part of an investigation made with the purpose of reviewing the scope of the right of the juveniles to be judged by a specialized system in criminal cases in comparison with the prosecution of crimes committed by adults. The project established that there are special standards developed in the subject and also attempted to identify their use in national legislations. In this context, the specific goal of the paper is to analyze how this right has been introduced in the Chilean legislation but more specifically the way in which our High Courts have developed their contents in the case law. For those purposes the paper focuses its analysis in three main axes: strengthening of due process guarantees;

\footnotetext{
${ }^{1}$ Este texto corresponde a un producto de trabajo desarrollado en el contexto de la ejecución de un proyecto Fondecyt n ${ }^{\circ} 1080644$ denominado "El Principio de Especialidad en el Derecho Penal y Procesal Penal de Adolescentes. Análisis Dogmático y Jurisprudencial" adjudicado para el período comprendido entre los años 2008-2010. En dicho proyecto tengo la calidad de co-investigador, correspondiendo al profesor Jaime Couso la calidad de investigador responsable. Quiero agradecer el valioso apoyo de investigación para la elaboración de este trabajo realizado por la ayudante del proyecto Andrea Collell quien efectuó la observación de audiencias y contribuyó en la recopilación de jurisprudencia y doctrina nacional. También al alumno ayudante Jaime Cerda quien me apoyó en la edición final del texto.
} 
DUCE, MAURICIO. "El Derecho a un Juzgamiento Especializado de los Jóvenes Infractores en el Nuevo Proceso Penal Juvenil Chileno".

aspects of procedural structure, and necessity of having a broad policy of diversification of cases.

\section{Key words}

Juvenile Criminal Procedure, Specialized Judgment, High Court Case Law.

\section{Introducción}

El presente trabajo corresponde a la tercera parte de una investigación realizada con el propósito de revisar los alcances del derecho a un juzgamiento especializado ${ }^{2}$ de los jóvenes que cometen delitos. Se pretende identificar la existencia de estándares especiales para el juzgamiento de niños y adolescentes por infracciones penales y luego establecer la manera en que ellos son recogidos por las legislaciones nacionales. Así, en una primera etapa, se avanzó en identificar la manera en que este derecho ha sido consagrado en el derecho internacional de los derechos humanos (tantos en normas internacionales generales como en otros instrumentos especializados). ${ }^{3}$ Luego se revisó como ha sido recogido y desarrollado en el derecho y jurisprudencia comparada (analizando cuatro países específicos: Alemania, Costa Rica, España y Estados Unidos). ${ }^{4}$ Finalmente, en esta última etapa, se pretende ver cómo ha sido incorporado en el nuevo sistema de responsabilidad penal juvenil instalado en nuestro país a partir del año 2007.5 En este contexto, el objetivo especifico del presente trabajo es analizar la forma en que dicho derecho ha sido regulado en la normativa nacional y, especialmente, como ha sido desarrollado en la práctica de los actores del sistema, principalmente a nivel jurisprudencial. Por lo mismo, este trabajo se estructura considerando como marco la información producida en las dos etapas previas a la cual sólo haré referencias de carácter general.

Para cumplir con el objetivo descrito, la presente investigación se ha basado centralmente en cuatro fuentes diversas de información. En primer lugar, se ha realizado una revisión de la literatura disponible en nuestro país, tanto de libros como artículos de carácter académico, producidos en el contexto del nuevo sistema de responsabilidad penal juvenil. ${ }^{6}$ En segundo término, se ha realizado una revisión de la jurisprudencia desarrollada por las Cortes de Apelaciones y Suprema del país desde la entrada en vigencia del nuevo sistema

\footnotetext{
${ }^{2}$ Este derecho será identificado también en este trabajo como el "Principio de Especialidad" de la justicia penal juvenil.

${ }^{3}$ Véase DUCE, Mauricio, "El Derecho a un Juzgamiento Especializado de los Jóvenes Infractores en el Derecho Internacional de los Derechos Humanos y su Impacto en el Diseño del Proceso Penal Juvenil", Ius et Praxis, ${ }^{\circ} 1$ (2009), pp. 73-120.

${ }^{4}$ Véase DUCE, Mauricio; COUSO SALAS, Jaime, El Derecho a un Juzgamiento Especializado de los Jóvenes Infractores en el Derecho Comparado, Documento no Publicado, disponible en formato electrónico en los archivos del autor.

${ }^{5}$ Véase Ley ${ }^{\circ} 20.084$ que Establece un Sistema de Responsabilidad de los Adolescentes por Infracciones a la Ley Penal (en adelante LRPA), publicada en el Diario Oficial el 7 de diciembre de 2005. El texto original ha sido objeto de modificaciones posteriores en dos ocasiones (Leyes $\mathrm{n}^{\circ} 20.110 \mathrm{y} \mathrm{n}^{\circ} 20.191$ ).

${ }^{6}$ Desafortunadamente se trata de una literatura todavía no muy abundante y que, en una porción significativa, tiene mas pretensiones de revisión sistemática de las reglas que un análisis en detalle y con profundidad de las mismas.
} 


\section{Polit. crim. Vol. 5, № 10 (Diciembre 2010), Art. 1, pp. 280-340. [http://www.politicacriminal.cl/Vol_05/n_10/Vol5N10A1.pdf]}

hasta el año 2009. ${ }^{7}$ Además, se ha realizado una observación de audiencias en juzgados de garantía de la ciudad de Santiago. ${ }^{8}$ Finalmente, estas fuentes han sido complementadas con una revisión de las estadísticas disponibles del sistema y otros estudios de carácter empírico que han intentando evaluar su impacto. Este conjunto de fuentes de información nos permiten construir una visión no solo acerca de los elementos de diseño teórico del sistema, sino que también de su operación concreta y de cómo las diversas instituciones son utilizadas en su funcionamiento diario. Con todo, la orientación central de este trabajo es de identificación dogmática de los elementos de especialidad recogidos por nuestra legislación y jurisprudencia más que descripción o evaluación empírica de funcionamiento del nuevo sistema de responsabilidad juvenil.

Al igual que en los trabajos que han precedido a este, el derecho a un juzgamiento especializado será analizado en tres ejes centrales que he identificado forman parte del núcleo central del "principio de especialidad" en la materia. Estos tres ejes son: reforzamiento del debido proceso; aspectos de estructura procesal; y, necesidad de contar una política amplia de diversificación de respuestas y desestimación de casos. ${ }^{9}$

Para cumplir con los objetivos descritos, el presente trabajo se divide en cuatro capítulos más esta introducción. Los capítulos uno a tres estarán destinados a revisar la forma en que

\footnotetext{
${ }^{7}$ La captura de jurisprudencia se hizo en las bases de datos de Legal Publishing y Microjuris entre los meses de agosto y septiembre de 2009. La búsqueda se basó en palabras claves relacionadas con el sistema de responsabilidad penal adolescente. Con este método se tuvo acceso a 68 sentencias de Cortes de Apelaciones y 17 sentencias de la Corte Suprema. Dicha búsqueda fue complementada entre los meses de enero y marzo de 2010 con la revisión de publicaciones periódicas especializadas y sitios web que hacen seguimiento jurisprudencial para identificar fallos posteriores u anteriores no incluidos en la búsqueda de las bases de datos referidas. Esto nos permitió identificar otras 11 sentencias de Cortes de Apelaciones y 4 de la Corte Suprema. Esto sin considerar otras sentencias que son objeto de análisis en algunos textos que citaré en el desarrollo del trabajo.

${ }^{8}$ Las audiencias fueron observadas en el mes de enero de 2009 en el Centro de Justicia de Santiago en donde se observaron 181 audiencias de control de detención y 29 audiencias programadas. En cada audiencia se tomaron notas en una pauta de recolección de información preparada al efecto y luego dicha pauta fue revisada y completada con la escucha de los audios de las mismas audiencias. Las audiencias de control de la detención corresponden a todos los Juzgados de Garantía del Centro de Justicia y las audiencias programadas exclusivamente el $13^{\circ}$ Juzgado que concentraba en esa época el conocimiento de las materias de la LRPA. Tanto las pautas de recopilación de información como los audios se encuentran a disposición de los investigadores del proyecto.

${ }^{9}$ Al igual que en los otros componentes de esta investigación, no será parte de este texto el análisis del impacto que debiera tener el derecho ser juzgado por un sistema especializado a nivel de las reglas que regulan los aspectos de diseño orgánico del sistema de justicia juvenil por infracciones a la ley penal. La razón de no abordar los aspectos orgánicos se debe a que esta dimensión lleva al análisis de los más diversos tipos de arreglos institucionales, tanto respecto a la forma de organizar a las instituciones que integran al sistema de justicia, como en sus sistemas de capacitación y entrenamiento, selección de personal, entre otras múltiples variables que nos alejan de los aspectos en los que más directamente recae la legislación procesal propiamente tal y sobre los cuales se pronuncia la jurisprudencia. Con todo, me parece indispensable dejar en claro que dicha dimensión es esencial para el cumplimiento adecuado tanto de los aspectos procesales como los substantivos del derecho a un juzgamiento especializado y se trata de un tema en que nuestro sistema de responsabilidad penal juvenil tiene debilidades importantes que podrían explicar muchas de las prácticas que se describirán a lo largo de este trabajo. La opción de no abordar los aspectos orgánicos del sistema no significa, en todo caso, que algunas cuestiones que revisaré no tengan un impacto en aspectos orgánicos del sistema, sino simplemente que el enfoque del trabajo no es abordar desde esa perspectiva las consecuencias del derecho de los jóvenes a ser juzgado en un sistema especializado.
} 
DUCE, MAURICIO. "El Derecho a un Juzgamiento Especializado de los Jóvenes Infractores en el Nuevo Proceso Penal Juvenil Chileno".

han sido recogidos los elementos centrales del derecho a un juzgamiento especializado de los jóvenes infractores, agrupados en los tres ejes que ya han sido mencionados: reforzamiento del debido proceso (capítulo uno); aspectos de estructura procesal (capítulo dos); y, necesidad de contar una política amplia de diversificación de respuestas y desestimación de casos (capítulo tres). El trabajo finalizará en su capítulo cuarto con algunas breves conclusiones y comentarios generales.

Antes de dar inicio al análisis es necesario señalar una cuestión general acerca de la estructura del proceso penal juvenil contemplado en nuestra LRPA. De acuerdo a lo que establece su artículo 27, la investigación, juzgamiento y ejecución de la responsabilidad por infracciones a la ley penal por parte de adolescentes se rige tanto por las normas de la propia LRPA como supletoriamente por la del Código Procesal Penal (en adelante el CPP). Una observación general de la LRPA muestra con claridad que la regulación específica procesal que contiene ésta es relativamente escueta. En efecto, las normas de procedimiento están contenidas en su título II que incluye sólo 15 artículos (desde el 27 al 41) destinados al procedimiento. En un análisis más detallado de estas normas se puede apreciar que los párrafos $1^{\circ}$ y $2^{\circ}$, referidos a disposiciones generales y al sistema de justicia, no contemplan normas de regulación estrictamente procesal, por lo que la cantidad total de artículos destinados a regular el proceso penal juvenil disminuye a 11. Como podrá intuir el lector, se trata de una legislación relativamente escasa para desarrollar de manera completa y en detalle las complejidades de un proceso de carácter penal. ${ }^{10}$ Esto tiene como consecuencia que buena parte del proceso contemplado en la LRPA descanse en el diseño del CPP. ${ }^{11}$ Desde este punto de vista, es posible afirmar que, en términos generales, los niveles de especialidad recogidos en la LRPA son bastante limitados. ${ }^{12}$ Por lo mismo, me parece que para tener una visión clara del grado de reconocimiento del derecho a un juzgamiento especializado de los jóvenes en nuestro país el estudio no debe detenerse exclusivamente en un análisis de las disposiciones de la LRPA, sino que debe incluir el cómo la idea de especialidad ha sido reconocida por la jurisprudencia de los tribunales más allá del texto legal. $^{13}$

\footnotetext{
${ }^{10}$ A modo de referencia puede tenerse presente el Código Procesal Penal, que regula el proceso penal para los adultos, contiene 485 artículos.

${ }^{11}$ Se trata de un elemento de diseño del sistema que viene desde la versión original del proyecto presentado por el ejecutivo en agosto del año 2002 para su tramitación legislativa. Sobre esta elección realizada por el legislador en Chile Bustos ha señalado críticamente que "...la LRPA ha sido sumamente tradicional, a pesar que ya existen diferentes modelos alternativos que podrían haberse utilizado y que son mucho más adecuados para un derecho penal del adolescente". Véase BUSTOS, Juan, Derecho Penal del Niño-Adolescente, Santiago: Ediciones Jurídicas de Santiago, 2007, pp. 71 y 72.

${ }^{12}$ Un análisis del proyecto original en este mismo sentido, pero también recogiendo algunas ventajas del modelo escogido véase en DUCE, Mauricio, "El Proceso Establecido en el Proyecto de Ley que Crea un Sistema de Responsabilidad de los Adolescentes por Infracciones a la Ley Penal: Avances y Problemas", Revista de Derechos del Niño, Santiago: $\mathrm{n}^{\mathrm{o}} 2$ (2004), pp. 99-113 (véase especialmente pp. 100-102). En el mismo sentido pronunciándose sobre la LRPA véase CERDA, Mónica; CERDA, Rodrigo, Sistema de Responsabilidad Penal para Adolescentes, Santiago: Librotecnia, 2007, p. 159.

${ }^{13}$ En efecto, por las propias disposiciones de la LRPA (artículo $2^{\circ}$ inciso segundo) los tribunales deben considerar en su aplicación todos los derechos y garantías que son reconocidos en la Convención de Derechos del Niño y en los demás instrumentos internacionales ratificados por Chile que se encuentren vigentes. Esto abre un enorme espacio de construcción para la jurisprudencia nacional. Un ejemplo en el cual nuestra jurisprudencia avanza en la incorporación de la legislación internacional en materia de adolescentes como parámetro para resolver cuestiones no establecidas en la LRPA puede verse en un reciente fallo de la Corte de
} 
Polit. crim. Vol. 5, № 10 (Diciembre 2010), Art. 1, pp. 280-340.

[http://www.politicacriminal.cl/Vol_05/n_10/Vol5N10A1.pdf]

\section{Primer eje: reforzamiento del debido proceso de los jóvenes respecto de los adultos en el sistema chileno.}

Un primer eje temático en donde el principio de especialidad tiene un impacto relevante en materia procesal penal es en la necesidad de reforzar ciertas garantías que integran al debido proceso tratándose de los jóvenes imputados por infracciones penales, cuestión que ha sido reconocida ampliamente por la doctrina y en el derecho internacional de los derechos humanos. ${ }^{14}$ Un análisis más específico de los instrumentos del sistema internacional lleva a concluir que los principales aspectos en donde el principio de especialidad se traduce en diferencias significativas de reforzamiento o ampliación de garantías del debido proceso son cuatro: El fortalecimiento de la libertad y las mayores restricciones a su privación en el proceso; exigencias más estrictas respecto a la extensión temporal del proceso; mayores resguardos al derecho de defensa (en diversas manifestaciones); y, exigencias más estrictas para la renuncia de derechos del debido proceso. A continuación revisaré la manera en que cada uno de estos cuatro temas ha sido consagrado a nivel normativo y luego desarrollado jurisprudencialmente en nuestro país.

\subsection{Fortalecimiento de la libertad y mayores restricciones a su privación en el proceso.}

La privación de libertad en el proceso a la espera de una decisión definitiva constituye una de las afectaciones más significativas a los derechos de las personas objeto de una investigación criminal y, por lo mismo, es objeto de preocupación especial en la legislación internacional de derechos humanos y comparada tanto tratándose de adultos como jóvenes. ${ }^{15}$ El punto que justifica esta preocupación es que los niños y jóvenes, por su estado de desarrollo, se encuentran en una situación de vulnerabilidad mayor que los adultos que hacen que los efectos negativos de la privación de libertad sean más profundos y tengan consecuencias que se extiendan por un período más largo en el tiempo. Estas exigencias más altas debieran traducirse en nuestra legislación en mayores restricciones a la procedencia de esta medida, a su duración temporal y a las condiciones de su cumplimiento. A continuación se revisará como cada uno de estos aspectos han sido recogidos en nuestro país.

\subsubsection{Procedencia de la internación provisoria.}

La definición básica que debiera regir la procedencia de la prisión preventiva (o como la denomina la LRPA "internación provisoria") en nuestro país es que esta constituye una medida cautelar excepcional tratándose de jóvenes imputados por infracciones penales. Esta definición no se encuentra de manera explícita contenida en la LRPA, pero indirectamente se contempla por hacerse aplicables las reglas generales del CPP en donde dicho principio se expresa de manera clara, como por ejemplo el artículo 139 inciso

Apelaciones de Temuco como producto de un recurso de protección. Véase Sentencia de la Corte de Apelaciones de Temuco rol n ${ }^{\circ}$ 545-2010 (recurso de protección) de 13 de mayo de 2010.

${ }^{14}$ DUCE, "El Derecho a un Juzgamiento", cit. nota n ${ }^{\circ} 3$, pp. 82 y ss.

${ }^{15}$ DUCE, "El Derecho a un Juzgamiento", cit. nota n ${ }^{\circ}$ 3, pp. 85-86 y DUCE / COUSO, El Derecho a un Juzgamiento, cit. nota $\mathrm{n}^{\circ} 4$. 


\section{DUCE, MAURICIO. "El Derecho a un Juzgamiento Especializado de los} Jóvenes Infractores en el Nuevo Proceso Penal Juvenil Chileno".

segundo del mismo. ${ }^{16}$ Por otra parte, se trata de un principio que encuentra amplio reconocimiento en la doctrina nacional de adultos y que, por tanto, en el que no debieran haber problemas para su reconocimiento en materia juvenil. ${ }^{17}$

Lo que en un principio aparece como una carencia de la LRPA, es corregido por la existencia de varias disposiciones específicas que va mas allá que la consagración de este principio como una declaración general y que dan cuenta de una voluntad clara del legislador nacional respecto a que el uso de la internación provisoria de los jóvenes debiera ser más excepcional que el uso de la prisión preventiva tratándose de adultos. ${ }^{18}$ En efecto, la principal norma al respecto está contenida en el artículo 32 de la LRPA. En su redacción actual este artículo regula el tema estableciendo dos reglas que limitan el uso de la internación provisoria. ${ }^{19}$ En la primera de ellas se establece que la internación provisoria "...solo será procedente tratándose de la imputación de las conductas que de ser cometidas por una persona mayor de 18 años constituirán crímenes...". Como se puede apreciar, se trata de una norma que restringe de manera muy significativa el universo posible de casos objeto de esta medida cautelar, tratándose de la imputaciones de figuras penales de gravedad. Para tener un punto de comparación con el sistema de adultos, debe recordarse que el CPP solo limita la procedencia de la prisión preventiva en su artículo 141 a) cuando se trate de delitos que únicamente tuvieran prevista como sanción las penas pecuniarias o privativas de derecho. En consecuencia, la LRPA representa una clara limitación en el uso de esta medida cautelar y una ampliación relevante de la idea de excepcionalidad establecida en nuestro CPP. Por lo mismo se puede concluir que en este punto en reforzamiento de la garantía de la libertad que hace la LRPA es muy significativo.

\footnotetext{
${ }^{16}$ Dicha disposición señala: "La prisión preventiva procederá cuando las demás medidas cautelares personales fueren estimadas por el juez como insuficientes para asegurar las finalidades del procedimiento, la seguridad del ofendido o de la sociedad". Esta norma debe ser complementada con el artículo 122 referido a las medidas cautelares personales en general que señala que éstas “....sólo serán impuestas cuando fueren absolutamente indispensables para asegurar la realización de los fines del procedimiento y sólo durarán mientras subsistiere la necesidad de su aplicación" Esta idea de excepcionalidad también ha sido reconocida por la jurisprudencia de la Corte Suprema en materia de LRPA en la causa rol n ${ }^{\circ}$ 6811-08, sentencia de 11 de noviembre de 2008. Por tratarse de una sentencia que centra su desarrollo en el tema de la extensión temporal de la internación provisoria reservaré su análisis detallado para la próxima sección de este trabajo.

${ }^{17}$ No parece existir discrepancia sobre este punto en la literatura nacional en el ámbito de los adultos. Véase, entre otros: HORVITZ, María Inés; LÓPEZ, Julián, Derecho Procesal Penal Chileno, Tomo I, Santiago: Editorial Jurídica de Chile, 2002, p. 352; CHAHUÁN, Sabas, Manual del Nuevo Procedimiento Penal, Santiago: Lexis Nexis, 2007, pp. 220-221; CASTRO, Javier, Introducción al Derecho Procesal Penal Chileno, Santiago, Legal Publishing, 2008, p. 272, CERDA, Rodrigo, Manual del Nuevo Sistema de Justicia Criminal, Santiago: Librotecnia, 2005, p. 207; y DUCE, Mauricio; RIEGO, Cristián, Proceso Penal, Santiago: Editorial Jurídica, 2007, pp. 250-251.

${ }^{18}$ En este sentido BERRÍOS, Gonzalo, Jóvenes Presos: La Otra "Cota Mil”, Santiago: La Tercera, Miércoles 25 de Febrero de 2009, p 2.

${ }^{19}$ El artículo 32 fue modificado por la Ley no 20.191 publicada en el Diario Oficial el 2 de junio de 2007 con el objetivo de aclarar el contenido de su redacción original que se presento para debates y confusiones. Como señala el mensaje, esta reforma “... resuelve los problemas de interpretación que podrían suscitarse con respecto a la internación provisoria, estableciendo en la norma la procedencia de esta cautelar personal cuando la pena en abstracto lo permita." Véase Mensaje $\mathrm{N}^{\circ} 170-355$ de S.E. la Presidenta de la República, p. 4. En este mismo sentido también véase Fiscalía Nacional, Oficio $n^{0} 687$ de 23 de mayo de 2007, Instructivo $\mathrm{n}^{\mathrm{o}} 12$ de la ley $\mathrm{n}^{\mathrm{o}} 20.084$, p. 8 .
} 


\section{Polit. crim. Vol. 5, № 10 (Diciembre 2010), Art. 1, pp. 280-340. [http://www.politicacriminal.cl/Vol_05/n_10/Vol5N10A1.pdf]}

Además de esta primera regla, el artículo 32 señala que, aun en los casos en que proceda, la internación provisoria solo debiera aplicarse "...cuando los objetivos señalados en el inciso primero del artículo 155 del Código Procesal Penal no pudieren ser alcanzados mediante la aplicación de alguna de las demás medidas cautelares personales". Es decir, se establece, tal como lo recomienda la legislación internacional, que se privilegie el uso de las alternativas a la internación reguladas en la legislación procesal penal ordinaria. Visto desde otro ángulo, sólo sería procedente el uso de la internación provisoria cuando ninguna otra medida cautelar permitiere cumplir con los objetivos de cautela del sistema.

Finalmente, el artículo 33 de la LRPA establece una limitación adicional que nuestra legislación procesal penal de adultos no regula de manera explícita: el denominado "principio de proporcionalidad" de las medidas cautelares. ${ }^{20}$ De acuerdo a lo que señala la norma en estudio "En ningún caso podrá el juez dar lugar a una medida que parezca desproporcionada en relación con la sanción que resulte probable de aplicar en caso de condena". Se trata de un principio general para las medidas cautelares ${ }^{21}$ pero que, tratándose de la internación provisoria de los jóvenes, cumple la función de poner un límite adicional en casos en que no obstante imputarse un hecho constitutivo de crimen, la pena esperada (especialmente considerando la escala que la propia LRPA regula) no sea de privación de libertad. $^{22}$

A esta altura es posible concluir que, respecto al tema de la procedencia de la internación provisoria, nuestra legislación ha recogido los mandatos de la legislación internacional por

${ }^{20}$ El texto original del CPP contenía una alusión explícita al principio de proporcionalidad en el inciso primero de su artículo 141 que fue suprimido por la Ley no 20.074 de noviembre del año 2005. Antecedentes sobre esta modificación y sus objetivos véase DUCE, Mauricio; RIEGO, Cristián, "La Prisión Preventiva en Chile: El Impacto de la Reforma Procesal Penal y Sus Cambios Posteriores", Prisión Preventiva y Reforma Procesal Penal en América Latina: Evaluación y Perspectivas, Santiago: Centro de Estudios de Justicia de las Américas, pp. 151-212 (véase especialmente pp. 197-203).

${ }^{21}$ En forma reciente la Comisión Interamericana de Derechos Humanos se ha pronunciado explicando los alcances del principio de proporcionalidad de la prisión preventiva en términos que me parece útil tener presente. El pronunciamiento de la Comisión se produjo en el Informe 35/07 de $1^{\circ}$ de mayo de 2007 en el Caso Hermanos Peirano Basso contra Uruguay. En concreto la Comisión señaló en sus párrafos 109 y 110 lo siguiente: "109. Otro de los principios limitadores de la prisión preventiva se refiere a la proporcionalidad, en virtud del cual una persona considerada inocente no debe recibir peor trato que una condenada ni se le debe deparar un trato igual a ésta. La medida cautelar no debe igualar a la pena en cantidad ni en calidad (artículo 5(4) y 6 de la Convención Americana). La proporcionalidad se refiere justamente a eso: se trata de una ecuación entre el principio de inocencia y el fin de la medida cautelar. No se trata de una equivalencia. No se debe confundir la equiparación que se establece entre la prisión preventiva y la pena a los fines de computar los plazos de detención, con la equiparación de su naturaleza.

110. En ese sentido, no se podrá recurrir a la prisión cautelar cuando la pena prevista para el delito imputado no sea privativa de la libertad. Tampoco cuando las circunstancias del caso permitan, en abstracto, suspender la ejecución de una eventual condena. También se deberá considerar en abstracto, si de haber mediado condena los plazos hubieran permitido solicitar la libertad provisoria o anticipada."

${ }^{22}$ De acuerdo a Bustos se trata de un principio básico del derecho penal que es corolario del principio general de necesidad de la pena, por consiguiente la internación provisoria “....sólo debe llevarse a cabo en la medida de su necesidad y en ese sentido la proporcionalidad es un criterio para apreciar dicha necesidad". BUSTOS, Derecho Penal, cit. nota $\mathrm{n}^{\circ} 11$, p. 79. En esta dirección más sustantiva, el principio de proporcionalidad también tiene un reflejo en el artículo 26 inciso segundo de la LRPA que sostiene que "En ningún caso se podrá imponer una pena privativa de libertad si un adulto condenado por el mismo hecho no debiere cumplir una sanción de la misma naturaleza". 
DUCE, MAURICIO. "El Derecho a un Juzgamiento Especializado de los Jóvenes Infractores en el Nuevo Proceso Penal Juvenil Chileno".

medio de contemplar mecanismos de restricción significativos para su uso. Incluso más, también me parece posible afirmar que se trata de restricciones más intensas que los que han sido identificados en el ámbito comparado en alguno de los países foco de esta investigación. En efecto, si bien en ellos se reconocen los principios de excepcionalidad y proporcionalidad, en ningún caso encontré una norma de exclusión de procedencia tan amplia como la prevista en el artículo 33 de la LRPA. ${ }^{23}$

No obstante lo anterior, para tener una imagen más completa acerca del impacto de estas normas es necesario revisar el cómo ellas impactan en concreto en el funcionamiento del sistema. Me parece a esta altura bastante obvio señalar que una cosa es la forma en que la ley está descrita en los libros y otra muy distinta es cómo ella opera en la práctica. En este contexto, la revisión de la práctica y jurisprudencia en la que se desenvuelven estas reglas tiende a mostrar una imagen un tanto más matizada del impacto que tendrían estas disposiciones en la realidad del sistema.

Los datos estadísticos disponibles para el primer año de funcionamiento de la LRPA (junio 2007 a junio 2008) publicados por la Defensoría Penal Pública ${ }^{24}$, muestran situaciones preocupantes para la vigencia de las normas expuestas. Así, un primer hallazgo de la Defensoría es que la implementación de la LRPA no se tradujo en una disminución del número de jóvenes imputados en internación provisoria. En efecto, el 8,9\% de los imputados fue sometido a internación provisoria, porcentaje que es mayor al período previo del año anterior a la vigencia de la LRPA en donde no regían las reglas especiales sobre la materia, el cual fue de un $8,7 \%{ }^{25}$ De acuerdo estos mismos datos, si se consideran exclusivamente la categoría de jóvenes entre 16 y 17 años durante el período LRPA con el período anterior (se excluye 14 y 15 años de edad) ${ }^{26}$ el porcentaje de internación provisoria aumenta a un $9,1 \% .{ }^{27}$ En consecuencia, de acuerdo a los datos proporcionados por la Defensoría, los instrumentos jurídicos diseñados para limitar el uso de esta medida cautelar tendrían un impacto restringido. En todo caso, la Defensoría llama la atención que se trata de un porcentaje inferior al que se utiliza tratándose de adultos, pero sugiriendo que ello podría deberse a que en la LRPA las penas son más bajas, por lo que no se trata de un indicador muy definitivo.

Me parece que estas conclusiones deben ser tomadas con cautela ya que hay varios factores que podrían hacer que la comparación entre cifras del año anterior a la puesta en marcha de la reforma con las de su primer año del nuevo sistema presente algunas distorsiones. Además, hay varios otros factores externos al sistema de la LRPA que también podrían influir en el aumento del uso de medidas cautelares personales sin que ello signifique que

\footnotetext{
${ }^{23}$ Esto ocurre al menos en los casos de Alemania, Costa Rica, España y Estados Unidos.

${ }^{24}$ Véase Defensoría Penal Pública, Informe Estadístico de Primer año de Vigencia Ley de Responsabilidad Penal Adolescente (8 de junio 2007 a 7 junio de 2008), pp.1-123, p. 8, en: http://www.defensoriapenal.cl/Documentos/estadisticas/2009/INFORME-PRIMER-ANO-RPA.pdf [visitado el 06.06.2010].

${ }^{25}$ Defensoría Penal Pública, Informe, cit. nota ${ }^{\circ} 24, \mathrm{p} .10$.

${ }^{26}$ Esto hace posible la comparación ya que el universo de jóvenes en el sistema antiguo que podían estar en prisión preventiva eran los jóvenes de 16 y 17 años que habían sido declarados con discernimiento o estaban en proceso de tal trámite.

${ }^{27}$ Defensoría Penal Pública, Informe, cit. nota $\mathrm{n}^{\circ} 24$, p. 10.
} 
sus normas no hayan cumplido un rol limitador, especialmente en comparación a lo que ocurre con el sistema de adultos. No me es posible en un trabajo de esta naturaleza entrar al fondo en esta materia. El punto que me interesa destacar es que -desde el punto de vista de la Defensoría- el tema del uso de la internación provisoria en el nuevo sistema ha sido puesto como una cuestión crítica prácticamente desde el inicio de funcionamiento de la LRPA.

La Defensoría también entregó algunos datos que dan cuenta de problemas en materia de vigencia del principio de proporcionalidad. Es así como se indica que el 89,2\% de los casos que atendió la Defensoría en donde se decreto una internación provisoria, la sanción que finalmente decretada no correspondió a una de régimen cerrado. Esta cifra baja a un 72,8\% de los casos si es que se consideran las situaciones en que la medida aplicada fue de régimen semi-cerrado. ${ }^{28}$ Aun considerando este escenario, estamos hablando de que en 3 de cada 4 casos en que se ocupó la internación provisoria hubo un potencial conflicto con el principio de proporcionalidad ya que la sanción definitivamente impuesta no significó ningún tipo de privación de libertad del condenado. Estos datos sí parecieran ser más decisivos respecto a dar cuenta de una brecha importante entre el mandato normativo contenido en el artículo 33 de la LRPA y el funcionamiento práctico del sistema.

Por su parte, UNICEF también ha llamado recientemente la atención acerca de un potencial sobre uso de la internación provisoria, indicando que "Los jueces estaban reaccionando apretando el botón fácil de la internación provisoria". ${ }^{29}$

En ese contexto, en el cual el uso de la internación provisoria ha sido objeto de críticas y debates, se podría esperar un terreno fértil para el desarrollo de una jurisprudencia que guiara con más precisión el uso de esta medida cautelar, especialmente desarrollando con mas profundidad los estándares especiales contenidos en la LRPA. La revisión de jurisprudencia de tribunales superiores de justicia no arroja muchas luces sobre la materia.

En primer lugar, los casos identificados en donde nuestros tribunales superiores se discuten algunos aspectos de la aplicación internación provisoria con algún nivel de sustancia (no referidos simplemente al aceptar o rechazar apelaciones sobre decisiones en la materia sin mayores fundamentos) suelen referirse a cuestiones de carácter más bien procesal, como por ejemplo la procedencia del recurso de apelación en contra de las resoluciones en las que se decreta la internación provisoria u otras cuestiones de similar naturaleza. ${ }^{30}$ Los pocos

\footnotetext{
${ }^{28}$ Defensoría Penal Pública, Informe, cit. nota $\mathrm{n}^{\circ} 24$, p. 10.

${ }^{29}$ Véase "UNICEF Impulsa Plan para Corregir Sistema de Justicia de Menores", en El Mercurio, Domingo 30 de Mayo de 2010, en: http://diario.elmercurio.com/2010/05/30/nacional/nacional/noticias/DCF8578D-ECAE4CE6-9F49-4227BF837119.htm? id $=\{$ DCF8578D-ECAE-4CE6-9F49-4227BF837119 $\} \quad$ [visitado el 31.05.2010].

${ }^{30}$ Ejemplo de esto son los fallos en causa rol no 203-2009 de la Corte de Apelaciones de Santiago de 20 de febrero de 2009, por la cual la Corte admite un recurso de hecho y señala que procede la apelación en contra de las resoluciones en las que se decreta la internación provisoria no obstante la LRPA nada señala al respecto (aplicando las normas generales del CPP). Otro ejemplo es la sentencia en causa rol n ${ }^{\circ}$ 196-2008 de 3 de junio de 2008 por medio del cual la Corte de Apelaciones de Iquique admite un amparo presentado por la defensa como consecuencia el rechazo de plano (sin audiencia) que realizó el juez de garantía a una solicitud de sustitución de la prisión preventiva. La Corte afirma que al no realizarse una audiencia se alteró la ritualidad
} 


\section{DUCE, MAURICIO. "El Derecho a un Juzgamiento Especializado de los Jóvenes Infractores en el Nuevo Proceso Penal Juvenil Chileno".}

casos en donde la jurisprudencia se hace cargo de aspectos de proporcionalidad, no se desarrolla una interpretación que precise los alcances y sentido de esta limitación. ${ }^{31}$ Un caso interesante en este sentido es el resuelto por la Corte de Apelaciones de Rancagua en causa rol $n^{\circ}$ 177-2008 de 10 de mayo de 2008. Se trata de una apelación interpuesta por el abogado de un joven imputado en contra de la resolución del juez de garantía en el que se decretó la internación provisoria por un delito previsto en la Ley de Violencia Intrafamilar (ley $\mathrm{n}^{\mathrm{o}}$ 20.066). El abogado alega que dicha internación provisoria fue decretada en contravención a lo dispuesto en el artículo 32 de la LRPA ya que se trataba de un simple delito y no de crimen como lo establece la disposición ya mencionada. En su resolución, la Corte confirma la decisión del juez de garantía manteniendo la internación provisoria. La Corte afirma que existe una colisión de normas entre el artículo 32 de la LRPA y el artículo 15 de la Ley $\mathrm{n}^{\mathrm{o}} 20.066^{32}$ y que en dicha colisión prima la aplicación de esta última por proteger valores constitucionales de mayor jerarquía (vida e integridad física de las víctimas versus la libertad del imputado). ${ }^{33}$

del proceso y se dejó en indefensión al imputado (en un sentido similar véase también la sentencia de 3 de junio de 2008 de la Corte de Apelaciones Iquique Causa rol n ${ }^{\circ}$ 196-2008). Otro ejemplo lo constituye la resolución de la Corte de Apelaciones de San Miguel en causa rol 399-2009 de 13 de abril de 2009 en la que se da lugar a un recurso de amparo frente a la decisión de un Tribunal de Juicio Oral de no admitir la apelación en contra de la decisión de internación provisoria basado en la norma del artículo 364 del CPP que impide que las resoluciones del Tribunal de Juicio Oral sean apelables. La Corte entiende que ello se refiere a las resoluciones del juicio y su secuela y no a las de otra naturaleza como la internación provisoria en el caso. Otro ejemplo puede revisarse en el fallo rol 643-2008 de la Corte de Apelaciones de San Miguel de 24 de junio de 2008 referida a un recurso de hecho en el que la Corte admite una apelación verbal (en similar sentido véase sentencia en causa rol n $\mathrm{n}^{\mathrm{0}}$ 36-2008 de la Corte de Apelaciones de Antofagasta de 8 de agosto de 2008, en un sentido contrario a estos fallos véase sentencia de la Corte de Apelaciones de la Corte de Apelaciones de Valdivia en causa rol no 28-2009 de 24 de enero de 2009). Finalmente, puede revisarse fallo de la Corte de Apelaciones de Valparaíso en causal rol no 343-2009 de 5 de agosto de 2009 en el cual la Corte rechaza un recurso de amparo por considerar que "la resolución que originara el amparo, fue dictada por autoridad competente, dentro de la esfera de sus atribuciones y en un caso previsto por la Ley" y sin pronunciarse sobre temas de fondo planteados por la defensa en el mismo.

${ }^{31}$ Por ejemplo véase la sentencia de la Corte de Apelaciones de San Miguel de 5 de mayo de 2008 en causa rol $n^{\circ}$ 589-2008. La Corte revoca la decisión del juez de garantía de no conceder la internación provisoria argumentando que existe peligro para la sociedad y que se trata de una medida proporcional, sin especificar el tipo de delito que se trata ni hacer referencia alguna al alcance y razones que justifican dicha proporcionalidad.

32 El artículo 15 dispone "En cualquier etapa de la investigación o del procedimiento sobre delitos constitutivos de violencia intrafamiliar, y aun antes de la formalización, el tribunal con competencia en lo penal podrá decretar las medidas cautelares que sean necesarias para proteger a la víctima de manera eficaz y oportuna, tales como las que establece el artículo 92 de la ley $\mathrm{N}^{\circ} 19.968$ y las aludidas en el artículo $7^{\circ}$ de esta ley".

${ }^{33} \mathrm{El}$ considerando $2^{\circ}$ de la Corte señala expresamente "Para decidir cuál disposición rige, entonces, cuando la colisión se produzca, ha de atenderse a la jerarquía de las normas constitucionales que en cada cual cristalizan. En el caso de la ley de responsabilidad juvenil se protege la libertad, en tanto que en el caso de la ley de violencia intrafamiliar se protege la vida y la integridad física y psíquica de las personas; valores supremos, bienes jurídicos primeros que la Constitución ampara, por lo que estando ambos en las balanza han de primar los que merecen el mayor amparo, razón por la cual prevalece el artículo 15 de la Ley 20.066. Así pues, ante una situación de ataques reiterados y serios, como los que describe el Ministerio Público y señala también el juez a quo en su resolución, que afectan a una mujer también menor de edad y a su hijo lactante, los que no han podido ser detenidos con otras medidas cautelares de menor rango, es imprescindible asegurar la vida e integridad de la víctima con la internación provisoria del agresor" 
Al tratarse de un caso ante una Corte de Apelaciones no es posible conocer algunos hechos relevantes del caso que podrían explicar y justificar la corrección de esta decisión. Lo que me interesa destacar es que más allá de las particularidades del caso concreto, la decisión de la Corte establece una excepción de carácter general a la regla contemplada en el artículo 32 de la LRPA que disminuiría los alcances limitadores de dicha norma en forma importante utilizando para ello un argumento en extremo general y sin hacerse cargo de los valores que estarían protegidos por la regla de la LRPA que podrían verse afectados en el ejercicio de ponderación que se realizó.

Otro caso de interés fue resuelto por la Corte Suprema a pocos días de haber entrado en vigencia la LRPA. ${ }^{34}$ Se trata de un caso de sustitución de medidas cautelares del artículo 155 del CPP por la medida de internación provisoria debido a reiterados incumplimientos del joven imputado a la misma. La defensa alega que dar lugar a la internación provisoria afectaría el principio de proporcionalidad ya que la pena en juego en el caso no excedería de presidio menor en su grado mínimo (entre 61 y 540 días de privación de libertad). Con todo, la Corte señala que no hay desproporcionalidad debido a que por vía de esta medida cautelar se está tratando de llegar a una decisión en un plazo razonable en el caso, cuestión que no se ha podido lograr por la rebeldía del imputado. Nuevamente, más allá de la afirmación general de la Corte, no se desarrolla ninguna explicación que permita justificar con claridad la primacía del valor del plazo razonable en este caso.

Como se puede apreciar, en un escenario en donde se han formulado críticas importantes al uso de la internación provisoria parece no haberse desarrollado una doctrina clara en nuestros tribunales superiores de interpretar restrictivamente las normas que autorizan su uso. Esto ha llevado a argumentar que la proporcionalidad no puede ser entendida en forma matemática $\mathrm{y}$, por lo mismo, que debe considerarse al momento de dar lugar a la internación provisoria otros valores del sistema, como ha ocurrido en los dos casos citados. ${ }^{35}$ Concuerdo con la idea que la norma de proporcionalidad no puede operar exclusivamente como un criterio de limitación matemático y que en casos concretos podrían existir otros valores afectados de tal magnitud que hicieran indispensable su uso. Con todo, el problema es que frente a la falta de una delimitación más clara de los tribunales superiores, esta idea presentada genéricamente podría dejar sin contenido alguno al principio de proporcionalidad, especialmente en un sistema de medidas cautelares como el nacional que contempla causales muy abiertas que no dicen relación con fines estrictamente cautelares (como por ejemplo el peligro para la seguridad de la sociedad). Es decir, leer esta idea como un principio general de actuación sin un desarrollo jurisprudencial que fije limitaciones o precisiones respecto al mismo, podría ser una suerte de cheque en blanco para saltarse la norma de proporcionalidad y vaciarla de sentido limitador. Se trata de un riesgo que debiera ser minimizado por la propia jurisprudencia de los tribunales superiores de nuestro país por medio de establecer análisis más finos de ponderación al momento en que se presenten conflictos como los descritos en los casos ya identificados.

\footnotetext{
${ }^{34}$ Véase Sentencia de la Corte Suprema en causa rol no 3191-2007 de 27 de junio de 2007.

${ }^{35}$ En este sentido véase MERINO, Guillermo Felipe, "Comentario a la Resolución que no Decreta Cautelares del art. 155 del Código Procesal Penal, por Hechos Ocurridos al Interior del Centro Semicerrado de Limache", Revista Jurídica del Ministerio Público, Santiago: no 39, Junio (2009), pp. 244-246.
} 
DUCE, MAURICIO. "El Derecho a un Juzgamiento Especializado de los Jóvenes Infractores en el Nuevo Proceso Penal Juvenil Chileno".

Sin perjuicio del problema descrito, es obviamente en los juzgados de garantía en donde se resuelven con mucha más habitualidad las solicitudes de internación provisoria. Así, si se quiere tener una imagen más real del funcionamiento diario del sistema se debe observar la práctica desarrollada en esa instancia también. Como he señalado, la observación de audiencias no ha tenido por propósito construir una imagen que pretenda ser una representación estadísticamente confiable del funcionamiento del sistema, por lo que el análisis en el punto sólo tiene por objeto relevar algunas hipótesis.

La observación realizada arroja que sólo en una cantidad menor del total de casos en los que se discutió una medida cautelar personal fue solicitada la internación provisoria de uno o más de los jóvenes imputados ( 8 de 28 casos). ${ }^{36}$ La discusión de la internación provisoria se dio siempre en el contexto de imputaciones por delitos graves que cabían dentro de la categoría de crimen de conformidad a lo establecido en el artículo 32 de la LRPA (en todos los casos se trató de robos en lugar habitado y robos con violencia o intimidación). En la resolución, en cuatro casos los jueces no dan lugar a la internación provisoria (al menos de uno de los imputados) justificando su decisión en la potencial vulneración de la regla de proporcionalidad establecida en la LRPA. ${ }^{37}$ Así, en la causa RIT 94-2009 del 13 Juzgado de Garantía de Santiago la falta de proporcionalidad se deriva de la existencia de la atenuante de irreprochable conducta anterior de los jóvenes imputados (de 16 y 17 años) que produciría una rebaja de pena que permite proyectar una pena no privativa de libertad en el caso de condena (se imputaba un robo con intimidación). Se concede en cambio la prisión preventiva de dos adultos imputados por el mismo delito. En la causa RIT 133-2009 del $14^{\circ}$ Juzgado de Garantía de Santiago, no se da lugar a la internación provisoria en contra de un joven de 14 años imputado de cometer un robo en lugar habitado, considerando que se trataría de un delito frustrado sancionable como tal (no utilizando la regla del artículo 450 del Código Penal) lo que haría bajar en un grado la pena. Se trataba de un joven reincidente, no obstante lo cual en su decisión el juez de garantía considera que sería desproporcionado el uso de la internación provisoria sin antes privilegiar una intervención del SENAME que le entregue una oportunidad de reinserción al imputado. En la causa RIT 292-2009 del $2^{\circ}$ Juzgado de Garantía de Santiago se rechaza la solicitud de internación provisoria en contra de uno de los dos jóvenes imputados por cometer un robo con intimidación por carecer de antecedentes previos lo que haría desproporcionada la medida cautelar. En cambio, al joven que cuenta con antecedentes previos se le decreta la

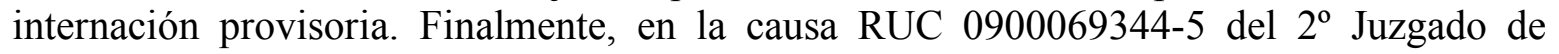
Garantía de Santiago no se concede la internación provisoria de un joven imputado de 16 años por el delito de robo con violencia por considerarse que debido a no tener antecedentes previos es muy probable que la condena que obtenga sea a una pena en

\footnotetext{
${ }^{36}$ Debe tenerse presente que en una cantidad muy significativa de casos observados no hubo discusión de medida cautelar personal ya sea porque no se solicitó ninguna o debido a que el caso concluyó por vía de una decisión temprana (por ejemplo por una suspensión condicional del procedimiento o un reconocimiento de responsabilidad en un procedimiento simplificado flagrante).

${ }^{37}$ Cabe señalar que de acuerdo a los datos estadísticos disponibles en el sistema de adultos, aproximadamente de cada 10 solicitudes de prisión preventiva el sistema judicial la otorga en 9 casos. Véase: http://www.poderjudicial.cl/noticias/File/estadisticas_prisiones_preventivas_2009.pdf_ [visitado el 16.11.2009].
} 
libertad, lo que hace improcedente la medida cautelar solicitada. En el mismo caso si se decreta prisión preventiva en contra de dos adultos que son co-imputados (de 18 y 21 años).

Los casos brevemente reseñados muestran una tendencia importante de los jueces de garantía de ocupar el artículo 33 de la LRPA como un criterio limitador en el uso de la internación provisoria, incluso en casos que en abstracto podrían tener pena de crimen. ${ }^{38}$ Algunos de ellos también dan cuenta que frente a una misma imputación adultos son puestos en prisión preventiva y jóvenes en otras medidas cautelares personales. Todo ello apuntaría a una práctica consistente con los valores plasmados en la LRPA. Con todo, una mirada global de estas audiencias y de las en que se dio lugar a la internación provisoria o se discutió la procedencia de otras medidas cautelares personales obliga a matizar un poco estos hallazgos. En primer lugar, la argumentación que tienden a realizar los jueces para afirmar o descartar la proporcionalidad tiende a ser un ejercicio relativamente automático de proyección de pena, sin referencia a objetivos político criminales de tal principio limitador. ${ }^{39}$ Por otra parte, en los casos en que se da lugar a la internación provisoria tiende a primar un ejercicio relativamente formal de "contar" la concurrencia de circunstancias mencionadas en el artículo 140 del CPP, para a partir de ello justificar el uso de esta medida sin hacerse cargo de razones específicas de su necesidad o, peor aún, del impacto o efecto que esta medida podría tener tratándose de jóvenes. ${ }^{40}$ Por lo mismo, de la observación de audiencias parece derivarse una situación bastante heterogénea en el comportamiento de los jueces de garantía que impide afirmar con fuerza el impacto uniformador de comportamientos judiciales que habrían tenido las disposiciones especiales de la LRPA en materia de uso de la internación provisoria.

Para concluir esta sección, la investigación me permite afirmar que se ha producido un avance muy importante en el diseño normativo de nuestro sistema contenido en la LRPA que hace que nuestro país en general cuente con un sistema legal que recoge las orientaciones que emanan del sistema internacional de protección de derechos humanos y que esta a la par (o incluso más avanzado) que lo que ocurre en la legislación comparada.

\footnotetext{
${ }^{38}$ Las estadísticas del Ministerio Público tienden a reforzar esta impresión ya que muestran una estabilización e incluso disminución en el uso de la internación provisoria con el correr de los años. Así, durante el año 2008 el Ministerio Público reporta que 2.753 jóvenes imputados estuvieron en internación provisoria mientras que en el año 2009 esa cifra habría bajado a 2.447, es decir, una disminución cercana al 10\%. Esto se produce en un contexto en el que los casos ingresados al sistema fue prácticamente idéntico (año 2008: 53.120 y año 2009: 52.770). Véase Ministerio Público, Boletín Estadístico Anual año 2008, pp. 135-144 y Boletín Estadístico Anual año 2009, pp. 46-50.

${ }^{39}$ Como se mencionó precedentemente sólo en un caso parece considerarse el tema más allá del ejercicio proyectivo de determinación de pena (causa RIT 133-2009 del 14º Juzgado de Garantía de Santiago).

${ }^{40}$ Esto coincide con el hallazgo de varios estudios acerca del comportamiento de jueces en materia de uso de la prisión preventiva de adultos que coinciden respecto a una tendencia al uso automático de esta medida en delitos graves. Véase DUCE / RIEGO, "La prisión", cit. nota $\mathrm{n}^{\circ}$ 20, pp. 193-194. Véase también AHUMADA, Alejandra; FARREN, Diego; WILLIAMSON, Bernardita, Encuesta de Opinión de Jueces: Evaluación de las Medidas Cautelares y Otros Temas Relacionados, Santiago: Fundación Paz Ciudadana, 2009 , pp. 33-34 (referido eso sí al impacto "agenda Corta" en la materia) en: http://www.pazciudadana.cl/docs/pub_20100310181248.pdf [visitado el 05.04.2010], y MONTERO, Jorge, La Prisión Preventiva ¿Es una Medida Cautelar de Carácter Excepcional?, Santiago: Trabajo de Seminario I, Facultad de Derecho Universidad Diego Portales, 2010, Marzo (disponible en la biblioteca de la misma Facultad).
} 
DUCE, MAURICIO. "El Derecho a un Juzgamiento Especializado de los Jóvenes Infractores en el Nuevo Proceso Penal Juvenil Chileno".

Estas normas aparentemente han permitido desarrollar un comportamiento en los jueces que tiende a utilizar la internación provisoria con mayores resguardos que la prisión preventiva de adultos. Sin embargo, no aparece con claridad que estos comportamientos se hayan desarrollado al alero de interpretaciones profundas de los nuevos estándares legales sino más bien con una aplicación relativamente mecánica de los mismos. Con todo, me parece que el trabajo en la justicia de garantía da cuenta de mucha heterogeneidad de criterios, lo que podría explicarse, entre otras hipótesis posibles, por la falta de especialización de los jueces que ven este tipo de audiencias en donde se resuelve la internación provisoria.

\subsubsection{Duración o extensión temporal de la internación provisoria.}

La afirmación de la garantía de la libertad individual no sólo debe traducirse en una preocupación en el uso restringido de la privación de libertad durante el proceso seguido en contra de jóvenes, sino que también debe reflejarse, en los casos excepcionales en que sea procedente, en restricciones temporales muy estrictas a su extensión. En este sentido, en los instrumentos internacionales especializados en materia de proceso juvenil el énfasis en la regulación de la garantía específica en la materia está en la idea que el plazo de privación de libertad durante el proceso en contra de un joven sea "lo más breve posible", lo que constituye un lenguaje mucho más estricto que la noción más abierta de "plazo razonable" establecida para adultos. ${ }^{41}$ En este contexto el Comité de Derechos del Niño recomienda dos tipos de acciones legislativas a los Estados parte para hacer efectivo este derecho. Por una parte, la necesidad que las leyes internas establezcan límites temporales a la duración de la prisión preventiva y, por la otra, un sistema de examen o revisión periódica de la misma (preferentemente cada dos semanas). ${ }^{42}$ Estas medidas son habitualmente recogidas en el ámbito del derecho comparado por medio del establecimiento de plazos máximos de duración de la misma (por ejemplo en el caso de Costa Rica la duración máxima es de cuatro meses y en España es de nueve meses, en ambos casos se toma en consideración los tiempos máximos de duración lo que incluye las potenciales prórrogas). ${ }^{43}$

Una revisión de la LRPA muestra que no existe regulación especial acerca de la duración de la internación provisoria, ni tampoco algún sistema de revisión de la medida especial al contemplado en el CPP para adultos. En efecto, la única disposición que establece una revisión de oficio de la misma es el regulado en el artículo 145 inciso segundo del CPP que señala que transcurrido seis meses que se hubiere decretado la prisión preventiva o desde el último debate oral en que ella se hubiere decidido, el tribunal debe citar de oficio a una audiencia para discutir su continuación. Se puede apreciar que se trata de un mecanismo de revisión bastante menor debido a la periodicidad con la que funciona.

La única particularidad de la LRPA en materia de plazos de duración de la internación provisoria no emana de límites explícitos a la misma, sino que de la regulación de plazos

\footnotetext{
${ }^{41}$ Véase DUCE, “E1 Derecho a un Juzgamiento", cit. nota no 3, pp. 88-89.

${ }^{42}$ Véase Comité de Derechos del Niño Observación General n ${ }^{\circ} 10$ (2007), párrafo 80.

${ }^{43}$ En el caso de Costa Rica esto se encuentra regulado en el artículo 59 inciso segundo de la Ley de Justicia Penal Juvenil (en adelante LJPJ) del año 1996 y España el artículo 28.3 de la Ley Orgánica 5/2000 (en adelante LO 5/2000).
} 
más breves que el procedimiento de adultos de duración de sus distintas etapas. El artículo 38 de la LRPA establece que la duración máxima de la etapa de investigación es de seis meses desde la formalización de la investigación ampliable por dos meses más a solicitud fundada del fiscal. Es decir, se trata de un máximo de ocho meses allí donde de acuerdo al artículo 247 del CPP se establece uno de dos años. Además, el artículo 39 de la LRPA establece que el juicio oral debe tener lugar no antes de 15 ni después de 30 días de la notificación del auto de apertura del juicio oral (en el CPP dicho plazo es no antes de 15 ni después de 60 días según dispone su artículo 281 inciso tercero). Como se puede observar, se trata de una disminución de los plazos máximos de duración del proceso, pero que no están referidos específicamente al uso de la internación provisoria. Por otra parte, si bien constituyen una rebaja potencial significativa respecto a los procesos de adultos, permiten la extensión del proceso por tiempos bastante más amplios que el óptimo considerado por el Comité de Derechos del Niño (seis meses máximo) o de lo contemplado en legislaciones como la de Costa Rica y España según ya tuve oportunidad de mencionar.

Los datos proporcionados por la Defensoría Penal Pública al primer año de funcionamiento de la LRPA arrojan algunas luces sobre la práctica en la materia, aún cuando son bastante preliminares como para obtener conclusiones muy definitivas sobre la base de los mismos. ${ }^{44}$ De acuerdo a la Defensoría, durante el primer año de la LRPA el promedio de duración de la internación provisoria habría sido de 74,1 días. ${ }^{45}$ Se trataría de un dato positivo ya que reflejaría que en concreto los casos en los que se ocupa la internación provisoria tienden a correr más rápido que los máximos legales establecidos para su duración o que ésta es utilizada en porciones menores de tiempo que la extensión completa del proceso. Se trataría, además, de plazos dentro de los márgenes establecidos en el derecho internacional y comparado. Con todo, cuando ese dato se pone en un contexto de comparación con el año anterior a la entrada en vigencia de la LRPA se puede apreciar un aumento de duración del mismo. En efecto, de acuerdo a la propia Defensoría se habría producido un aumento de 13 días en la duración promedio de la internación provisoria respecto al año anterior a su entrada en vigencia. Así, esta habría pasado de un promedio de 60,8 días a 74,1 días, lo que de acuerdo a la propia Defensoría representaría una contradicción con la exigencia de "brevedad" de la internación provisoria. ${ }^{46}$

Se trata nuevamente de un resultado interesante ya que no obstante ponerse en marcha un sistema especializado juvenil, estas cifras darían cuenta de un impacto limitado en el tema. Ello no debiera extrañar frente a la constatación que en el punto en análisis la LRPA no contiene herramientas novedosas de límite o control de la duración de las internaciones provisorias. $^{47}$

\footnotetext{
${ }^{44}$ Entre otras razones, al tratarse sólo de un primer año lo natural es que el promedio de duración de procesos $\mathrm{y}$, vinculado a ello de internaciones provisorias, tienda a ser más bajo que cuando el sistema tenga acumulado casos de mayor duración temporal.

${ }^{45}$ Defensoría Penal Pública, Informe, cit. nota n ${ }^{\circ} 24$, p. 11.

${ }^{46}$ Defensoría Penal Pública, Informe, cit. nota n ${ }^{\circ} 24$, p. 11.

47 Además, varias otras hipótesis, como por ejemplo, la falta de especialización orgánica del sistema, que podrían explicar este impacto limitado.
} 
DUCE, MAURICIO. "El Derecho a un Juzgamiento Especializado de los Jóvenes Infractores en el Nuevo Proceso Penal Juvenil Chileno".

En este contexto, existe un caso muy interesante del año 2008 resuelto por la Corte Suprema en apelación de un recurso de amparo decidido por la Corte de Apelaciones de Talca $^{48}$ que ilustra sobre la forma en que la idea de "brevedad" o "plazo razonable" de duración de la internación provisoria es reconocida en nuestra práctica jurisprudencial. El caso se inicia por vía de la interposición de un Recurso de Amparo de un joven de 16 años imputado de participar en conjunto con otros cuatro imputados (otro menor de edad y tres adultos) en un robo con violencia y, además, por porte de armas. Una vez cerrada la investigación y enviado el auto de apertura de juicio oral al Tribunal Oral, éste -debido a problemas importantes de congestión- fijó el juicio oral a una fecha de aproximadamente once meses después de recibido el caso. Frente a eso, el imputado interpuso Recurso de Amparo con el objetivo de que se le otorgue la libertad y se fije una fecha más cercana para la realización del juicio oral. La Corte de Apelaciones de Talca rechaza el amparo argumentando que la causa de privación de libertad del joven no es ilegal y, por tanto, no se da el supuesto previsto para acoger el recurso de amparo interpuesto. La Corte Suprema, en cambio, revoca la decisión de la Corte de Apelaciones y decide acoger el amparo, adoptando como remedio a la situación del amparado la sustitución de su internación provisoria por las medidas cautelares de las letras a), b) y d) del artículo 155 del CPP. ${ }^{49} \mathrm{Al}$ resolver, la Corte Suprema argumenta varias cuestiones de interés. En primer lugar, la Corte señala -correctamente en mi opinión- que no es su función resolver acerca de la internación provisoria decretada sino que analizar "..la posibilidad de ser jurídicamente razonable mantener al adolescente bajo esta medida hasta la celebración del juicio". ${ }^{50}$ Con esto en mi opinión la Corte pone el foco precisamente en el análisis de la garantía en estudio. Para pronunciarse sobre esto, la Corte considera que el imputado ya llevaba un período superior a los nueve meses en internación provisoria y que esperar otro tanto en tal calidad hasta la realización del juicio no sería razonable. La Corte señala “...esta demora vulnera la presunción de inocencia al permitir un trato que de hecho la desconoce y porque el retardo dificultaría la finalidad de reinserción social que establecen el proceso penal de los adolescentes y las sanciones que a éstos corresponde",51

Según se puede apreciar, tanto las medidas de amparo adoptadas por la Corte Suprema como su argumento general acerca de la "razonabilidad" de la extensión de la internación provisoria, parecen orientarse en la dirección correcta. Con todo, en ninguna parte del caso se fundamenta la decisión en algún análisis específico de las condiciones de razonabilidad o de cómo determinar cuando un plazo de privación de libertad excede tal límite. De otra parte, al fundar normativamente su decisión la Corte Suprema recurre a estándares internacionales generales de duración de los procesos (por ejemplo al artículo 14.4 del Pacto Internacional de Derechos Civiles y Políticos), sin identificar las normas específicas referidas a la duración de la privación de libertad en el proceso. A su vez, menciona garantías generales como la presunción de inocencia o ideas como el proceso de reinserción

\footnotetext{
${ }^{48}$ Véase Sentencia de la Corte Suprema en causa rol $\mathrm{n}^{\circ}$ 6911-08 de 11 de noviembre de 2008. El fallo de la Corte de Apelaciones de Talca corresponde a la causa rol n ${ }^{\circ}$ 504-2008 de 21 de octubre de 2008.

${ }^{49}$ Véase considerando $5^{\circ}$ de la decisión de la Corte Suprema. Se trata de las medidas cautelares de arresto domiciliario total (letra a), sujeción a la vigilancia de Carabineros (letra b) y prohibición de salir del país (letra d).

${ }^{50}$ Véase considerando $2^{\circ}$.

${ }^{51}$ Véase considerando $4^{\circ}$.
} 
social del joven sin referencia a la garantía específica en juego en el caso concreto. Esto nos habla de un escaso nivel de desarrollo concreto de esta garantía específica a pesar que la Corte, como sostuve, identifica correctamente el problema sobre el cual tiene que pronunciarse.

A modo de conclusión, se puede señalar que nuestra legislación y práctica jurisprudencial no parecen recoger con claridad la idea que la limitación temporal en el uso de la internación provisoria es una garantía autónoma al de la extensión general del proceso. Ello debilita su comprensión y representa una deuda en materia de juzgamiento especializado tanto en comparación con las exigencias establecidas a nivel de la legislación internacional como respecto de mecanismos regulados en el derecho comparado. Con todo, debido a los plazos con los que el sistema estaría funcionando en los hechos, la extensión temporal de la internación provisoria no sería un problema muy significativo en la práctica lo que explicaría en parte la falta de preocupación de nuestra doctrina y jurisprudencia. Pero como el lector puede apreciar, se trata de una situación de hecho que podría cambiar. En efecto, las cifras del sistema de adultos tienden a mostrar que con el paso del tiempo los promedios de tiempo de duración de la prisión preventiva han ido en aumento de manera significativa los últimos años. ${ }^{52}$

\subsubsection{Condiciones de cumplimiento de la internación provisoria.}

Las condiciones de cumplimiento de la internación provisoria representan otra área en donde existe un conjunto de garantías específicas en favor de los niños y jóvenes imputados que no se contemplan en favor de los adultos en la legislación internacional. La manifestación más evidente de estas condiciones especiales es la necesidad que exista separación entre adultos y jóvenes sometidos a esta medida cautelar. ${ }^{53}$

La LRPA y su legislación reglamentaria de complemento consagran el principio de separación con bastante fuerza. En efecto, el artículo 48 de la LRPA establece que las personas privadas de libertad de conformidad a esta ley, no importando su calidad procesal, deberán siempre permanecer separados de los adultos privados de libertad. Además, se establece un deber general a todos los organismos que intervienen en el proceso juvenil (incluyendo policías, tribunales y autoridades penitenciarias) de adoptar todas las medidas necesarias para el cumplimiento de este principio. Finalmente, se establece que su no cumplimiento constituye una infracción grave a los deberes funcionarios. El artículo 31 de la LRPA también hace referencia al principio de separación y de manera expresa hace una remisión al artículo 37 letra c) de la CDN que lo regula y al artículo 17 de la Ley ${ }^{\circ} 16.618$ que lo establecía en nuestro país aún antes de la vigencia de la LRPA. El Reglamento de la ley establece también en principio de separación en su artículo 50 letra c).

No pareciera haber discrepancia en nuestro país respecto a que la separación de jóvenes y adultos es un principio central del sistema de la LRPA. ${ }^{54}$ En esta dirección, el propio

\footnotetext{
${ }^{52}$ Véase DUCE / RIEGO, "La prisión”, cit. nota no 20, pp. 185-188.

${ }^{53}$ Véase DUCE, "El Derecho a un juzgamiento", cit. nota $n^{\circ} 3$, pp. 90-92.

${ }^{54} \mathrm{La}$ escasa doctrina sobre la materia incorpora este elemento en su descripción de los rasgos centrales del nuevo sistema, por ejemplo véase OBERG, Héctor, "Ley de Responsabilidad Penal Juvenil", Revista
} 
DUCE, MAURICIO. "El Derecho a un Juzgamiento Especializado de los Jóvenes Infractores en el Nuevo Proceso Penal Juvenil Chileno".

Ministerio Público ha dictado instrucciones tanto a fiscales como policías en términos de tener especial cuidado con el cumplimiento del principio de separación. ${ }^{55}$

Junto con lo anterior, la LRPA (especialmente su reglamento) regula con cierto detalle un conjunto de otros derechos de los jóvenes durante su internación provisoria, por ejemplo en su artículo 31 (que hace referencia al artículo $37 \mathrm{c}$ ) de la CDN y a otras garantías de la misma Convención y del CPP). Entre ellos se incluyen los derechos a recibir visitas, a mantener comunicación con sus padres o adultos a cargo de su cuidado, a mantener comunicación con su abogado, a recibir atención en salud y educación, derecho a revisar periódicamente la medida respectiva, a acceder a medios de información, etc. ${ }^{56}$

Al igual que en otros derechos, este panorama de reconocimiento normativo contrasta con un conjunto de información empírica que indica que una de las áreas más problemáticas para la vigencia de los derechos de los jóvenes privados de libertad en el contexto del funcionamiento del nuevo sistema de responsabilidad juvenil se encuentra precisamente en las condiciones que se cumple su privación de libertad. Si bien se trata de una situación común a todas las privaciones de libertad, evidentemente cubre el caso de los jóvenes sometidos a internación provisoria que son objeto de mi análisis. Es así como desde el año 2008 un conjunto de instituciones han dado a conocer la situación crítica en que se encontrarían los jóvenes en centro de privación de libertad en nuestro país que, entre otras cuestiones incluiría problemas serios de segregación entre jóvenes y adultos, de acceso a salud y educación en los recintos y de falta de debido proceso en la aplicación de sanciones disciplinarias al interior de los mismos. ${ }^{57}$

En este escenario conflictivo, nuevamente podría esperarse una jurisprudencia intensa de tribunales superiores que se pronunciara estableciendo precisiones acerca de los alcances de los derechos en la materia. El caso paradigmático en la materia dio cuenta de una actitud refractaria de nuestros tribunales superiores de enfrentar el tema. En efecto, como consecuencia de un incidente grave producido en octubre de 2007 el centro de privación de libertad de Puerto Montt en el que murieron diez jóvenes, se presentaron recursos de amparo para proteger el derecho de jóvenes en centros de privación de libertad en cuatro

Actualidad Jurídica, no 15 (2007, Enero), Universidad del Desarrollo, p. 188, BUSTOS, Juan, Derecho Penal, cit. $\mathrm{n}^{\circ}$ 12, p. 81, y SOTO, Elizabeth; NAREA, Juan Andrés, Responsabilidad Penal Adolescente y su Nuevo Ordenamiento Jurídico, Santiago: Editorial Jurídica Congreso, 2007, pp. 152-153.

${ }^{55}$ Véase Fiscalía Nacional Oficio no 714 Instructivo no 14 de la ley n ${ }^{\mathbf{o}} 20.084$ de 29 de mayo de 2007, pp. 5-6.

${ }^{56}$ Para más detalle se recomienda revisar los artículos 50 a 61 y 139 a 142 del Reglamento de la Ley $\mathrm{n}^{\circ}$ 20.084 .

${ }^{57}$ Esta información ha sido dada a conocer en detalle por el Informe de Derechos Humanos de la Facultad de Derecho de la Universidad Diego Portales, véase Informe Anual sobre Derechos Humanos en Chile 2008, Santiago: Facultad de Derecho Universidad Diego Portales, 2008, pp. 107-133, e Informe Anual sobre Derechos Humanos en Chile 2009, Santiago: Facultad de Derecho Universidad Diego Portales, pp. 98-103. En la misma dirección se ha pronunciado también UNICEF en un documento denominado "Principales Nudos Problemáticos de los Centros Privativos de Libertad para Adolescentes y Secciones Juveniles" dado a conocer en abril de 2008, una Comisión Investigadora Especial de la Cámara de Diputados en su informe final de noviembre de 2007 y la Contraloría General de la República en su Informe Final 132 de 2008 como producto de una auditoria efectuada al Servicio Nacional de Menores (SENAME). Información más detallada sobre los informes de UNICEF, la Comisión Investigadora y la Contraloría pueden verse en los informes de derechos humanos citados precedentemente. 
Polit. crim. Vol. 5, № 10 (Diciembre 2010), Art. 1, pp. 280-340.

[http://www.politicacriminal.cl/Vol_05/n_10/Vol5N10A1.pdf]

regiones del país. ${ }^{58}$ Entre otros derechos vulnerados, los recursos incluían la falta de segregación de jóvenes con adultos. Todos los recursos fueron rechazados. Los argumentos centrales del rechazo estuvieron en la carencia de facultades de la cortes para superar las deficiencias detectadas por los recurrentes (falta de idoneidad del Recurso de Amparo para corregir el problema denunciado) y el carácter legal de la privación de libertad de los jóvenes por emanar de resoluciones judiciales formalmente válidas. Los recursos de amparo fueron apelados y las resoluciones originales fueron confirmadas por la Corte Suprema sin agregar antecedentes o fundamentos adicionales. ${ }^{59}$

Otro caso relevante, aún cuando mucho menos directo respecto al tema en análisis, también se produjo como consecuencia de la interposición de un Recurso de Amparo que fue resuelto por la Corte de Apelaciones de Temuco. ${ }^{60}$ Se trata del caso de un joven imputado en conjunto con otros adultos por conductas encuadradas en los artículos 1 y 2 de la Ley $n^{\circ}$ 18.314 (que determina conductas terroristas), por lo que en conformidad al artículo 11 de la misma el Ministerio Público pidió ampliación de la detención por el plazo de 10 días previsto en la ley. La defensa interpone amparo argumentando que dicho plazo es contrario a lo dispuesto por la LRPA. El amparo es rechazado por la Corte al considerar que la Ley $\mathrm{n}^{\mathrm{o}}$ 18.314 prima por sobre las disposiciones de la LRPA. Pero, además, el recurso va sobre una segunda cuestión que es de interés para el presente análisis. Cuando se había concedido la ampliación de la detención por parte del juez de garantía, el joven imputado fue enviado a un recinto penitenciario de adultos en el cual no fue recibido por las autoridades del mismo, debiendo pernoctar en el recinto policial. Al día siguiente, al constatar esta irregularidad, el tribunal de garantía ordena la remisión del joven al centro de privación de libertad juvenil. La Corte confiere el amparo en esta materia señalando que no se cumplió con el deber de dar "ingreso inmediato" del joven a un centro penitenciario lo que afectó al artículo 11 inciso tercero de la Ley $\mathrm{n}^{\circ}$ 18.314. Con todo, esto no cambia la situación procesal del imputado sino que sólo se traduce en poner los antecedentes del caso en conocimiento del pleno de la Corte.

En la materia que es objeto de análisis, me parece que el caso presenta dos cuestiones de interés. Lo primero es que da cuenta de una práctica de los funcionarios penitenciarios consistente con el principio de separación al decidir no aceptar el ingreso del joven a un recinto de adultos. En segundo término, da cuenta que la Corte de Apelaciones no recoge ningún elemento de especialidad del sistema de responsabilidad juvenil para resolver el asunto y mas bien lo que hace es la aplicación de una regla general de la Ley $\mathrm{n}^{\mathrm{o}}$ 18.314.

Se puede apreciar nuevamente una brecha significativa entre el reconocimiento legal de los derechos de los jóvenes y la forma en que estos son incorporados por la práctica jurisprudencial en nuestro país. Más allá de la corrección o no de las decisiones de los

\footnotetext{
${ }^{58}$ Los recursos fueron presentados ante las cortes de apelaciones de Puerto Montt, Valparaíso, Rancagua y Puerto Montt en noviembre del año 2007.

${ }^{59}$ Un relato detallado del caso y sus antecedentes puede revisarse en CILLERO, Miguel; ESPEJO, Nicolás, "Derechos de los Adolescentes Privados de Libertad en Chile: En Busca de la Tutela Judicial Efectiva", en Revista General de Derecho Penal Iustel, no 9 (2008), 12 pp. Véase también Informe Anual sobre los Derechos Humanos en Chile 2008, cit. n 56, pp. 128-130.

${ }^{60}$ Véase Sentencia de la Corte de Apelaciones de Temuco en causa rol 1089-2008 de 7 de noviembre de 2008.
} 
DUCE, MAURICIO. "El Derecho a un Juzgamiento Especializado de los Jóvenes Infractores en el Nuevo Proceso Penal Juvenil Chileno".

tribunales en los casos relatados, ellos constituían una muy buena oportunidad para desarrollar con más precisión los estándares en análisis, pero lamentablemente no hubo pronunciamiento de fondo sobre los mismos.

\subsection{Exigencias más estrictas respecto a la extensión temporal del proceso.}

La extensión temporal de los procesos es una preocupación muy importante en el sistema internacional de derechos humanos a tal punto que una garantía central del debido proceso es el derecho a ser juzgado en un plazo razonable y que ha sido recogido también por las legislaciones analizadas en el ámbito comparado. Las ideas que fundamentan a esta garantía tienen que ver tanto con el impacto negativo que la extensión temporal del proceso produce en los derechos de las personas imputadas (extendiendo en demasía el estado de incertidumbre generado por el proceso, dificultando la posibilidad de ejercer derecho de defensa, entre otros) como en la legitimidad del sistema frente a la comunidad. ${ }^{61}$ Por lo mismo, dicha garantía ha sido reconocida de una forma especial por la legislación internacional juvenil al exigirse que en los procesos en contra de niños y jóvenes infractores la duración total del proceso para ellos debiera ser más breve que tratándose de adultos, aún cuando no hubiera privación de libertad en su desarrollo. ${ }^{62}$

El mecanismo principal a través del cual esta garantía se regula en el derecho comparado es a través de establecimiento de plazos máximos de duración del proceso que en general tienden a ser bastante más breves que los existentes en los procesos de adultos y a ello se agrega una tendencia a simplificar las etapas de desarrollo del proceso juvenil. ${ }^{63}$

Nuestro legislador ha seguido una estrategia similar en la LRPA. A la disminución de plazos máximos de duración de la etapa de investigación contemplada en el artículo $38^{64} \mathrm{y}$ de realización del juicio oral del artículo 39 que ya he mencionado ${ }^{65}$, la LRPA establece una ampliación de la aplicación del procedimiento simplificado al ámbito juvenil en su artículo 27 inciso segundo por medio de dos vías. En primer lugar, en dicha disposición se

\footnotetext{
${ }^{61}$ Véase, DUCE, “E1 Derecho a un Juzgamiento”, cit. nota n ${ }^{\circ} 3$, pp. 93-94.

${ }^{62}$ DUCE, "El Derecho a un Juzgamiento", cit. nota no 3, pp. 93-94.

${ }^{63}$ Un ejemplo de esto lo constituye el sistema Español regulado en la LO 5/2000 que establece que el diseño del procedimiento juvenil contenido se basa en el procedimiento abreviado regulado por la Ley de Enjuiciamiento Criminal de adultos. Esto es complementado con el establecimiento de plazos relativamente breves en las distintas fases procesales reguladas en los artículos 31 a 38 de la misma ley.

${ }^{64}$ La Corte Suprema ha propuesto complementar esta disposición modificando el artículo 38 en el sentido de facultar al juez para que, vencido el plazo, pueda citar de oficio a los intervinientes a una audiencia destinada a que se solicite el apercibimiento del fiscal para el cierre de la investigación y que frente a su no comparecencia o negativa al cierre el juez pueda declarar el sobreseimiento definitivo de la causa. Con ello la Corte pretende incorporar de manera explícita la misma regla establecida para el sistema de adultos en el artículo 247 del CPP. Resulta interesante que la justificación de esta propuesta está en la idea de que es “...necesario que los procedimientos contra menores no se prolonguen por más tiempo que el que resulta estrictamente necesario". Véase Corte Suprema, Informe 601-2009 de 21 de octubre de 2009 por el cual la Corte Suprema informa a la Comisión de Constitución, Legislación, Justicia y Reglamento del Senado sobre modificaciones y perfeccionamientos para la LRPA.

${ }^{65}$ Indirectamente podría sostenerse que esta idea de abreviación de plazos también se refleja en el artículo $5^{\circ}$ de la LRPA que establece una norma de prescripción de la acción penal y la pena que opera con márgenes temporales mucho más estrictos que en la legislación ordinaria (simples delitos dos años, crímenes cinco años $\mathrm{y}$ faltas seis meses).
} 
señala que, tratándose de infracciones en las que el Ministerio Público solicite una pena no privativa de libertad, se debe ocupar este procedimiento. Debido a que el sistema de medidas establecido en la LRPA privilegia el uso de este tipo de penas en varios casos en que tratándose de adultos correspondería una privación de libertad, ello amplía el margen de uso de este procedimiento especial. En segundo término, de acuerdo a las reglas generales en el CPP, también correspondería utilizar el procedimiento simplificado cuando la pena requerida sea privativa de libertad y no exceda de 540 días. Si bien ha existido debate sobre esta segunda cuestión (algunos sostienen que en caso de penas privativas de libertad siempre debe utilizarse el proceso ordinario), la escasa doctrina nacional sobre el punto concuerda en la necesidad de utilizar el simplificado en esta segunda hipótesis fundándolo, entre otros argumentos, en la necesidad de contar con procedimientos más expeditos en delitos menos complejos y poco graves que satisfagan el derecho a ser juzgado en un plazo razonable. ${ }^{66}$ Comparto esta opinión. El procedimiento simplificado es un tipo de procedimiento que mantiene vigentes las garantías del debido proceso y contempla como mecanismo de resolución del caso el juicio oral ante el juez de garantía. De esta forma constituye un buen mecanismo para compatibilizar las necesidades de tiempo y garantías en el proceso juvenil. ${ }^{67}$

Los datos estadísticos disponibles del primer año de funcionamiento indican que un porcentaje importante de los casos del nuevo sistema son procesados de conformidad a las reglas del procedimiento simplificado y, en todo caso, un porcentaje superior al que eran conocidos el año anterior a su entrada en vigencia. Así, el año antes de la entrada en vigencia de la LRPA un $22,3 \%$ de los casos fue llevado en procedimiento simplificado y en cambio con la LRPA dicho porcentaje aumentó a un $29,7 \%$ de 10 casos. ${ }^{68}$ Estas mismas cifras dan cuenta que la duración promedio de los procesos juveniles son bastante breves y, por lo mismo, el problema de la falta de razonabilidad de duración de los mismos debiera ser relativamente excepcional. ${ }^{69}$ En efecto, las estadísticas muestran que al año de puesta en marcha del nuevo sistema el $72,7 \%$ de los casos ingresados se encontraban concluidos. De ellos, un $67 \%$ había concluido en menos de dos meses $(55,5 \%$ en menos de un mes y un $11,5 \%$ en menos de dos meses), otro $15,9 \%$ lo había hecho entre 2 y cuatro meses, un $10,3 \%$ entre cuatro y seis meses y sólo un $6,8 \%$ entre seis meses y un año. ${ }^{70}$

\footnotetext{
${ }^{66}$ Véase CERDA / CERDA, cit. nota $\mathrm{n}^{\circ} 12$, pp. 162-168.

${ }^{67} \mathrm{Me}$ parece que una cuestión distinta es lo que ocurre con la posibilidad de utilizar el mecanismo de reconocimiento de responsabilidad previsto en el procedimiento simplificado. En ese evento creo que es necesario fortalecer las garantías vinculadas al derecho a no autoincriminarse del joven imputado, tema que se revisaré un poco más adelante en este trabajo.

${ }^{68}$ Véase Defensoría Penal Pública, Informe, cit. nota $\mathrm{n}^{\circ} 24, \mathrm{p}$. 7. Aun cuando las cifras representan un incremento respecto a la situación previa, igualmente se podría pensar que se trata de un porcentaje bajo a la luz de la ampliación que habría tenido normativamente el procedimiento simplificado, especialmente por el tipo de penas previstas en la LRPA. No tengo respuestas claras para explicar esto. Una posibilidad es que la interpretación más limitativa respecto al uso del procedimiento simplificado esté limitando su impacto. Lamentablemente, las estadísticas e información disponible no me permiten avanzar mucho más en la explicación de esto.

${ }^{69}$ Debe tenerse presente eso si la distorsión que las cifras presentan debido a tratarse sólo del primer año de funcionamiento del sistema y, por ende, la tendencia que tienen a disminuir las duraciones promedio de los casos concluidos.

${ }^{70}$ Véase Defensoría Penal Pública, Informe, cit. nota $n^{\circ} 24$, p. 9.
} 
DUCE, MAURICIO. "El Derecho a un Juzgamiento Especializado de los Jóvenes Infractores en el Nuevo Proceso Penal Juvenil Chileno".

En esta misma dirección, la observación de audiencias permitió establecer que en la gran mayoría de casos en donde se discuten medidas cautelares personales también se produjo un debate ante el juez de garantía acerca de la determinación de un plazo judicial inferior al máximo establecido para el cierre de la investigación en el artículo 38 de la LRPA. Para ello se invoca la disposición general contenida en el artículo 234 del CPP. ${ }^{71}$ En la gran mayoría de los casos, los jueces accedieron a fijar dicho plazo judicial en rangos que normalmente se ubicaron entre los 30 y 60 días para el cierre de la investigación. ${ }^{72}$ En casos excepcionales ese plazo fue superior, siendo el plazo de 90 días el mayor concedido para el cierre dentro de las audiencias que se observaron. ${ }^{73}$

Tanto los promedios de las cifras de la Defensoría como los plazos judiciales que se fijaron en las audiencias observadas están muy por debajo de la duración total de los procesos considerando los máximos establecidos para el procedimiento ordinario en la LRPA. Por lo mismo, ello podría constituir una explicación de la inexistencia de jurisprudencia en los tribunales superiores en la materia (salvo el caso de la Corte Suprema citado en la sección previa en donde se utiliza la cláusula de plazo razonable contenida en los tratados internacionales de derechos humanos para resolver un problema de duración de internación provisoria). El sistema estaría funcionando en un ritmo razonablemente expedito, lo que no ha generado una litigación intensa sobre la materia en los tribunales superiores.

\subsection{Mayores resguardos al derecho de defensa.}

Otra de las garantías bases del debido proceso en las que se exige reforzamiento en favor de los jóvenes está constituida por el derecho de defensa. El derecho de defensa es uno de los

\footnotetext{
${ }^{71}$ Por tratarse de un mecanismo general regulado a propósito de nuestra legislación procesal penal de adultos no realizo un análisis detallado del mismo. Para quien quiera tener más información sobre el mismo recomiendo revisar además de los textos generales citados en nota pie de página 17 y también en SALAS ASTRAIN, Jaime, Problemas del Proceso Penal, Santiago: Librotecnia, 2009, pp. 100-112.

${ }^{72}$ A modo de ejemplo se pueden citar las siguientes audiencias: caso RIT 144-2009 del $7^{\circ}$ Juzgado de Garantía de Santiago de 6 de enero de 2009 que fija plazo de 60 días (se trata de un joven imputado de 17 años por lesiones leves en contexto de violencia intrafamiliar y amenazas quedando sujeto a la medida cautelar de prohibición de acercamiento a la víctima); caso RIT 128-2009 del $2^{\circ}$ Juzgado de Garantía de Santiago de la misma fecha que también fija plazo de 60 días (se trata de un joven de 16 años imputado por robo con intimidación quedando sujeto a las medidas cautelares de sujeción a la vigilancia de SENAME y prohibición de acercamiento a la víctima); caso RIT 154-2009 del 1er Juzgado de Garantía de Santiago de 7 de enero de 2009 que fija plazo de 60 días (se trata de dos jóvenes imputados por robo con violencia quedando sujetos a la medida cautelar de sujeción a la vigilancia de SENAME); caso RIT 147-2008 del 5 Juzgado de Garantía de Santiago de 14 de enero de 2009 que fija un plazo de 30 días (se trata de un joven de 16 años imputado por el delito de tenencia ilegal de armas quedando sujeto a las medidas cautelares de firma mensual ante la fiscalía y prohibición de acercamiento a la víctima).

${ }^{73}$ A modo ejemplar pueden mencionarse las audiencias en los siguientes casos: RIT 413-2009 del $9^{\circ}$ Juzgado de Garantía de Santiago de 8 de enero de 2009 en el que se fija el plazo de 90 días (se trata de un joven de 16 años imputado por el delito de porte ilegal de arma de fuego que quedó sujeto a las medidas cautelares de firma mensual ante la fiscalía y prohibición de acercamiento a la víctima); RIT 395-2009 del 1er Juzgado de Garantía de Santiago de 22 de enero de 2009 en el que se fija el plazo de 90 días (se trata de un joven de 17 años imputado por el delito de porte ilegal de arma de fuego que quedó sujeto a la medida cautelar de sujeción de vigilancia del SENAME); y, RIT 396-2009 del 1er Juzgado de Garantía de Santiago de 22 de enero de 2009 en el que se fija el plazo de 90 días (se trata de un joven de 14 años imputado por el delito de robo por sorpresa que quedó sujeto a la medida cautelar de sujeción a la vigilancia del SENAME).
} 
componentes del debido proceso de mayor complejidad en relación a los elementos que lo integran. A continuación revisaré cómo han sido recogidas en nuestra legislación las tres principales manifestaciones del derecho de defensa en donde he identificado previamente existen exigencias especiales en el derecho internacional. ${ }^{74}$

\subsubsection{Derecho a la información directa y sin demora de los cargos.}

El elemento base sobre el cual se construye el derecho de defensa es el conocimiento oportuno de los cargos que se imputan a la persona objeto de persecución penal de manera tal que, a partir de ese conocimiento, pueda desarrollar actividades conducentes a la construcción de su defensa. Sin información de cargos no hay posibilidad de desarrollar una estrategia de defensa efectiva. Es por ello que la legislación internacional ha exigido que esta información se realice en forma temprana y, especialmente, que la comunicación de los cargos se haga de una manera que sea comprensible en relación al nivel de desarrollo y madurez del joven imputado. ${ }^{75}$

Este derecho podría ser reconocido ya sea en forma directa en las leyes juveniles especializadas o por vía de aplicación de principios generales a los jóvenes. Esta segunda vía es la que es posible identificar en nuestro país. La LRPA no contiene ninguna norma que de manera específica se haga cargo de este derecho, no obstante la escasa doctrina sobre el tema reconoce explícitamente la existencia de esta dimensión del derecho de defensa. ${ }^{76}$ De otra parte, se trata de un derecho regulado en diversas disposiciones del CPP. En efecto, este derecho se encuentra consagrado de manera general en el artículo 93 a) del CPP que establece el derecho de todo imputado a que se le informe de manera "específica y clara" acerca de los hechos que se le imputaren. Esta norma pareciera resolver adecuadamente una primera exigencia del derecho referida a la información y su claridad. Además, ella es complementada por disposiciones que establecen deberes de información de este derecho, tales como el artículo 135 referido a la obligación de los funcionarios públicos a cargo de los procedimientos de detención de informarle los cargos al detenido y los artículos 132 y 230 referidos a la formalización de la investigación en la primera audiencia judicial. Estas últimas normas establecen un mecanismo temprano de aseguramiento del cumplimiento de este deber de información por vía de establecer un momento inicial de la persecución penal (la detención o la formalización de la investigación) en la que los cargos deben ser comunicados. Además, se instaura un mecanismo concreto de control de cumplimiento de ambas dimensiones de la garantía por medio de establecer la intervención de un control del juez en una audiencia temprana del caso en donde se analizará si se ha dado cumplimiento con el deber de información.

De lo expresado, se puede colegir que en nuestra legislación procesal penal una parte importante del derecho a información de los cargos se juega en la posibilidad de tener una audiencia temprana en donde se pueda verificar, ante un juez de garantía, que esta información se ha producido o se deba realizar (en caso que decida formalizarse la investigación). En esta última cuestión, la LRPA contempla una regla que podría

\footnotetext{
${ }^{74}$ Véase DUCE, “El Derecho a un Juzgamiento", cit. nota no 3, pp. 95-96.

${ }^{75}$ DUCE, "El Derecho a un Juzgamiento", cit. nota $n^{\circ} 3$, pp. 97-98.

${ }^{76}$ CERDA / CERDA, cit. nota ${ }^{\circ} 12$, pp, 191-192.
} 
DUCE, MAURICIO. "El Derecho a un Juzgamiento Especializado de los Jóvenes Infractores en el Nuevo Proceso Penal Juvenil Chileno".

considerarse de especialidad. En efecto, el artículo 31 sostiene que los adolescentes que hayan sido detenidos por la policía (ya sea en casos de flagrancia o por orden judicial) deben ser puestos a disposición del juez de garantía "de manera directa y en el menor tiempo posible", no pudiendo exceder las 24 horas. ${ }^{77}$ Si bien se trata de una regla orientada principalmente a la protección de la libertad del joven y no al derecho a la información, tiene un impacto en este último por vía de asegurar la adecuada "oportunidad" en el cumplimiento del derecho a la información de los cargos $\mathrm{y}$, por tanto, que tiende a satisfacer la idea que esta información sea "temprana". La diferencia con el sistema de adultos está en la idea de "menor tiempo posible" que ha sido interpretado con mayor exigencia que tratándose de adultos que cuentan con el mismo límite máximo de 24 horas para la realización de la audiencia. ${ }^{78}$

En las audiencias de control de la detención no se observó ningún caso en donde se impugnara la falta de información de cargo a los jóvenes detenidos. Si se pudo, en cambio, observar como en muchos casos el juez le dirigió directamente la palabra al joven imputado con el objetivo de explicarle el significado y consecuencias de lo que estaba ocurriendo en la audiencia, por ejemplo cuando se discutía una suspensión condicional del procedimiento o la posibilidad de poner término al caso en la primera audiencia. ${ }^{79}$ Además, fue muy frecuente que se le preguntara al imputado si entendía la formalización que estaba realizando el fiscal o las consecuencias de diversas instituciones procesales que se solicitaban en la audiencia.

Junto con lo anterior, la legislación internacional recomienda como mecanismo de aseguramiento de esta dimensión del derecho de defensa que se comunique a los padres o representantes legales del joven los cargos y sus derechos para asegurarse que éste los comprende. ${ }^{80}$ En esta misma dirección la LRPA contiene una norma de especialidad. En efecto, en el artículo 36 se establece que en la primera audiencia a la que deba comparecer el joven debe notificarse a sus padres o a la persona que lo tenga bajo su cuidado. En las audiencias que se observaron, se pudo establecer que la presencia de los padres era frecuente, pero en una cantidad de casos equivalentes no había comparecencia de un adulto responsable del cuidado del imputado. Frente a esto, el comportamiento de los jueces era muy heterogéneo. En algunos casos los jueces se preocupaban por averiguar si la

\footnotetext{
${ }^{77}$ En su versión original la LRPA establecía una regla más fuerte al señalar que la puesta a disposición del juez de garantía debía ser "de preferencia de manera inmediata, no pudiendo en caso alguno exceder de un máximo de 12 horas". Una explicación de esta regla y su evolución en la tramitación legislativa véase en BERRÍOS, Gonzalo, "Derecho de los Adolescentes y Actividad Persecutoria Previa al Control Judicial de la Detención", Santiago: Revista de Estudios de la Justicia, $\mathrm{n}^{\circ} 7$ (2006), pp. 141-144.

${ }^{78}$ En este sentido véase CERDA / CERDA, cit. nota ${ }^{\circ}$ 12, pp. 171-172, BUSTOS, Derecho Penal, cit. nota $\mathrm{n}^{\mathrm{o}} 11$, p. 80 aun cuando referido a la redacción original del artículo 31.

${ }^{79}$ Véase por ejemplo audiencias RIT 28-2009; 53-2009; 81-2009; y, 83-2009, todas del $14^{\circ}$ Juzgado de Garantía de Santiago realizadas el día 5 de enero de 2009. En materia de suspensión condicional del procedimiento véase como ejemplos audiencias: RIT 209-2009 del $9^{\circ}$ Juzgado de Garantía de Santiago de 8 de enero de 2009; RIT 492-2009 del $4^{\circ}$ Juzgado de Garantía de Santiago de 13 de enero de 2009; RIT 3032009 del $13^{\circ}$ Juzgado de Garantía de Santiago de 13 de enero de 2009; y, RIT 496-2009 del 15 de enero de 2009.

${ }^{80}$ Véase DUCE, “El Derecho a un Juzgamiento”, cit. nota nº 3, pp. 97-98.
} 
notificación había sido realizada y en otros la audiencia simplemente continuaba sin que existiera ninguna indicación especial del juez respecto a la inasistencia de los padres. ${ }^{81}$

\subsubsection{Derecho a ser oído en forma directa.}

Un elemento central del derecho de defensa establecido en favor de los jóvenes objeto de una imputación penal es el derecho que tienen a ser escuchado por las diversas autoridades y en las diversas etapas de tramitación de los procesos penales. En esta dirección, la CDN contempla exigencias fuertes respecto a la participación de los niños en el proceso, especialmente enfatizando la posibilidad que intervengan en forma directa dando su opinión respecto a las decisiones que lo puedan afectar, lo cual supone como mínimo contar con información que permita a los jóvenes expresar su punto de vista. ${ }^{82}$ La importancia de este derecho ha sido recientemente enfatizada por el Comité de Derechos del Niño por medio de la elaboración de una nueva observación general referida específicamente al tema del derecho del niño a ser oído. ${ }^{83}$ En la sección relativa al derecho a ser escuchado en procedimientos penales judiciales, se contienen recomendaciones similares a las ya identificadas en el trabajo que sirve de base del presente. ${ }^{84}$

La LRPA no parece contener disposiciones específicas sobre la materia que sean distintas a las reglas generales del CPP en donde se permite al imputado intervenir y se establece su derecho a ser oído. Con todo, la poca doctrina especializada ha resaltado la existencia de este derecho como un principio central del proceso del nuevo sistema. Así, Bustos, siguiendo las normas internacionales, señala que este derecho "...surge del reconocimiento de la dignidad en cuenta persona del niño o adolescente, y más concretamente, de su carácter ciudadano...." ${ }^{85}$ Incluso más, Bustos argumenta, basándose en alguna jurisprudencia de España, que la omisión de escuchar al joven podría acarrear la nulidad de la actuación respectiva. ${ }^{86}$ En cuanto a sus alcances, Bustos señala que se trata de un derecho que se extiende no sólo a lo largo del proceso sino que también cubre la etapa de ejecución de la pena e impone deberes no sólo a los jueces, sino a que a toda autoridad administrativa (incluyendo a fiscales, defensores, autoridades penitenciarias entre otros). ${ }^{87}$ Finalmente, sostiene que este derecho supone como base, al igual que lo que ha sido argumentado en sede internacional, una información adecuada de sus derechos al joven. ${ }^{88}$

No obstante la carencia de normas y escasa doctrina en esta materia, durante la investigación fue posible encontrar uno de los fallos más interesantes sobre el principio de especialidad emanados de las Cortes de Apelaciones nacionales. Se trata de un caso

\footnotetext{
${ }^{81}$ Volveré sobre este tema con algo más de detalle en Infra 1.3.3 citando algunas audiencias específicas a modo de ejemplo.

${ }^{82}$ Véase DUCE, "El Derecho a un Juzgamiento", cit. nota no 3, pp. 98-99.

${ }^{83}$ Véase Comité de Derechos del Niño, Observación General n ${ }^{\circ} 12$ "El Derecho del Niño a Ser Escuchado", Julio de 2009.

${ }^{84}$ Véase párrafos 57 a 64 referidos tanto al niño infractor como al niño víctima y testigo.

${ }^{85}$ BUSTOS, Derecho Penal, cit. nota ${ }^{\circ} 11$, p. 75.

${ }^{86}$ BUSTOS, Derecho Penal, cit. nota $n^{\circ} 11$, p. 75.

${ }^{87}$ BUSTOS, Derecho Penal, cit. nota ${ }^{\circ} 11$, p. 75.

${ }^{88}$ BUSTOS, Derecho Penal, cit. nota n ${ }^{\circ} 11$, p. 76.
} 
DUCE, MAURICIO. "El Derecho a un Juzgamiento Especializado de los Jóvenes Infractores en el Nuevo Proceso Penal Juvenil Chileno".

resuelto por la Corte de Apelaciones de Concepción el 8 de agosto de 2008 originado por un recurso de amparo. ${ }^{89}$ El amparo fue interpuesto por el defensor del joven en contra de la resolución de la juez de garantía por medio de la cual se decretó el quebrantamiento de la medida originalmente impuesta en la sentencia (60 días de libertad asistida simple) y se la reemplazó por 30 días de internación en régimen semi-cerrado. La defensa argumentó que no se cumplió con el deber de oír al adolescente ya que si bien su abogado estuvo presente en la audiencia respectiva, el joven no participó de ella sin que el tribunal pudiera ponderar la gravedad del quebrantamiento. La defensa argumenta que al no ser oído el joven en forma directa, no se dio cumplimiento al artículo 52 de la LRPA que establece que para decretar el quebrantamiento es necesario realizar una audiencia previa. La defensa interpreta que ello supone la comparecencia personal del imputado. En su informe, la juez de garantía argumenta que el joven no asistió tanto a la audiencia para determinar el plan de intervención individual que suponía la libertad vigilada meses antes y que tampoco lo hizo, a pesar de estar debidamente notificado, a la audiencia de quebrantamiento. Agrega que en ella sí compareció su abogado defensor quien accedió a discutir el quebrantamiento.

En este contexto, la Corte de Apelaciones de Concepción realiza un análisis muy interesante. Parte por señalar que la exigencia de "audiencia previa" del artículo 52 de la LRPA busca permitir el ejercicio de la contradicción, elemento que habría estado presente el caso al haber participado el defensor y tenido la posibilidad de argumentar y debatir sobre el quebrantamiento. ${ }^{90}$ Con todo, señala que con eso no basta ya que en esta materia:

“...el juez debe ser aún más cuidadoso en el respeto a los principios más arriba indicados, desde que en virtud del interés superior del adolescente a que se refiere el artículo $2^{\circ}$ de la ley en comento, el reconocimiento y respeto de los derechos del menor infractor deben ser estrictamente controlados para que puedan así tener un cumplimiento efectivo y no simplemente ficto". 91

De esta forma, invocando el derecho a ser oído contemplado en el artículo 12 de la CDN la Corte establece que ella “...obligaba a la juez recurrida a ser más estricta en lo concerniente a la presencia del menor infractor en la audiencia mencionada, ya que evidentemente lo obrado en ella podía afectarle, tal como en los hechos acaeció, porque de una sanción no privativa de libertad se pasó a una privativa de la misma". ${ }^{92}$ Por lo mismo, la Corte concluye señalando "Así las cosas, y acorde a una interpretación conforme a la norma de rango superior anotada, el citado artículo 52 debe ser aplicado entendiendo que la "previa audiencia" de que trata, debe contar necesariamente con la presencia del adolescente infractor". ${ }^{93}$ Como se puede suponer, a partir de las consideraciones previas la Corte acogió el amparo revocando la decisión de la juez de garantía y ordenando una nueva audiencia de artículo 52 de la LRPA con comparecencia personal del joven.

\footnotetext{
${ }^{89}$ Véase Sentencia de la Corte de Apelaciones de Concepción de 8 de agosto de 2008 en causa rol n ${ }^{\circ} 89-2008$.

${ }^{90}$ Véase considerando $2^{\circ}$.

${ }^{91}$ Véase Considerando $3^{\circ}$.

${ }^{92}$ Véase considerando $4^{\circ}$.

${ }^{93}$ Véase considerando $4^{\circ}$.
} 
Hay varios temas que me interesa destacar de la sentencia brevemente resumida. La primera de ellas tiene que ver con el uso que hace la Corte de la legislación internacional. Como se puede apreciar, la Corte recurre expresamente a la CDN e identifica con precisión el derecho a ser oído como el punto que se pone en juego en el caso, argumentando acerca de la necesidad de utilizar esta normativa para interpretar la legislación nacional. En segundo lugar, la Corte identifica la necesidad de interpretar las normas de la LRPA tomando en consideración un estándar más estricto que tratándose de la legislación común debido a los valores en juego en el sistema, especialmente el interés superior del niño. Finalmente, el esfuerzo de la Corte por construir un estándar a partir de una norma que podría haberse interpretado con relativa formalidad. En efecto, la Corte podría haberse quedado con la idea que al participar el defensor en la audiencia, el joven tuvo la posibilidad de expresar su punto de vista al tribunal. Con todo, la Corte señala que la idea de ser oído supone una cuestión de fondo que es que el propio joven participe en forma directa en la audiencia. Me parece que esto recoge con bastante precisión el sentido profundo de esta garantía tal cual como es concebida en el ámbito del derecho internacional de los derechos humanos.

La observación de audiencias también permite tener una idea acerca de cómo se desarrollan algunas prácticas vinculadas al ejercicio de este derecho en los juzgados de garantía. Señalé precedentemente que en una cantidad importante de casos se pudo observar un esfuerzo especial de parte de los jueces de explicar con claridad a los jóvenes imputados las diversas cuestiones que ocurrían en la audiencia, lo que he señalado constituye un supuesto para permitir la participación de los jóvenes y el correcto ejercicio del derecho a ser oídos en el tribunal. En muchos casos los jueces preguntaban en forma directa a los jóvenes si comprendían lo que estaba ocurriendo.

Respecto al ejercicio de su derecho a ser oído de parte de los jóvenes imputados, se pudo constatar que sólo en casos excepcionales estos manifestaron su punto de vista respecto a alguna solicitud del Ministerio Público o debate en la audiencia o el juez preguntó directamente la opinión que tenían sobre ellas. Un ejemplo de esto último se produjo en la audiencia del caso RIT 133-2009 de 7 de enero de 2009 ante el $14^{\circ}$ juzgado de garantía de Santiago. Allí se pudo observar como frente a la solicitud de internación provisoria y a la negativa de la defensa el tribunal preguntó a los padres acerca de la situación escolar del joven y luego preguntó al mismo su opinión sobre la solicitud del Ministerio Público ante lo cual su respuesta fue quería entrar a estudiar y no estar privado de libertad. ${ }^{94}$

Casos como el descrito fueron excepcionales. Esto me lleva a preguntar acerca de las razones de este comportamiento. En primer lugar, parece que parte de la heterogeneidad de comportamiento de los jueces podría explicarse como consecuencia de un problema de falta de especialización de los mismos. En segundo termino, me parece que una parte importante del escaso ejercicio del derecho a ser oído de parte de los jóvenes es una consecuencia de la dinámica adversarial que se ha adquirido el proceso juvenil en nuestro país, el cual ha

\footnotetext{
${ }^{94}$ Otro ejemplo puede verse en la audiencia RIT 319-2009 del 8 Juzgado de garantía de Santiago de 13 de enero de 2009 en donde la jueza pregunta al joven imputado si tiene algo que agregar antes de dictar sentencia en un caso en el que el imputado admite responsabilidad en procedimiento simplificado. El joven no señala nada adicional. Esto mismo se repitió en varios casos en que la misma jueza llevó adelante la audiencia.
} 
DUCE, MAURICIO. "El Derecho a un Juzgamiento Especializado de los Jóvenes Infractores en el Nuevo Proceso Penal Juvenil Chileno".

asumido y se ha construido sobre la base del modelo instalado en el sistema de adultos sin una reflexión especial de parte de los actores del sistema (jueces, fiscales y defensores) ni por parte de la doctrina nacional acerca de las limitaciones que presenta dicha dinámica para el cumplimiento de los objetivos del sistema de justicia juvenil. Finalmente, me parece que también se pueden identificar carencias respecto al las condiciones que se dan para que el joven pueda ejercer su derecho (información, ámbito de confidencialidad, etc.). Me parece que se trata de un área en la cual se requeriría más información para obtener algún tipo de respuesta más definitiva. Con todo, intuyo la existencia de un problema de diseño institucional en extremo complejo cuyo alcance creo supera los objetivos de este trabajo.

\subsubsection{Derecho a la asistencia apropiada.}

El ejercicio personal del derecho de defensa por parte del joven y el cumplimiento del derecho a ser oído normalmente no bastarán por sí solos para asegurar una defensa efectiva de los niños y jóvenes imputados. Para estos efectos, un derecho adicional contemplado en la legislación internacional es el de contar con una asistencia apropiada. A este respecto la legislación internacional, en especial la $\mathrm{CDN}$, permite que esa asistencia sea prestada por otros profesionales (por ejemplo asistentes sociales) en la medida que sea "apropiada". Además, se establece que para que esta garantía sea cumplida en forma correcta, se requiere que la asistencia sea prestada en forma oportuna (desde los momentos iniciales de la persecución penal), sea gratuita y tenga carácter permanente (es decir durante todos las etapas del proceso). ${ }^{95}$

En el ámbito comparado es posible identificar una tendencia a elevar el estándar de "asistencia apropiada" al hacerla equivalente a la asistencia letrada. De esta forma, un mecanismo común para asegurar este derecho es el de poner a disposición del joven un abogado defensor desde etapas muy tempranas del proceso seguido en su contra. Ejemplos de lo anterior son Costa Rica que regula este tema en los artículos 22 y 37 de la LJPJ y España que lo contempla en el artículo 22.1 y 22.2 de su LO/2000.

Nuestro sistema de responsabilidad penal juvenil ha seguido un camino similar al que se produce en el contexto de los países mencionados precedentemente. Si bien la LRPA no establece disposiciones explícitas en la materia ${ }^{96}$, por aplicación de las reglas generales del CPP (artículos 7, 8, 97 b y 102 y siguientes) se entiende que el joven imputado tiene derecho a contar con un defensor (de confianza o público) desde los actos iniciales del procedimiento y hasta la completa ejecución de la sentencia. Con esto se aseguraría la oportunidad y permanencia exigidas por la legislación internacional a la asistencia apropiada. Junto con lo anterior, la Defensoría Penal Pública ha creado, a partir de enero de 2006, la Unidad de Defensa Penal Juvenil cuyo objetivo básico ha sido el garantizar una

\footnotetext{
${ }^{95}$ DUCE, “El Derecho a un Juzgamiento”, cit. nota no 3, pp. 99-100.

96 Tal vez la única que se refiere a la presencia del defensor es el artículo 31 de la LRPA que establece que sólo se puede tomar declaración por parte del Ministerio Público en el período de detención policial del imputado si está presente el defensor del mismo, agregándose que la presencia de este es indispensable en cualquier actuación en que se requiera al adolescente y que exceda la mera acreditación de su identidad. Volveré sobre esta norma en la próxima sección a propósito de la renuncia de derechos y el derecho a no auto incriminarse del joven imputado.
} 
defensa técnica especializada de los jóvenes infractores. ${ }^{97}$ De esta forma no sólo se ha pretendido asegurar la presencia de un defensor, sino que de uno de carácter especializado. ${ }^{98}$ Todo ello permite satisfacer también la exigencia de gratuidad. En consecuencia, como se puede apreciar pareciera que se trata de una garantía en la cual nuestro sistema contempla un mecanismo idóneo de protección.

El artículo 36 de la LRPA que establece la necesidad de notificación de los padres del imputado de la realización de la primera audiencia podría ser leído como un complemento del derecho a una asistencia apropiada del joven. En efecto, la disposición citada no sólo establece la obligación de su notificación, sino que también permite que intervengan en la audiencia si es que el juez lo considera necesario. Debido a lo ambiguo de la cláusula que permite al juez aceptar la intervención de un adulto en la audiencia, ésta podría ser utilizada en casos en los que ella resultara contraria a la defensa de los intereses del joven imputado. La escasa doctrina nacional en la materia estima que se da el supuesto del artículo 36 cuando se trata de un adulto que vela por los intereses del joven teniendo siempre en consideración el interés superior del mismo. ${ }^{99}$ Con esta interpretación se reforzaría el rol de asistencia de los padres y se evitaría que su intervención pudiera jugar en contra de los intereses del joven. Me parece se trata de la interpretación más razonable de dicha norma. La intervención de los padres del joven imputado debe verse condicionada a que ella represente una forma en que el joven pueda expresarse y ejercer su derecho a defensa y no cómo un derecho autónomo de los padres. En esa misma dirección el hecho que el artículo 36 de la LRPA le entregue facultades al juez para calificar la necesidad de la intervención de los padres abona la idea que no se trata de un derecho de opinar autónomo, sino que la necesidad se asocia a la posibilidad que los padres sean un mecanismo para asegurar la asistencia apropiada del joven en cuestión.

El Ministerio Público ha interpretado que el término "notificación" se usa como equivalente a informar o dar aviso a los padres, por lo mismo no se establece una consecuencia procesal por la falta de notificación y, además, ello explica que la audiencia pueda ser llevada adelante sin que los padres del adolescente imputado participen en la misma. ${ }^{100} \mathrm{La}$ redacción del artículo 36 apoya dicha interpretación, toda vez que condiciona la posibilidad de otorgarle la palabra a los padres al hecho que estén presentes.

En la observación de audiencias se pudo apreciar un comportamiento muy heterogéneo en los jueces sobre el punto. Algunos jueces manifestaban preocupación preguntando siempre

\footnotetext{
${ }^{97}$ Antecedentes generales sobre esta unidad pueden verse en Defensoría Penal Pública, Memoria Anual 2008, Santiago: 2009, pp. 55-67.

${ }^{98}$ De acuerdo a la propia Defensoría señala en su Memoria Anual 2008, el total de adolescentes atendidos por un defensor penal juvenil fue de $61,7 \%$ del total de imputados a nivel nacional. Para quienes quieran conocer el desempeño de estos defensores juveniles, existe un reciente estudio encargado por la Defensoría a una consultora externa (CCI Ingeniería Económica) acerca de la valoración de los actores del sistema al trabajo de los defensores juveniles que arroja resultados muy positivos de su gestión en comparación con el trabajo de defensores públicos comunes y privados. Véase, Informe Final: Valoración de los Actores del Nuevo Sistema de Justicia Penal Adolescente Acerca de la Defensa Penal Juvenil, Santiago: Noviembre, 2009, 171 pp. (documento en formato electrónico en archivo del autor).

${ }^{99}$ Véase CERDA / CERDA, cit. nota $\mathrm{n}^{\circ} 12$, pp. 178.

${ }^{100}$ Fiscalía Nacional, Oficio $n^{\circ} 511$ Instructivo $n^{\circ} 7$ de la Ley 20.084, de 23 de abril de 2007, p. 7.
} 
DUCE, MAURICIO. "El Derecho a un Juzgamiento Especializado de los Jóvenes Infractores en el Nuevo Proceso Penal Juvenil Chileno".

sobre la presencia de adultos responsables. ${ }^{101}$ En caso de no estar presente se verificaba si había habido notificación y se seguía adelante. En algunos casos excepcionales los jueces ordenaron notificar a los adultos no presentes de los resultados de la audiencia ${ }^{102}$ o incluso oficiar a Carabineros por incumplimiento del deber de notificación de la misma. ${ }^{103}$ En el otro extremo, hubo jueces que derechamente no preguntaban siquiera si había presencia de algún adulto responsable o si había existido notificación. ${ }^{104}$ En todos los casos, la inasistencia o falta de notificación del adulto no se tradujo en la suspensión de la audiencia, la que continuó su curso regular.

\subsection{Exigencias más estrictas para la renuncia de derechos que integran al debido proceso.}

La legislación internacional reconoce a niños y jóvenes que son objeto de persecución penal la posibilidad de renunciar a ciertos derechos procesales, especialmente cuando esa renuncia les puede permitir obtener una mejor posición para satisfacer sus intereses. En ese contexto, el gran desafío que impone la legislación internacional a los Estados es el de reforzar los mecanismos de aseguramiento de la voluntariedad e información que deben tener los jóvenes al momento de renunciar a un derecho, tomando especialmente en consideración que por su madurez y estado de desarrollo personal no tienen las mismas capacidades que un adulto para comprender las consecuencias de sus decisiones. ${ }^{105}$

La posibilidad de renunciar a derechos se produce en una amplia gama de situaciones. Las dos que me parecen más paradigmáticas y en las que es posible encontrar alguna regulación especial y debate en nuestro país se refieren a la renuncia del derecho a no autoincriminarse (principalmente a la posibilidad del joven imputado de prestar declaración en el proceso, especialmente antes del juicio) y la renuncia del derecho a un juicio oral (básicamente por medio de la aceptación de un procedimiento abreviado). En lo que sigue analizaré las condiciones bajo las cuales nuestra legislación permite la renuncia a este derecho en estas dos hipótesis.

\subsubsection{Renuncia al derecho a no autoincriminarse.}

En materia de renuncia al derecho a no autoincriminarse (en su dimensión del derecho a guardar silencio), la LRPA reconoce la posibilidad del joven imputado de prestar declaración desde etapas tempranas en el procedimiento seguido en su contra, pero estableciendo un conjunto de exigencias que marcan una diferencia importante con el tratamiento de adultos en la materia. En efecto, el artículo 31 de la LRPA contiene una de

\footnotetext{
${ }^{101}$ Véase por ejemplo audiencias RIT $1144-2009$ y 252-2009, ambas del $7^{\circ}$ Juzgado de Garantía de Santiago de 6 de enero de 2009 y RIT 111-2009 del 14 Juzgado de Garantía de Santiago de 6 de enero de 2009.

${ }^{102}$ Véase audiencia RIT 67-2009 del $3^{\circ}$ Juzgado de Garantía de Santiago de 6 de enero de 2009.

${ }^{103}$ Véase audiencia RIT 351-2009 de 8 de enero de 2009.

${ }^{104}$ Por ejemplo véase audiencias RIT 303-2009 y 158-2009 del 7 de enero de 2009 y audiencia RIT 319-2009 del 13 de enero de 2009.

${ }^{105}$ Sobre la regulación internacional véase DUCE, "El Derecho a un Juzgamiento", cit. nota n 3, pp. 101 y 102; con más detalle sobre la justificación de este estándar más estricto véase ESTRADA, Francisco "La Renuncia al Derecho a Guardar Silencio por un Adolescente en Nuestro Ordenamiento y en el Estadounidense: Comentario a Propósito del Fallo In re E.T.C”, Revista de Derechos del Niño números 3 y 4 (2006), pp. 181-196.
} 
las normas más significativas en términos de la especialidad del proceso juvenil en nuestro país. De acuerdo a dicha norma se establece, a propósito de regular la detención en caso de flagrancia, que "El adolescente sólo podrá declarar ante el fiscal en presencia de un defensor, cuya participación será indispensable en cualquier actuación que se requiera al adolescente y que exceda de la mera acreditación de su identidad". ${ }^{106}$

Como se puede observar, nuestra legislación pareciera seguir en la materia una solución similar a la adoptada en países como España, Costa Rica y en algunos Estados de los Estados Unidos. ${ }^{107}$

En su base, la LRPA permite la declaración del joven, pero condiciona su validez a la presencia de un abogado defensor que cumpla con la función de asesoraría, mecanismo que ofrece garantías que la renuncia que se haga sea efectivamente voluntaria. La doctrina nacional concuerda que por esta vía se produce un elevamiento importante de los estándares de la LRPA en relación a nuestra legislación de adultos en donde no existe una exigencia equivalente. ${ }^{108}$ Además, específicamente se hace cargo que la presencia del defensor no se exige simplemente para que cumpla una función de observador neutral que entregue validez a la declaración, sino para que cumpla una función específica de "....aconsejar legalmente a su cliente y asegurar así su derecho a defensa."109 En consecuencia, esto supone que antes de decidir prestar su declaración el joven tiene que haber tenido la oportunidad de conversar con su abogado sobre la materia. El abogado no sólo debiera asegurarse que el joven conoce su derecho a no prestar declaración (el que debiera haber sido informado por la policía de acuerdo a las reglas generales en la materia previstas en el CPP), sino que también que comprende las consecuencias que podrían producirse a partir de decidir declarar o no.

Junto con la presencia del abogado, el artículo 31 de la LRPA establece una que la declaración del joven debe ser prestada ante el fiscal. Con esto se agrega una exigencia adicional destinada a asegurar la voluntariedad de la decisión a no guardar silencio, lo que "...resta toda validez incriminatoria a declaraciones prestadas ante la policía". ${ }^{110}$ La idea detrás de esta exigencia tiene que ver con el mayor riesgo que existiría al entregar en forma autónoma a la policía la posibilidad de obtener declaraciones autoinculpatorias del joven, aún con abogado presente. A su vez, la doctrina se ha preocupado de pronunciarse sobre los efectos que debiera tener la infracción de esta regla. Se ha sostenido que ella debiera dar lugar a la exclusión de todo el material probatorio obtenido directa o indirectamente gracias

\footnotetext{
${ }^{106}$ Cabe señalar que el artículo 31 fue modificado en la parte transcrita por la Ley no 20.191 publicada en el Diario Oficial el 2 de junio de 2007. Hasta antes de esa modificación la norma sólo contenía la regla que establecía que la declaración del adolescente sólo podía producirse ante el fiscal y en presencia de un defensor. Dicha modificación se produjo en el contexto de una reconfiguración de la norma respecto a la extensión temporal máxima de la detención en sede policial. En todo caso, se trata de una norma que tuvo diversas versiones en su etapa de debate legislativo. Sobre la evolución de esta disposición en su etapa legislativa véase BERRÍOS, "Derecho de los Adolescentes", cit. nota n 77, pp. 141-143.

${ }^{107}$ Véase DUCE / COUSO, El Derecho a un Juzgamiento, cit. nota ${ }^{\circ} 4$.

${ }^{108}$ Véase ESTRADA, "La Renuncia" cit. nota n 105, p.191; BERRÍOS, "Derecho de los Adolescentes", cit. nota $n^{\circ} 77$, pp. 150-151 y CERDA / CERDA, cit. nota $n^{\circ} 12$, p. 173.

${ }^{109}$ Véase BERRÍOS, "Derecho de los Adolescentes", cit. nota no 77, p. 152.

${ }^{110}$ Véase BERRÍOS, “Derecho de los Adolescentes”, cit. nota no 77, p. 150.
} 
DUCE, MAURICIO. "El Derecho a un Juzgamiento Especializado de los Jóvenes Infractores en el Nuevo Proceso Penal Juvenil Chileno".

al interrogatorio por infracción de garantías fundamentales ${ }^{111} \mathrm{y}$ otros han sostenido otra consecuencia es que debiera ser excluido de un proceso en contra de un adolescente imputado cualquier testimonio de oídas en el que se haga referencia a una supuesta declaración del mismo en sede policial sin cumplimiento de las condiciones analizadas previamente. $^{112}$

En esta misma dirección pudimos identificar alguna jurisprudencia. Así, existe un caso de la Corte de Apelaciones de Antofagasta que se pronuncia sobre el punto. ${ }^{113}$ La Corte conoce de un recurso de apelación interpuesto por el Ministerio Público en contra de un auto de apertura de juicio oral por el cual se excluyó por vulneración de garantías la declaración parcial de un Carabinero que incluía información de una supuesta declaración voluntaria que el joven imputado habría prestado al momento de practicar su detención y registro. El Ministerio Público argumenta que no se trata de una diligencia de investigación policial realizada sin la presencia del defensor, sino lo que podría identificarse como un "descubrimiento casual". La Defensa argumenta, por su parte, la infracción al artículo 31 de la LRPA, lo que justificaría la decisión del auto de apertura de juicio oral impugnado por el Ministerio Público. La Corte rechaza la apelación invocando el artículo 31 de la LRPA señalando:

“...que efectivamente la declaración de un adolescente incorporada al procedimiento penal, a través de la declaración de un funcionario policial, adolece de nulidad, como fuera declarado por el juez de la instancia, ya que vulnera su derecho a la defensa técnica, tanto o más imprescindible tratándose de un adolescente de quince años..."114

Como se puede observar existe coincidencia con la solución que propone la Corte, no obstante identifica que se trata de un problema de derecho de defensa. Por otra parte, se echa de menos que la Corte se haga cargo en forma más sistemática del argumento de la fiscalía en relación a la posible excepción que representaría un caso de este tipo. La Corte, en cambio, parece sostener un criterio absoluto de exclusión a todo evento de la declaración del imputado frente a la policía sin entrar a las peculiaridades del caso concreto.

El artículo 31 de la LRPA en estudio contempla otro mecanismo especializado de protección del derecho a no autoincriminarse al establecer que la participación del abogado defensor es necesaria en cualquier actuación que se requiera al adolescente y que exceda de la mera acreditación de su identidad. Como se puede apreciar, se trata de una norma que regula como condición de validez de diligencias en donde se requiera contar con la cooperación del adolescente imputado la presencia de su defensor (por ejemplo de un reconocimiento en rueda). Por lo tanto, apunta a una cuestión distinta al derecho a guardar silencio, pero que claramente se orienta a resguardar el derecho a no autoincriminarse. En efecto, lo que buscaría una norma de este tipo es evitar que se obtenga la cooperación del imputado (por ejemplo en permitir un registro de su domicilio) sin previamente contar con

\footnotetext{
${ }^{111}$ Véase ESTRADA, "La Renuncia”, cit. nota ${ }^{\circ} 105$, p. 193.

${ }^{112}$ Véase BERRÍOS, “Derecho de los Adolescentes", cit. nota n 77, p. 155.

${ }^{113}$ Véase Sentencia de la Corte de Apelaciones de Antofagasta de 29 de febrero de 2008 en causa rol n ${ }^{\circ} 28-$ 2008.

${ }^{114}$ Véase considerando $6^{\circ}$.
} 
la asesoría de su abogado defensor en los términos que hemos explicado respecto al derecho a guardar silencio. El imputado podría autoincriminarse sin tomar una decisión voluntaria permitiendo, por ejemplo, que la policía ingrese a su domicilio e incaute material que luego pueda ser ocupado como prueba en su contra en el caso. Establecer los alcances de esta norma de resguardo no es sencillo. Desafortunadamente se trata de un tema que no ha sido abordado por la doctrina nacional. ${ }^{115}$

Pude identificar algunos fallos a nivel de Cortes de Apelaciones que son interesantes en la materia. Una primera decisión en la materia proviene de la Corte de Apelaciones de Coyhaique. ${ }^{116}$ Se trata de un caso en que el Ministerio Público apela de un auto de apertura de juicio oral en el cual el juez de garantía excluyó como prueba para el juicio oral dos fotografías de la planta de la zapatilla del adolescente imputado al momento en que se encontraba detenido en situación de flagrancia sin la presencia de su abogado. La físcalía justifica la legalidad de la prueba argumentando que se trata de una actividad amparada por la facultad de la policía de registrar a los detenidos y que, en todo caso, se trataría de una diligencia realizada de buena fe. La Corte rechaza la apelación ya que considera que se trata de una diligencia que va más allá de la simple identificación del imputado, por lo cual al haberse practicado sin la presencia del defensor se han vulnerado garantías y resulta una prueba obtenida en forma espuria. La garantía que se identifica vulnerada es el derecho de defensa y a una investigación racional y justa. La Corte no profundiza sobre los objetivos de la norma en estudio o de las razones de fondo que justifican su aplicación.

Un segundo caso lo constituye una sentencia de la Corte de Apelaciones de La Serena recaída en una apelación de un auto de apertura de juicio oral presentada por el Ministerio Público frente a una exclusión de prueba por motivos de infracción de garantías fundamentales. ${ }^{117}$ La Corte sostiene que la presencia del defensor exigida por el artículo 31 de la LRPA no es sólo para las detenciones en flagrancia, sino que se extiende a cualquier otra actuación en la que se requiere al adolescente tal cual lo señala su tenor literal. Desafortunadamente, la sentencia no contiene más información que permita ver el contexto concreto en el que se presentó el problema que dio origen a la apelación del Ministerio Público en el caso específico. Esto dificulta un análisis mayor de esta sentencia.

Un tercer fallo que contiene más información sobre el punto corresponde a una sentencia dictada por la Corte de Apelaciones de Antofagasta. ${ }^{118}$ Se trata también de un caso en que el Ministerio Público interpone un recurso de apelación en contra de un auto de apertura de juicio oral en el que se excluyó del juicio, por vulneración de garantías fundamentales, un peritaje huellográfico practicado respecto del adolescente imputado que se encontraba en privación de libertad sin la presencia de su defensor. El Ministerio Público argumenta que la exclusión fue errónea ya que no se trataba de una situación de flagrancia y, por tanto, no

\footnotetext{
${ }^{115}$ El único texto que se refiere con alguna extensión sobre el tema es el de Gonzalo Berríos que ha sido citado en varias oportunidades en este capítulo. Desafortunadamente se refiere a la versión previa a la reforma del artículo 31 de la LRPA por lo que sus argumentos no se aplican directamente al actual estándar normativo.

${ }^{116}$ Véase Sentencia de la Corte de Apelaciones de Coyhaique en causa rol rol no 110-2007 de 11 de diciembre de 2007.

${ }^{117}$ Véase Sentencia de la Corte de Apelaciones de La Serena en causa rol no 7-2008 de 25 de enero de 2008.

${ }^{118}$ Véase Sentencia de la Corte de Apelaciones de Antofagasta en causa rol rol no $282-2008$ de 9 de diciembre de 2008 .
} 
DUCE, MAURICIO. "El Derecho a un Juzgamiento Especializado de los Jóvenes Infractores en el Nuevo Proceso Penal Juvenil Chileno".

se podía extender la regla prevista en el artículo 31 de la LRPA. La Corte confirma la decisión del juez de garantía señalando que la apelación no procede "...toda vez que el artículo 31 de la Ley 20.084 rige en toda circunstancia en que no se requiera al menor adolescente y no sólo en el ámbito de detención por flagrancia." ${ }^{119}$ Al identificar la garantía afectada la Corte indica que en este caso se afectó el derecho a defensa técnica y no se refiere al derecho a no autoincriminarse. Se trata también de un fallo escueto, pero en el que existe un intento de dar razones de fondo y no solo formales. Así, la Corte señala que para tomar esta decisión se debe tener presente la necesidad que los jóvenes de tener resguardos adicionales respecto a los adultos. ${ }^{120}$

Existe un cuarto caso más reciente resuelto por la Corte de Apelaciones de Arica que se pronuncia en el mismo sentido que los anteriores. ${ }^{121}$ También se trata de una apelación interpuesta por el Ministerio Público a un auto de apertura de juicio oral en donde se excluyo una pericia planimétrica por inobservancia de garantías producto de la no presencia del abogado defensor en la realización de la misma. Al decidir, la Corte señala que:

“...es necesario tener presente que la justicia aplicada a los menores de edad, debe contener resguardos adicionales, al tratarse de individuos en formación y deberían comparecer a los Tribunales de Justicia al menos en igualdad de condiciones que un adulto y tener la posibilidad incluso de obtener circunstancias más ventajosas"122

Esto lleva a la Corte a rechazar la apelación y hacer aplicable el artículo 31 de la LRPA a “...cualquier otra actuación en que se requiera al adolescente y que exceda de la mera acreditación de su identidad". 123

A pesar que ninguna de estas sentencias identifica en mi opinión en forma correcta la garantía en juego, como tampoco profundizan en los fundamentos del artículo 31 de la LRPA, ellas parecen consolidar al menos dos cuestiones relevantes para determinar los alcances de la norma en estudio. En primer lugar, parece quedar claro que la exigencia de defensor no solo abarca situaciones en las que el adolescente se encuentra detenido en una situación de flagrancia sino que se extiende a toda diligencia que se realice durante la investigación. En segundo lugar, las sentencias validan la decisión de los jueces de garantía de establecer como sanción al incumplimiento de la presencia del defensor la exclusión de la prueba obtenida por considerar que ha sido producida con vulneración de garantías del imputado. En consecuencia, la jurisprudencia no sólo parece sostener una interpretación amplia de la norma en estudio sino que ha consolidado un mecanismo de protección para la misma en el mismo sentido que la doctrina se ha pronunciado.

En este contexto, existe un fallo de la Corte de Apelaciones de Copiapó ${ }^{124}$ que va sobre un problema adicional que se plantea una vez asentada la doctrina anterior cual es determinar

\footnotetext{
${ }^{119}$ Véase considerando $5^{\circ}$.

${ }^{120}$ Véase considerando $7^{\circ}$.

${ }^{121}$ Véase Sentencia de la Corte de Apelaciones de Arica en causa rol n 211-2009 de 28 de septiembre de 2009.

${ }^{122}$ Véase considerando $6^{\circ}$.

${ }^{123}$ Véase considerando $7^{\circ}$.

${ }^{124}$ Véase Sentencia de la Corte de Apelaciones de Copiapó en causa rol n 307-2008 de 16 de marzo de 2009.
} 
Polit. crim. Vol. 5, № 10 (Diciembre 2010), Art. 1, pp. 280-340.

[http://www.politicacriminal.cl/Vol_05/n_10/Vol5N10A1.pdf]

en qué tipo de actuaciones de investigación realizadas por el Ministerio Público o la policía se exige la presencia del defensor. El caso se origina por un recurso de nulidad interpuesto por la defensa del adolescente en contra de la sentencia condenatoria basado en diversas infracciones de la causal del artículo 373 b) del CPP, es decir, por errónea aplicación del derecho que ha influido sustancialmente en lo dispositivo del fallo. En la infracción relevante para este estudio, la defensa alega infracción al artículo 31 de la LRPA por haberse admitido a juicio la introducción de las prendas de vestir incautadas al joven al momento de su detención sin la presencia de su defensor que contenían ciertas manchas y que dieron origen a otra prueba derivada de la misma (fotografías y pruebas de ADN). La Corte no admite el argumento señalando que

“...ciertamente se está refiriendo a diligencias de investigación que, sin autorización judicial, pueden ser practicadas previo consentimiento del imputado, como, por ejemplo, declaraciones voluntarias, práctica de exámenes corporales, pruebas caligráficas, entrada y registro de lugares cerrados, pues sólo en la medida que se asegura al menor imputado una correcta información de sus derechos y las consecuencias de su autorización, lo que, evidentemente se logra con la presencia de un abogado defensor, puede estimarse que su consentimiento resulta válido.

Por el contrario, tratándose de diligencias de investigación que la policía puede practicar sin mediar consentimiento del afectado, orden del fiscal o autorización judicial, como resulta ser precisamente la incautación de objetos conforme al artículo 187 del Código Procesal Penal, la presencia del abogado carece de sentido, como quiera que siempre la diligencia pueda efectuarse.

De aceptarse el predicamento del señor defensor, en orden a que siempre y para toda diligencia de investigación se requiere la presencia del defensor se llegaría a diversos absurdos lógicos y jurídicos como, por ejemplo, que aún mediando autorización judicial no podrían practicarse o dejar al arbitrio del abogado defensor la práctica de diligencias de investigación que, al mismo tiempo, son cuestiones de seguridad mínimas, como, por ejemplo y siempre dentro de lo dispuesto en el artículo 187 del Código Procesal Penal, la incautación de armas que menores detenidos en situación de flagrancia, portaren." 125

Me parece que la Corte de Apelaciones de Copiapó cualifica adecuadamente los alcances de la regla del artículo 31 de la LRPA en análisis. En estos casos no existe una situación de ventaja del sistema obtenida producto de un consentimiento del adolescente, por lo que no se pone en juego el derecho a no autoincriminarse, por lo mismo, la protección especial establecida en el artículo 31 de la LRPA no debiera regir.

\subsubsection{Renuncia al derecho a ser juzgado en un juicio oral (uso de procedimiento abreviado).}

La posibilidad que el joven imputado renuncie a su derecho a ser juzgado en un juicio oral y lo sea, en cambio, en un procedimiento abreviado ha sido objeto de debate en la práctica de funcionamiento del nuevo sistema, lo que ha generado interpretaciones opuestas en los

\footnotetext{
${ }^{125}$ Véase considerando $7^{\circ}$
} 
DUCE, MAURICIO. "El Derecho a un Juzgamiento Especializado de los Jóvenes Infractores en el Nuevo Proceso Penal Juvenil Chileno".

tribunales de garantía. ${ }^{126}$ Por de pronto, no se trata de un tema que sea abordado de manera explícita por la LRPA. En este contexto, el debate se ha centrado en dos posturas. ${ }^{127}$ Algunos jueces de garantía sostienen que el procedimiento abreviado no sería aplicable a los adolescentes imputados (especialmente cuando se solicita una pena privativa de libertad) ya que al no estar regulado en la LRPA su utilización importaría aplicar por analogía una norma inconveniente y, además, podría poner en riesgo la presunción de inocencia de los jóvenes. ${ }^{128}$ Una segunda postura, admite el uso del procedimiento abreviado entendiendo que resulta aplicable de conformidad a la remisión general que hace la LRPA en su artículo 27 inciso primero a las disposiciones del CPP. ${ }^{129}$

Más allá de las cuestiones de forma, parte central del debate se explica debido a la gravedad de las consecuencias que podría tener un procedimiento abreviado tratándose de jóvenes imputados que no se da en el caso de adultos, lo cual generaría un riesgo no conveniente para los adolescentes. ${ }^{130}$ En efecto, el procedimiento abreviado permite establecer penas privativas de libertad de hasta cinco años, lo cual corresponde a las penas más graves que pueden imponerse en el sistema de la LRPA, allí donde en el caso de adultos se trata de sanciones de mediana o baja gravedad. Por lo mismo, para quienes se oponen a su procedencia el mecanismo idóneo para determinar sanciones tan graves debiera ser necesariamente el juicio oral.

En mi opinión, este debate no ha puesto un énfasis en la renuncia del derecho a no autoincriminarse, sino más bien se ha centrado en normas procesales que permiten sostener su procedencia o no. Cuando el debate aborda la cuestión de fondo respecto a las potenciales garantías comprometidas, los partidarios de no admitir el procedimiento abreviado argumentan principios generales de protección de los adolescentes y la presunción de inocencia sin referirse de manera directa al tema objeto de estudio en esta sección. La Corte Suprema, por otra parte, no se ha pronunciado en favor de ninguna de las posturas, sino más bien solicitando al legislador que adopte alguna con claridad. ${ }^{131}$ Por esta vía podría deducirse que la Corte Suprema no considera que la renuncia al juicio oral (la admisión del procedimiento abreviado) presente problemas de validez ya que el legislador podría inclinarse legítimamente por esta opción. La Defensoría Pública especializada tampoco se ha manifestado en contra de su uso. ${ }^{132}$ Esta es, por otra parte, la solución que he

\footnotetext{
${ }^{126}$ Reconociendo esta situación el pleno de la Corte Suprema ha solicitado al legislador dicte una norma legal que resuelva el punto. Véase Corte Suprema, AD-6001-2009 del 21 de octubre de 2009.

${ }^{127}$ Un resumen de este debate puede verse en el documento de la Corte Suprema citado previamente y en MARÍN, Felipe, ¿Puede Condenarse a un Adolescente a Penas Privativas de Libertad en un Procedimiento Abreviado?, 5 pp., documento no publicado en poder del autor.

${ }^{128}$ Un ejemplo de esta línea puede verse en la decisión adoptada en la audiencia de 13 de junio de 2008, RIT 6229 - 2008, del $7^{\circ}$ Juzgado de Garantía de Santiago.

${ }^{129}$ Un ejemplo de un caso en el que se aceptó el procedimiento abreviado no obstante el fiscal solicitaba como pena tres años de internación en régimen semicerrado puede verse en Sentencia del Juzgado de Garantía de San Antonio en causa RIT 5337-2006 de 15 de junio de 2007, en Véase CERDA / CERDA, cit. nota $\mathrm{n}^{\mathrm{o}} 12$, pp. 286 a 292.

${ }^{130}$ En esta misma línea y con mayor detalle véase MARÍN, cit. nota ${ }^{\circ} 127$.

131 Aún cuando la Corte señala que de desestimarse el procedimiento abreviado respecto a los adolescentes podría dejarlos en un pie de desigualdad en relación a los adultos ya que no dispondrían de esta herramienta. Corte Suprema, cit. nota $\mathrm{n}^{\circ} 126$.

${ }^{132}$ Esto según lo constata el informe de la Corte Suprema ya citado.
} 
visto se ha adoptado en el ámbito comparado en los países en donde se produce una situación análoga y que me parece correcta. ${ }^{133}$

En el contexto del debate descrito, no me ha sido posible encontrar jurisprudencia que aborde con más detalle las condiciones que se debieran exigir para darle validez a la renuncia del derecho. La escasa doctrina sobre la materia se pronuncia sobre el punto señalando que la verificación de la voluntariedad del imputado "...requiere de mayor atención por parte de los jueces debido al estado de desarrollo de la autonomía de los adolescentes..."134, poniendo así un mayor énfasis al control que debiera realizarse respecto a los adultos. Se trata, como otros temas ya abordados, de un área en donde debiera esperarse un mayor desarrollo doctrinal y jurisprudencial en nuestro país. En mi opinión este desarrollo debiera reforzar muy significativamente las condiciones bajo las cuales debiera ser admisible una renuncia al derecho al juicio oral, particularmente cuando esa renuncia permite un procedimiento con el abreviado.

\section{Segundo eje: especialidad y estructura general del procedimiento de adolescentes en el sistema chileno.}

Un segundo eje de análisis en donde el principio de especialidad tiene un impacto relevante en el diseño de los procesos juveniles está vinculado a la protección de un conjunto de valores propios del sistema juvenil que necesariamente tienen consecuencias procesales, tales como el principio educativo. ${ }^{135}$ En un trabajo previo tuve oportunidad de explicar esto con más detalle. En dicha ocasión identifiqué tres elementos estructurales de diseño procesal concretos que surgen como consecuencia de la consideración de estos valores específicos que el sistema de justicia juvenil debe satisfacer, se trata de: la flexibilidad del proceso; la protección de la privacidad de los jóvenes y el énfasis en el joven. ${ }^{136}$

En lo que sigue, revisaré el cómo estos tres aspectos han sido recogidos en nuestra legislación juvenil.

\footnotetext{
${ }^{133}$ Véase DUCE / COUSO, El Derecho a un Juzgamiento, cit. nota ${ }^{\circ} 4$.

${ }^{134}$ MARÍN, cit. nota $n^{\circ} 127$, p. 5.

${ }^{135}$ Los alcances del principio educativo son objeto de amplio desarrollo y debate, tema sobre el cual no puedo ir en detalle este trabajo. Con todo, me parece es pacífico que se trata de un principio básico sobre el que se construyen los sistemas de responsabilidad penal juvenil. En este sentido se ha dicho "Se trata, en definitiva, de un principio configurador del derecho penal juvenil, en tanto afecta todos los ámbitos de este sistema desde el procesal (celeridad, carácter instructor del fiscal de menores, posibilidad de resolución informal del caso, etc.) hasta el relativo a las consecuencias jurídicas (catálogo variado de medidas, criterios flexibles de aplicación y modificación)-; siendo así que su análisis resulta imprescindible de cara a fijar los criterios que participan en la determinación de la intervención operada sobre el menor infractor" CRUZ, Beatriz, Educación y Prevención General en el Derecho Penal de Menores, Barcelona: Marcial Pons, 2006, p. 23. Información sobre el debate acerca de los alcances del principio educativo pueden revisarse en el mismo texto pp. 23-31.

${ }^{136}$ Véase DUCE, "El Derecho a un Juzgamiento”, cit. nota n 3, pp. 103 y ss.
} 
DUCE, MAURICIO. "El Derecho a un Juzgamiento Especializado de los Jóvenes Infractores en el Nuevo Proceso Penal Juvenil Chileno".

\subsection{Necesidad de un proceso flexible y liviano.}

La idea que los procesos seguidos en contra de niños y jóvenes presenten niveles mayores de flexibilidad o sean concebidos como "más livianos" que los de los adultos puede ser recogida en cuatro estrategias procesales específicas que a continuación revisaré.

\subsubsection{Simplificación Procesal.}

En primer lugar, están las estrategias que se podrían denominar como simplificación procesal. Es decir, estructurar al procedimiento juvenil desde un modelo simplificado o más sencillo que el proceso de adultos. Esto se logra fundamentalmente eliminando o centrando etapas o pasos procesales, de forma de evitar que por vía de trámites excesivos se produzcan alargamiento innecesario del proceso.

Si bien, la literatura nacional disponible no analiza el proceso contenido en la LRPA desde esta perspectiva, un análisis de la estructura de la LRPA da cuenta de una vocación de esta por la simplificación procesal, aún cuando representa un punto intermedio respecto a algunas de las propuestas que existieron en la etapa pre-legislativa que avanzaban más fuertemente en la materia. ${ }^{137}$

Como ya mencioné, el artículo 27 de la LRPA contempla al procedimiento simplificado, ejemplo típico de simplificación procesal, como el procedimiento de aplicación general para penas no privativas de libertad. A su vez, también sostuve que este proceso especial debiera ser utilizado, por aplicación de las disposiciones generales del CPP, para conocer de infracciones en las que el fiscal requiere una pena privativa de libertad que no exceda de 540 días. ${ }^{138} \mathrm{Si}$ bien esto último es discutido por un sector de los jueces de garantía que sostienen que cuando existe pena privativa de libertad siempre debe aplicarse el procedimiento ordinario, la escasa doctrina que se ha pronunciado sobre el punto concuerda con mi opinión. ${ }^{139}$ En la práctica, los datos de la Defensoría ya citados muestran como este procedimiento se aplica a cerca del $30 \%$ de los casos que ingresan al sistema como ya tuve oportunidad de mencionar previamente en este trabajo.

A lo anterior, debe agregarse la disposición contemplada en el artículo 37 de la LRPA respecto a la utilización del "juicio inmediato" en el proceso penal juvenil. El juicio inmediato es otro mecanismo de simplificación procesal previsto en el artículo 235 del CPP por el cual se permite transformar la audiencia de formalización de la investigación en una audiencia de preparación de juicio oral. Desafortunadamente la redacción de la norma no es muy clara y permite una interpretación de la misma que reduce la eficacia en el uso de este

\footnotetext{
${ }^{137}$ Una de las propuestas discutidas era establecer como regla general que el proceso no contaba con etapa de investigación con posterioridad a la primera audiencia de formulación de cargos. Sólo en casos excepcionales y calificados se permitía al Ministerio Público solicitar al juez un plazo de 90 días para llevara delante la investigación. Véase DUCE, “El Proceso”, cit. nota n 12, p. 104.

${ }^{138}$ Véase supra 1.2.

139 El detalle de los argumentos en favor y en contra de la procedencia del procedimiento simplificado tratándose de casos en los que el fiscal requiere una pena privativa de libertad puede revisarse en Véase CERDA / CERDA, cit. nota n ${ }^{\circ} 12$, pp.161-167.
} 
mecanismo simplificador al no establecer con claridad que su uso sea obligatorio. ${ }^{140}$ En efecto, el artículo 37 señala que las reglas del juicio inmediato son plenamente aplicables cada vez que el fiscal lo solicite y especialmente cuando se trate de una infracción flagrante. El problema de esta redacción es que aparentemente no regula nada distinto que el artículo 235 del CPP toda vez que establece la posibilidad de utilizar este procedimiento cuando el fiscal lo estime conveniente. Desde este punto de vista, esta disposición de la LRPA sería innecesaria e incluso redundante. Lo que ocurre es que en alguna etapa de tramitación legislativa la procedencia conforme a las reglas del juicio inmediato era obligatoria, lo que luego fue alterado quedando en definitiva una regla que aparentemente no establece la obligatoriedad en el uso de este procedimiento. ${ }^{141}$ Me parece que a partir del inciso segundo del artículo 37 de la LRPA sería posible construir una interpretación que estableciera el carácter obligatorio del juicio inmediato en casos de infracciones flagrantes. ${ }^{142}$ Con todo, en la práctica cotidiana del sistema parece haberse instalado la interpretación que se trata de una facultad discrecional del fiscal. Desafortunadamente no se pudo identificar sentencias de tribunales superiores que se pronunciaran en la materia.

Finalmente, una tercera herramienta de simplificación procesal está en la posibilidad de utilizar el procedimiento abreviado. Nuevamente, se trata de un mecanismo que no aparece regulado en forma explícita en la LRPA, por lo que se entendería aplicable como consecuencia del carácter supletorio que en la materia tienen las disposiciones del CPP, con el debate que ya he presentado previamente sobre si podría o no utilizarse, especialmente en los casos en que se imponga una pena privativa de libertad. ${ }^{143}$

\subsubsection{Abreviación de plazos.}

Un segundo tipo de estrategias para lograr el objetivo de tener un proceso liviano es el establecimiento de plazos más breves o límites temporales más estrictos para las distintas actividades procesales en el proceso juvenil en relación al de adultos. Ya he tenido oportunidad de mostrar como se trata de una estrategia que también ha sido recogida en nuestra LRPA en reducción de dos plazos: el máximo de la etapa de investigación (artículo 38 LRPA) y el de celebración del juicio oral (artículo 39 LRPA). A ello se suma la posibilidad del juez de garantía de fijar un plazo inferior al legal para el cierre de la investigación. ${ }^{144}$

\footnotetext{
${ }^{140}$ En parte el problema se debe en mi opinión a la falta de acuerdo del objetivo perseguido por esta norma en su debate legislativo. Ilustrativo en este punto es el debate sostenido en la Comisión de Legislación y Justicia del Senado. Véase Historia de la Ley no 20.084, pp. 747-748.

${ }^{141}$ En este sentido Véase CERDA / CERDA, cit. nota $n^{\circ} 12$, p. 179. Véase también la Historia de la Ley citada previamente.

${ }^{142}$ Este inciso establece que en caso de proceder el juicio inmediato, el juez podría aprobar, a solicitud del fiscal, la realización de diligencias concretas y determinadas de investigación por un plazo máximo de 60 días tratándose de un delito flagrante. Esta disposición carece de sentido si es que no fuera obligatorio proceder de conformidad al juicio inmediato en casos flagrantes. De otra forma no se entendería que el fiscal voluntariamente decida solicitar un juicio inmediato, pero a la vez pida un plazo con más restricciones de tiempo y facultades investigativas para llevar adelante la investigación ya que no está en condiciones de ir a juicio oral en este momento.

${ }^{143}$ Véase Supra 1.4.2.

${ }^{144}$ Con más detalle véase supra 1.1 .2 y 1.2.
} 
DUCE, MAURICIO. "El Derecho a un Juzgamiento Especializado de los Jóvenes Infractores en el Nuevo Proceso Penal Juvenil Chileno".

Sólo me interesa enfatizar un par de aspectos a los ya mencionados previamente en esta materia respecto a estas disposiciones. El plazo máximo de duración de la etapa de investigación (seis meses ampliables por dos más) no establece un límite particularmente estricto, especialmente pensando en delitos de baja complejidad investigativa y flagrantes, como son la mayoría de los que ingresan al sistema nacional. En segundo término, esta estrategia de reducción ha dejado de lado la reducción de los plazos establecidos en el CPP para la realización de la etapa de preparación de juicio oral ${ }^{145}$ con lo que se podría producir la paradoja que esta etapa tome mayor tiempo que el resto de las fases del proceso, no obstante cumple una función puramente instrumental.

Una norma adicional que podría considerarse como parte de la estrategia de reducción de plazos es la contenida en el inciso segundo del artículo 39 de la LRPA que señala que el juicio oral no puede nunca suspenderse o interrumpirse por un término superior a las 72 horas. Esto reduce al plazo de hasta 10 días que establece el CPP en su artículo 283. Existe un caso de la Corte de Apelaciones de Concepción en donde se hizo aplicación de esta norma. ${ }^{146}$ Se trata de un caso que fue llevado adelante de conformidad a las reglas del procedimiento simplificado. En el juicio oral el Ministerio Público pide la suspensión de la audiencia por la falta de comparecencia de de un perito. El juez de garantía suspende la audiencia por 95 horas. La defensa reclama que ello infringe el debido proceso y la norma explícita del artículo 39 inciso segundo de la LRPA. Su reclamo es rechazado, el juicio continúa su desarrollo y se condena al adolescente. La defensa interpone un recurso de nulidad basado en la causal del artículo 373 a) del CPP por infracción de garantías. La Corte le da la razón a la defensa constatando que se produjo una violación al principio de continuidad de la audiencia y a la disposición en análisis. Como consecuencia de esto, anula el juicio y ordena que sea realizado nuevamente ante juez no inhabilitado.

Como se puede observar se trata de un caso muy sencillo en donde el argumento de fondo de la Corte se orienta en reconocer la infracción al principio de continuidad del juicio, lo que la aleja del tema de reducción de plazos que vengo analizando.

\subsubsection{Limitación de sistemas de impugnación.}

Un tercer tipo de estrategias para lograr la rapidez del proceso consiste en el rediseño de los sistemas de impugnación, particularmente de la sentencia definitiva. En efecto, en muchos sistemas jurídicos una buena parte de la extensión de los procesos se explica a partir de la multiplicidad de mecanismos de impugnación disponibles y de las demoras que se producen a partir de su tramitación. En consecuencia, una restricción en el uso de los mismos, por vía de eliminar un recurso específico o por vía de limitar sus alcances o contenidos o la legitimación activa, podría traducirse en ganancias importantes en materia de abreviamiento de los plazos de duración de un proceso.

\footnotetext{
${ }^{145}$ De acuerdo al artículo 260 del CPP la audiencia de preparación de juicio oral deberá realizarse no antes de 25 ni después de 35 días desde presentada la acusación ante el juez de garantía. A ello debe agregarse el plazo que existe para que el auto de apertura de juicio oral se encuentre ejecutoriado (hay un plazo de 5 días para que el Ministerio Público pueda apelar según el artículo 366 del CPP).

${ }^{146}$ Véase Sentencia de la Corte de Apelaciones de Concepción en causa rol n ${ }^{\circ}$ 497-2008 de 28 de noviembre de 2008 .
} 
El análisis de la LRPA en la materia muestra que en este punto no existió ninguna innovación respecto a lo que regula el CPP. Sin embargo, ello corresponde a un cierto retroceso respecto al diseño contenido en varias versiones de los anteproyectos que dieron lugar a la LRPA. En ellos se contemplaba el recurso de nulidad como mecanismo de impugnación, pero sólo en favor del joven imputado o sancionado. Con ello se limitaba la legitimación activa del Ministerio Público para recurrir. Como contrapartida, se establecía también un Recurso de Modificación de la Sentencia Condenatoria que podía ser interpuesto por cualquier interviniente (en el caso del fiscal y la víctima sólo cuando la pena impuesta fuera inferior a la solicitada) para discutir el monto de la pena sin realizar un nuevo juicio. ${ }^{147}$ Ninguna de estas propuestas fue recogida finalmente, por lo que el diseño de la LRPA no innovó respecto al actual sistema de adultos.

\subsubsection{Limitación de contenidos a discutir en el proceso penal juvenil.}

Finalmente, una cuarta posibilidad para lograr un proceso más liviano y breve está en excluir del proceso juvenil algunos debates que normalmente forman parte de los procesos penales de adultos y que, por complejizar los contenidos de la discusión, tienden naturalmente a alargar el desarrollo de las distintas etapas del proceso. La idea entonces es que al limitarse los contenidos a debatir en el proceso esto debiera naturalmente producir una simplificación y acortamiento del mismo.

También se trata de un área en donde no existe ninguna innovación de la LRPA en relación al sistema de adultos. En consecuencia, en el proceso penal juvenil también es posible discutir la responsabilidad civil del adolescente surgida como consecuencia de los hechos imputados.

\subsection{Protección de la privacidad (vida privada).}

Otro mandato central de las normas internacionales en relación a la estructura del proceso es que en éste debe resguardarse al máximo la vida privada de los niños en todas sus etapas. La protección de la privacidad del niño durante el proceso seguido en su contra es un valor del sistema que corre bastante alto y que es propio o específico de los sistemas de responsabilidad juvenil y que encuentra un fuerte reconocimiento en la legislación internacional. ${ }^{148}$ En este marco, la protección de la privacidad del niño presenta tres alcances con implicancias de carácter procesal sobre los cuales analizaré la legislación y jurisprudencia nacional.

\subsubsection{Reconocimiento general de la privacidad.}

Un primer elemento en análisis es identificar la manera en que es reconocido en términos generales el derecho del joven a la privacidad en la LRPA.

\footnotetext{
${ }^{147}$ Antecedentes de estas propuestas véase en DUCE, "El Proceso", cit. nota no 12, pp. 110-111.

${ }^{148}$ DUCE, "El Derecho a un Juzgamiento", cit. nota no 3, pp. 106-109.
} 


\section{DUCE, MAURICIO. "El Derecho a un Juzgamiento Especializado de los} Jóvenes Infractores en el Nuevo Proceso Penal Juvenil Chileno".

En una revisión superficial de la LRPA se puede constatar que no contempla ninguna norma referida a la materia, tanto a nivel de principios generales como en el área específica de regulación del proceso juvenil. Esto contrasta con el proyecto original enviado por el ejecutivo al Congreso. En este se contenía una norma dentro de las disposiciones generales del procedimiento que se hacía cargo del tema. ${ }^{149}$ La eliminación de esta norma se produjo durante la tramitación legislativa en un momento avanzado de discusión en el Senado, donde se estimó que ella resultaba innecesaria debido a la existencia del artículo 33 de la Ley $n^{\circ} 19.733$ sobre Libertades de Opinión e Información y Ejercicio del Periodismo. ${ }^{150} \mathrm{Si}$ bien entre ambas normas existe una coincidencia importante, básicamente al establecer una prohibición de divulgación de la identidad de menores de edad involucrados el proceso (como imputados, testigos o víctimas), ${ }^{151}$ la eliminación del artículo 36 del proyecto de LRPA presenta dos problemas. En primer lugar, sus alcances de protección de la privacidad del joven eran más amplios que los del artículo 33, por ejemplo, ya que impedía a cualquier actor del sistema entregar información sobre el joven imputado a terceros sin el propósito de hacer divulgación de dicha información en un medio de comunicación social. Además, se deja un vacío a nivel de principios generales que podrían orientar el comportamiento de autoridades en situaciones distintas a las descritas por la Ley $\mathrm{n}^{\circ} 19.733$.

En consecuencia, la falta de una norma de carácter más amplio de protección de la privacidad de los adolescentes imputados podría constituir un déficit de nuestra legislación en la materia en la medida en que no exista una práctica especialmente intensa de nuestros tribunales y demás instituciones del sistema en esta dirección. Afortunadamente, el

\footnotetext{
${ }^{149}$ Se trataba originalmente del artículo 36 del proyecto: que señalaba: "Artículo 36.- Reserva del proceso. El procedimiento regulado en este título será reservado respecto de terceros.

La obligación de reserva se extiende a todos los funcionarios públicos que intervengan en dicho procedimiento en razón a sus funciones, y a los defensores penales, en su caso, quienes no podrán informar a los medios de comunicación social ni a terceros acerca del contenido de la investigación ni sobre la identidad de los adolescentes detenidos o imputados.

La infracción a lo dispuesto en el inciso anterior será sancionada con las penas previstas en el artículo 247 del Código Penal, a menos que los hechos constituyan otro delito sancionado con igual o mayor pena."

Este artículo fue aprobado en la Cámara de Diputados con modificaciones menores pasando a ser el artículo 37 que señalaba "Artículo 37.- Protección de la vida privada del adolescente. Durante todas las etapas del procedimiento se deberá resguardar la vida privada del adolescente.

Prohíbese a los funcionarios públicos y abogados defensores informar a terceros ajenos al proceso acerca de la identidad del adolescente detenido o imputado, o que sea víctima de una infracción, ni de aquellos datos o antecedentes que permitieren dicha identificación. La infracción a lo dispuesto en el inciso anterior será sancionada con las penas previstas en el artículo 247 del Código Penal, a menos que los hechos constituyan otro delito sancionado con igual o mayor pena.”. Una copia del proyecto aprobado por la Cámara de Diputados puede verse en GARCÍA-MÉNDEZ, Emilio; BELOFF, Mary (compiladores), Infancia Ley y Democracia en América Latina Tomo I, Bogotá: Temis, 2004, pp. 283-298.

${ }^{150}$ Véase Historia de la Ley $\mathrm{n}^{\mathrm{0}} 20.084$, páginas 709 y 710 , correspondientes al segundo informe de la Comisión de Constitución y Justicia del Senado.

${ }^{151}$ El artículo 33 de la Ley $n^{\circ} 19.733$ dispone expresamente: "Artículo 33.- Se prohíbe la divulgación, por cualquier medio de comunicación social, de la identidad de menores de edad que sean autores, cómplices, encubridores o testigos de delitos, o de cualquier otro antecedente que conduzca a ella.

Esta prohibición regirá también respecto de las víctimas de alguno de los delitos contemplados en el Título VII, "Crímenes y simples delitos contra el orden de las familias y contra la moralidad pública", del Libro II del Código Penal, a menos que consientan expresamente en la divulgación.

La infracción a este artículo será sancionada con multa de treinta a ciento cincuenta unidades tributarias mensuales. En caso de reiteración, la multa se elevará al doble.”
} 
Ministerio Público ha dado una interpretación amplia al artículo 33 señalando que "...frente a incidencias que promueva la defensa relativos a la reserva de identidad de imputados adolescentes, los físcales no deberán formular oposición si de ello no se devenga afectación o perjuicio a la función investigativa o al ejercicio de la acción penal."152 Incluso se va más allá al señalarse que si frente a una necesidad evidente de una reserva no solicitada, le corresponde al fiscal solicitar a los tribunales se adopten las cautelas básicas para asegurarla. ${ }^{153}$ Estimo que se trata de un área en donde se requiere más investigación para poder llegar a alguna conclusión acerca de las prácticas reales en la materia.

\subsubsection{Privacidad y publicad del juicio oral.}

Las normas que establecen la privacidad o confidencialidad de los procesos juveniles tienen un impacto muy significativo en una de las características básicas del proceso de adultos: su publicidad. El Comité de Derechos del Niño sostiene una posición bastante fuerte en este tema. Si bien es cierto no se impide la posibilidad que los juicios sean públicos se recomienda actuar en forma distinta. ${ }^{154} \mathrm{En}$ el derecho comparado se puede observar fragmentación en la regulación de este aspecto. Por una parte, algunos países establecen el carácter privado o reservado de las audiencias de juicio como regla general (por ejemplo Costa Rica y Alemania ${ }^{155}$ y otros establecen el carácter público de las mismas pero con posibilidad de limitarla en casos específicos (como España y los Estados Unidos). ${ }^{156}$

La legislación nacional parece optar por este segundo camino. En efecto, la LRPA no contiene ninguna regla especial acerca de la publicidad del juicio llevado adelante en contra de adolescentes, como tampoco ninguna norma genérica sobre la protección de la privacidad que pudiere aplicarse en forma directa. En este escenario, la reglas que se hacen aplicables son las disposiciones contenidas en el CPP que establecen la publicidad del juicio (artículos 1 y especialmente el 289). Estas mismas disposiciones admiten la posibilidad de adoptar algunas medidas de limitación a la publicidad de la audiencia basada en la protección del honor o intimidad de cualquier persona que debiere tomar parte en el juicio. Con todo, se trata de limitaciones específicas a la publicidad y no de normas que permitan el desarrollo en privado de una audiencia de juicio completa.

Durante la investigación no se pudo identificar ningún caso resuelto por nuestros tribunales superiores en los que se presentare una discusión específica sobre la materia.

\footnotetext{
${ }^{152}$ Fiscalía Nacional, Oficio $\mathrm{n}^{\mathrm{o}} 511$ Instructivo $^{\mathrm{o}} 7$ de la Ley 20.084, de 23 de abril de 2007, p. 7.

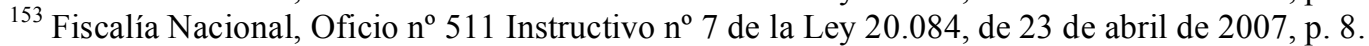

${ }^{154}$ Véase DUCE, "El Derecho a un Juzgamiento", cit. nota n 3 , p. 108.

${ }^{155}$ En el caso de Costa Rica la privacidad del juicio está regulada en el artículo 99 de su LJPJ que señala que la audiencia deberá ser oral y privada so pena de nulidad en caso de incumplimiento. En el caso de Alemania esto se regula en el artículo 48 párrafo 1 de la ordenanza procesal juvenil (JGG).

${ }^{156}$ En el caso español la publicidad de la audiencia de juicio está regulada en el artículo 35.2 de la LO 5/2000. En los Estados Unidos la publicidad de las audiencias de juicio es resultado de un conjunto de decisiones jurisprudenciales que han extendido esa garantía de los adultos a las regulaciones juveniles.
} 
DUCE, MAURICIO. "El Derecho a un Juzgamiento Especializado de los Jóvenes Infractores en el Nuevo Proceso Penal Juvenil Chileno".

2.2.3. Uso de antecedentes o registros del sistema juvenil.

Un último aspecto que suele ser cubierto de manera específica por las normas de protección de la privacidad de los jóvenes tiene que ver con el uso de antecedentes o registros como consecuencia de la persecución en contra de un niño. La exigencia internacional apunta a impedir que un registro o antecedente juvenil pueda ser invocado en un caso contra la misma persona en el sistema de adultos o al menos a limitarlo en forma importante. ${ }^{157}$

Nuevamente se trata de un tema en el que la LRPA no contiene disposiciones específicas. A falta de las mismas rigen la materia un conjunto de normas de aplicación general a toda la población condenada del país. ${ }^{158}$ Se ha señalado que ellas no reconocen adecuadamente las particularidades de los jóvenes objeto de persecución penal. ${ }^{159}$ En efecto, el punto de partida en nuestra legislación es la existencia de anotaciones prontuariales y, por lo tanto, la posibilidad de utilizarlas en casos futuros, lo cual entra en tensión con el mandato internacional en la materia. A continuación revisaré los aspectos centrales de esta normativa en relación a los jóvenes condenados para poder observar en concreto el nivel de adecuación de nuestra legislación a las exigencias especiales del sistema juvenil. ${ }^{160}$

Las anotaciones prontuariales se generan a partir se sentencias condenatorias por crímenes, simples delitos o faltas (a la tercera condena en este último caso) según lo dispone el Decreto Supremo $\mathrm{n}^{\mathrm{o}}$ 64. ${ }^{161}$ Estas anotaciones se incluyen en los certificados de antecedentes que entrega en Servicio de Registro Civil e Identificación (en adelante el Registro Civil). En este punto se observa una diferencia establecida en favor de los jóvenes. La regla general para adultos es que todas las condenas aparezcan en los certificados respectivos con la posibilidad, en casos de excepción, de ser omitidas. Tratándose de los adolescentes la regla general es la omisión de antecedentes. Es decir, en principio las condenas de los jóvenes no debieran figurar en los certificados de antecedentes, salvo que se emitan para postular a alguna institución de las Fuerzas Armadas, Carabineros de Chile, Gendarmería de Chile, Policía de Investigaciones o a los que soliciten el Ministerio Público y los tribunales con competencia en materia penal para efectos de comprobar reincidencia (artículo 2 Decreto Ley $\mathrm{n}^{\mathrm{0}}$ 645). ${ }^{162} \mathrm{Si}$ bien esta regla especial recoge en parte la idea de evitar la estigmatización de los jóvenes condenados por vía de no incluir sus condenas en registros que podrían utilizarse, por ejemplo, en la postulación a trabajos en el mercado privado, llama la atención que aún se incluyan para la prestación de servicios en algunas

\footnotetext{
${ }^{157}$ Véase DUCE, “El Derecho a un Juzgamiento”, cit. nota no 3, p. 109.

${ }^{158}$ Se trata del Decreto ley $n^{\circ} 645$ del año 1925 que crea el Registro Nacional de Condenas; el Decreto Ley $n^{\circ}$ 409 de 1932 sobre Regeneración y Reintegración del Penado a la Sociedad; y, el Decreto Supremo nº 64 de 1960 que reglamenta la Eliminación de Prontuarios Penales de Anotaciones y el Otorgamiento de Certificado de Antecedentes.

${ }^{159}$ En este sentido véase FUENZALIDA, Iván, "Regulación y Efectos de las Anotaciones Prontuariales de los adolescentes", Santiago: Revista jurídica del Ministerio Público, no 35, julio (2008), p. 321.

${ }^{160}$ En este punto sigo el trabajo de Iván Fuenzalida ya citado. Este trabajo contiene un análisis detallado de las diversas normas aplicables en la materia y constituye el punto de referencia central para mi análisis en esta sección del trabajo. Recomiendo su lectura íntegra para quienes estén interesados en conocer con mayor profundidad y detalle el tema

${ }^{161}$ Véase FUENZALIDA, Iván, cit. nota 159, p. 323.

${ }^{162}$ Véase FUENZALIDA, Iván, cit. nota 159, p. 324.
} 
agencias estatales y que, además, no se excluya su uso en el sistema de justicia penal en donde más impacto tiene la existencia de una condena previa debido a la posibilidad de utilizarla como fuente de agravación de su conducta.

Junto con lo anterior, existe una regulación bastante detallada acerca de la posibilidad de eliminar anotaciones prontuariales en nuestro sistema legal. La regla general respecto a los adolescentes está contenida en el artículo 8 letra h) del Decreto Supremo no 64 que establece una distinción dependiendo si la condena impuso o no una pena aflictiva (superior a los tres años de privación de libertad). Si la condena impuso una pena no aflictiva, la eliminación de antecedentes procede una vez cumplida la pena. Junto con esto, se exige que para que proceda la eliminación el adolescente goce de irreprochable conducta anterior y se trate de su única anotación prontuarial. El Registro Civil debe proceder de oficio a la eliminación de antecedentes, pero en la práctica está imposibilitado a hacerlo en la medida que no reciba la información acerca del efectivo cumplimiento de la pena de parte del órgano encargado de la ejecución de las mismas (en este caso el SENAME). ${ }^{163}$ Finalmente, una eliminación de antecedentes de conformidad a este mecanismo puede ser objeto de revocación en caso de una nueva condena, según dispone el artículo 14 del Decreto Supremo $n^{0} 64$.

Si se trata de una condena a pena aflictiva, la eliminación procede una vez que han transcurrido tres años del cumplimiento de la pena, exigiéndose también irreprochable conducta anterior y que se trate de la anotación única. ${ }^{164}$

La principal diferencia en el tratamiento que hace el Decreto Supremo $n^{0} 64$ entre adolescentes y adultos radica en que en el caso de estos últimos los plazos para eliminación de antecedentes son mucho más amplios (3 años luego del cumplimiento de la condena de faltas, 5 años en condenas por simples delitos y 10 en casi de crímenes, según lo dispone el artículo 8 letras f y g).

Junto con el Decreto Supremo $n^{0} 64$ los adolescentes condenados podrían beneficiarse del sistema de eliminación de antecedentes regulado en el Decreto Ley $n^{0} 409$ de 1932. Con todo, se trata de una reglamentación que no hace diferencias entre jóvenes y adultos.

En definitiva, se trata de un sistema que recoge parcialmente las recomendaciones establecidas en materia internacional, especialmente considerando que los diversos mecanismos estudiados permiten una utilización de los antecedentes previos en los procesos penales futuros, lo que podría dificultar el proceso de reintegración social de jóvenes infractores. ${ }^{165}$ Sin embargo, no se trata de una cuestión pacífica ya que hay varios que sostienen la legitimidad de este uso de los antecedentes previos como forma de determinar la gravedad de las conductas de los jóvenes imputados. Me parece que el

\footnotetext{
${ }^{163}$ Véase FUENZALIDA, Iván, cit. nota ${ }^{\circ} 159$, pp. 325 a 327.

${ }^{164}$ Véase FUENZALIDA, Iván, cit. nota ${ }^{\circ} 159$, p. 327.

165 En este sentido la Corte Suprema ha manifestado la necesidad de incorporar en la LRPA una norma respecto a los adolescentes condenados a penas no privativas de libertad que no cuenten con condenas previas una regla de omisión de dichas condenas en los certificados de antecedentes que se otorguen para fines particulares. Véase Corte Suprema, AD-601-2009, de 21 de Octubre de 2009, p. 8 punto 10.
} 
DUCE, MAURICIO. "El Derecho a un Juzgamiento Especializado de los Jóvenes Infractores en el Nuevo Proceso Penal Juvenil Chileno".

problema resulta acertadamente descrito por Fuenzalida cuando concluye su trabajo señalando "Lo que no parece razonable es que el sistema no se haga cargo de una y otra arista del problema y mantenga una regulación que no atiende a realidades tan diversas como la de adolescentes y adultos y, peor aún, sustente su accionar en disposiciones y criterios adoptados en el primer tercio del siglo pasado". ${ }^{166}$ En definitiva, el punto es la falta de debate sobre los alcances que debiera tener un sistema de registro de antecedentes de los jóvenes condenados en el contexto de entrada en vigencia de la Convención de Derechos del Niño y un nuevo sistema especializado de responsabilidad penal juvenil en nuestro país.

Una segunda área en donde se ha producido alguna polémica respecto a la utilización de registros en donde consten jóvenes imputados se refiere a la aplicación al sistema juvenil del Sistema Nacional de Registro de ADN establecido en la Ley n ${ }^{\circ}$ 19.970. De acuerdo a esta normativa (artículos 5 y 17) se crea un registro de huella genética de condenados a una cantidad importante de delitos que se agrega como información adicional al prontuario penal. El artículo 6 también crea un registro de imputados. El material biológico producido para estos fines podría conservarse hasta por 30 años (artículo 14). La Ley no 19.970 no contiene ninguna referencia de su aplicación a los procesos regulados por la LRPA. Esto ha generado dudas en cuanto a que los adolescentes puedan ser objeto de inclusión en los registros que regula esta ley. ${ }^{167}$ Un sector de la doctrina se ha opuesto muy fuertemente a la aplicabilidad de estos registros a los adolescentes, invocando tanto razones de sistemática de la ley, de orden temporal de su aplicación, de orden institucional (no regulación de la institución responsable de producir la huella genética), de compatibilidad con los instrumentos internacionales y de lógica del derecho público (la falta de autorización explícita en la materia). ${ }^{168}$

La Corte Suprema, por su parte, ha manifestado su preocupación poniendo especial énfasis al hecho que la Ley $\mathrm{n}^{\circ} 19.970$ no le ha otorgado facultades al SENAME para implementar el proceso de obtención de las muestras genéticas para efectos de la elaboración de los registros de condenados e imputados. Reconociendo lo discutible que resulta incluir a los jóvenes en estos registros, ha señalado la necesidad de una reforma legal en donde se establezca con claridad encargada de implementar el sistema en el caso de los adolescentes. $^{169}$

Durante la investigación no se pudo identificar jurisprudencia que se pronunciara sobre el punto, como tampoco mayor información doctrinaria sobre el mismo.

\footnotetext{
${ }^{166}$ FUENZALIDA, Iván, cit. nota ${ }^{\circ} 159$, p. 335.

${ }^{167}$ En este sentido véase Corte Suprema, AD-6001-2009, p. 9 punto 11.

168 CORTÉS, Julio; ESTRADA, Francisco, Sobre la Inaplicabilidad de la Ley que crea el Sistema Nacional de Registros de ADN en el Sistema Penal de Adolescentes, Diciembre de 2008, 3 pp., documento en formato electrónico disponible en el archivo del autor.

${ }^{169}$ Véase Corte Suprema, AD-601-2009, de 21 de Octubre de 2009, punto 12, pp. 8-9.
} 
Polit. crim. Vol. 5, № 10 (Diciembre 2010), Art. 1, pp. 280-340.

[http://www.politicacriminal.cl/Vol_05/n_10/Vol5N10A1.pdf]

\section{3. Énfasis en el joven.}

Cuando revisé la legislación internacional identifiqué que el sistema para jóvenes infractores opera con un supuesto básico y es que las decisiones que se adopten por parte de las autoridades, particularmente al momento de establecer consecuencia para la conducta que se imputa, se hagan considerando de manera especial las características y necesidades concretas y específicas del joven infractor. A esto lo llamé el énfasis en el joven. ${ }^{170}$ Este énfasis en el joven debiera tener impacto en el diseño del proceso en varias cuestiones. Me parece que las dos más relevantes se refieren a la cesura del debate y a la existencia de un sistema de producción de información especializada respecto al imputado. A continuación examinaré la forma en que ambas cuestiones son recogidas en nuestro nuevo sistema.

2.3.1. Cesura o división del debate: establecimiento de una fase procesal especial para determinar las consecuencias de la infracción juvenil.

Una primera consecuencia procesal del énfasis en el joven tiene que ver con la necesidad del proceso penal de los adolescentes de contar con un procedimiento de determinación de consecuencias o penas más sofisticado que el de los adultos de forma de abrir espacio para la introducción y el debate de información no vinculada con los hechos y la responsabilidad del joven.

En caso que el sistema no prevea una fase procesal específica para este tema, se corre el riesgo de que el conjunto de variables especiales que se establecen en la propia LRPA para determinar las consecuencias tengan menos posibilidades de ser presentadas y valoradas adecuadamente. Como lo demuestra la experiencia del proceso penal de adultos en la tradición continental o inquisitiva, el concentrar en un mismo debate tanto los aspectos propios de la determinación de responsabilidad (esclarecimiento del hecho y la participación) como los vinculados a la individualización de la pena ha relegado los ejercicios de individualización de la pena a cuestiones muy abstractas o formales. ${ }^{171}$ Llevado esto al ámbito juvenil se traduce en que todos los mandatos de consideración especial del niño para determinar la sanción adecuada se transformen en una pura formalidad.

En esta dirección, la LRPA asumió la solución procesal conocida como la cesura o división del debate de juicio en dos partes distintas, una exclusivamente destinada al la discusión de la responsabilidad y otra a la determinación de consecuencias. En efecto, el artículo 40 de la LRPA regula la materia estableciendo la obligatoriedad de la audiencia de determinación de pena en caso de condena y agregando que en ella el tribunal podría requerir la opinión de peritos. Se trata de una norma que no estaba en el proyecto original y que fue introducida en el Senado durante el segundo tramite constitucional con el propósito explícito de generar un espacio para la discusión de la sanción más idónea. ${ }^{172}$ Esta norma representaba un avance en comparación con el esquema originalmente contemplado en el CPP, ya que tratándose de adultos la audiencia de determinación de pena era opcional para

\footnotetext{
${ }^{170}$ Véase DUCE, “El Derecho a un Juzgamiento”, cit. nota no 3, pp. 109-110.

${ }^{171}$ Véase MAIER, Derecho Procesal Penal Tomo I, Buenos aires: Editores del Puerto, 1996, p. 382.

${ }^{172}$ Véase Historia de la Ley $n^{\circ} 20.084$, p. 752.
} 
DUCE, MAURICIO. "El Derecho a un Juzgamiento Especializado de los Jóvenes Infractores en el Nuevo Proceso Penal Juvenil Chileno".

el tribunal, lo que luego fue modificado estableciendo el carácter obligatoria de la misma. $^{173}$

No obstante el avance que representa el contemplar la idea de cesura (especialmente considerando que originalmente esta regulación iba más allá de lo contemplado en el CPP), el modelo optado por nuestro legislador presenta algunos problemas estructurales para satisfacer las necesidades de un debate intenso sobre la idoneidad de la sanción. Una primera cuestión que dificulta el logro del objetivo planteado para la cesura del debate es que en nuestro sistema se trata de una audiencia que se realiza a continuación e inmediatamente luego de entregado el veredicto condenatorio de parte del tribunal que llevó el juicio oral (véase artículo 343 inciso final del CPP). Esto significa que en general no hay posibilidad para, a partir de la condena, producir información y recopilar antecedentes adicionales que son propios del ejercicio de determinación de la sanción idónea y que se hacen relevantes sólo a partir de este momento. En esta misma dirección, la norma que le entrega facultades al juez para solicitar la opinión de un perito se transforma en una aspiración poco realista por lo plazos establecidos en el CPP tanto para la audiencia como para la redacción de la sentencia.

Una segunda cuestión es que no existe una regulación clara, tanto en la LRPA como en el CPP, acerca del método de trabajo en estas audiencias, particularmente en materia de introducción de prueba. De esta forma, no es del todo claro si la prueba que puede presentarse en esta audiencia debe haber sido anunciada en el auto de apertura de juicio oral o no, si las exigencias de admisibilidad son las mismas que las contempladas para la prueba en el juicio de responsabilidad y si su introducción en la audiencia se rige por las disposiciones del juicio o más bien por un método similar al que se utiliza en las audiencias en las etapas previas al juicio. Más que entrar al debate sobre estas cuestiones, lo que me interesa marcar es que el legislador optó por un modelo de cesura, pero no resolvió la forma concreta en que éste debiera ejecutarse, lo que obviamente limita el impacto que este proceso tiene en la efectiva individualización de la sanción que sea más idónea de acuerdo a las características particulares del adolescente condenado.

Finalmente, una tercera cuestión que me parece relevante y en la cual el modelo plasmado en la LRPA presenta problemas se refiere a la falta de definición clara del rol que cumple el o los jueces en la audiencia de determinación de la condena. Me parece que existen buenas razones para sostener que la idea de modelo adversarial que prima durante el desarrollo del juicio, es decir, en donde los jueces deben tener una conducta generalmente pasiva, no debiera tener aplicación con tanta intensidad en este momento. ${ }^{174}$ De alguna forma, esto es reconocido en el artículo 40 de la LRPA que le da la posibilidad al tribunal de requerir opinión de peritos, aún cuando las partes no la presenten. Es decir, en donde se le otorgan más facultades en materia probatoria que en el desarrollo del juicio. Con todo, más allá de esto nuestra legislación no es muy explícita en la materia ni tampoco existe un desarrollo jurisprudencial ni doctrinal sobre la misma.

\footnotetext{
${ }^{173}$ Con más detalle sobre este punto véase DUCE / RIEGO, "Proceso" cit. nota no 17, pp. 402-403.

${ }^{174}$ En este misma dirección se pronuncian CERDA / CERDA, cit. nota $n^{\circ} 12$, p. 182.
} 
En suma, se trata de un área en donde la LRPA ha realizado un avance, pero en mi opinión incompleto para cumplir adecuadamente el objetivo establecido con la introducción de la cesura. Lamentablemente, como en otras áreas, ha sido un tema en donde la doctrina no tiene pronunciamientos claros que permitieran resolver parte de los problemas identificados, como tampoco hemos identificado jurisprudencia de los tribunales superiores acerca de los mismos.

\subsubsection{Producción de información especializada.}

Una segunda derivación relevante para el diseño de los procesos juveniles que surge del énfasis especial que se pone en el joven para determinar las consecuencias de los hechos delictivos que cometen, tiene que ver con la necesidad que surge de producir de información sobre el niño que es objeto de persecución penal que le permita al sistema hacer un ejercicio de individualización adecuado de la respuesta al caso concreto. Se trata de información para determinar la consecuencia y no la responsabilidad.

Este es un tema que presenta ramificaciones tanto orgánicas como procesales en su estudio. Dentro de las orgánicas está el identificar la existencia de normas e instituciones que contemplen la existencia de equipos técnicos especializados o de cuerpos de expertos que tienen por función el producir esta información para ponerla a disposición de fiscales o jueces encargados de llevar adelante el proceso juvenil. Sin perjuicio que esta perspectiva no es objeto de análisis en este trabajo, ${ }^{175}$ me parece que se trata de un área en donde en el nuevo sistema existen carencias importantes que debieran ser corregidas.

En las ramificaciones procesales, básicamente lo que se debe observar es la existencia de reglas que regulen la forma de incorporar esta información en el proceso y el rol que ella cumple en las decisiones que se adoptan en su desarrollo. Como ya he señalado, un problema de la LRPA sobre el punto el la falta de definiciones claras en esta materia, las que lamentablemente tampoco han sido objeto de desarrollo a nivel de la doctrina nacional o de la jurisprudencia de los tribunales superiores.

\section{Tercer eje: herramientas para contar con una política amplia de diversificación de respuestas y desestimación de casos en el sistema chileno.}

Un tercer eje en donde el derecho a un juzgamiento especializado tiene un impacto directo es en el establecimiento como elemento orientador del sistema de la idea que se debe evitar al máximo el contacto de los jóvenes con el mismo. La legislación internacional tiene una importante regulación en la materia por la que se exige a los sistemas de responsabilidad de los jóvenes infractores establecer un conjunto de mecanismos que permitan la posibilidad de implementar políticas amplias de remisión (diversión y desestimación) de los casos antes que ingresen al proceso judicial formal $y$, en el evento que lo hagan, establecer facultades amplias a las diversas autoridades para poder prescindir de la persecución de responsabilidad de dichas infracciones. ${ }^{176}$

\footnotetext{
${ }^{175}$ Véase supra nota a pie de página 10.

${ }^{176}$ DUCE, “El Derecho a un Juzgamiento”, cit. nota no 3, pp. 112-120.
} 
DUCE, MAURICIO. "El Derecho a un Juzgamiento Especializado de los Jóvenes Infractores en el Nuevo Proceso Penal Juvenil Chileno".

Para efectos de ver cómo estas ideas han sido recogidas en nuestra legislación y jurisprudencia dividiré mi presentación en las dos principales categorías de desestimación o remisión de casos que se estructuran sobre el momento en que se producen (antes o después de la intervención judicial) y de las características de la remisión (con o sin condiciones).

\subsection{Remisión o desestimación no condicionada previa a la intervención judicial.}

Una primera hipótesis en donde es posible analizar la existencia de reglas especiales en nuestra legislación se refiere a situaciones en las que existe la posibilidad de los distintos actores del sistema que tienen un primer contacto con el caso (normalmente la policía o los fiscales del Ministerio Público) de desestimarlo antes que se decida iniciar un proceso formal (por medio de la formalización de la investigación o un requerimiento según sea el caso) de persecución de la responsabilidad del joven infractor sin que exista ninguna condición asociada a tal desestimación. Se trata de una facultad asociada a la lógica de evaluación político criminal acerca de la inconveniencia de llevar adelante una persecución en una hipótesis en donde ella pueda provocar más daños que efectos positivos para el joven. ${ }^{177}$

El principal mecanismo regulado en la LRPA es el principio de oportunidad contenido en su artículo 35. Esta disposición hace aplicable al proceso penal juvenil la misma facultad que disponen los fiscales tratándose del sistema de adultos (artículo 170 del CPP). Es decir, le permite no iniciar o poner término a la persecución penal cuando se trate de hechos que no comprometan gravemente el interés público, en la medida que no sean delitos cometidos por un funcionario público en el ejercicio de sus funciones o que la pena establecida en la ley para los mismos supere en su mínimo al presidio o reclusión menor en su grado mínimo. ${ }^{178}$ En consecuencia, se trata de una facultad que no constituye una novedad en nuestra legislación ya que está prevista hace años en la normativa procesal penal de adultos.

No obstante lo anterior, el artículo 35 de la LRPA agrega dos particularidades específicas del principio de oportunidad para el sistema juvenil. Por una parte, señala que para su aplicación “...los fiscales tendrán en especial consideración la incidencia que su decisión podría tener en la vida futura del adolescente imputado". Con esto se pone un énfasis en el tipo de consideraciones que debiera considerar el fiscal al momento de decidir el ejercicio del principio de oportunidad. Allí en donde en materia de adultos las consideraciones de carácter político criminal acerca de utilizar o no esta facultad podrían estar centradas en la víctima o intereses sociales generales, la LRPA parece poner un claro acento en el bienestar del joven imputado. Desde este punto de vista me parece que la respectiva norma se orienta en el sentido de los principios contemplados en el sistema internacional. Una segunda particularidad de la LRPA dice con el ámbito de aplicación de la oportunidad. Por el límite

\footnotetext{
${ }^{177}$ Se trata de casos en que existiría la posibilidad concreta de llevar adelante la persecución penal en contra del adolescente imputado. No considero para los efectos del presente análisis las hipótesis en las que un fiscal puede desestimar casos debido a la falta de antecedentes para llevar adelante la persecución penal o porque el hecho denunciado no sea constitutivo de delito. En ese caso dichas facultades no se asocian al "principio de especialidad" en análisis ya que son aplicables a todo tipo de personas sin ninguna distinción.

${ }^{178}$ Un análisis más detallado acerca del principio de oportunidad en el CPP puede verse en DUCE / RIEGO, Proceso, cit. nota ${ }^{\circ} 17$, pp. 212-216; y HORVITZ / LÓPEZ, cit. nota $n^{\circ} 17$ pp. 487 a 489.
} 
de pena establecido en el CPP el principio de oportunidad en general se aplica a delitos de muy baja gravedad (entre ellos las faltas) y en casos excepcionales a otras figuras que podrían considerarse como de gravedad mediana. El inciso segundo del artículo 35 de la LRPA amplía este límite al señalar que para su cálculo debe considerarse como base la pena resultante luego de la aplicación del artículo 21 de la LRPA. Según éste, la pena correspondiente a los jóvenes infractores es la inferior en un grado al mínimo establecido en la ley para el ilícito correspondiente. Esto se traduce en un aumento importante de los casos que pueden ser objeto de principio de oportunidad en el sistema de la LRPA. ${ }^{179}$

Estas particularidades de la LRPA en materia de aplicación del principio de oportunidad se reflejan en un mayor uso porcentual que éste tiene en relación a los adultos. Así, el año 2008 el principio de oportunidad representó el 11,3\% de los términos en el sistema de adultos y un $27 \%$ en el caso de los jóvenes, es decir, se utilizó más del doble. ${ }^{180} \mathrm{El}$ año 2009 representó el $8,84 \%$ de los términos en el sistema de adultos y un $18,08 \%$ en el sistema de la LRPA. ${ }^{181} \mathrm{Si}$ bien se produce una baja respecto al año anterior, también representa un porcentaje que supera el doble de su utilización para el sistema de adultos.

En consecuencia, pareciera que las particularidades establecidas en el artículo 35 de la LRPA, especialmente en su inciso segundo, han cumplido con el objetivo de ampliar en la práctica el margen para el uso de este mecanismo. Por otra parte, en la observación de audiencias se pudo constatar que en los pocos casos en donde el imputado llegaba detenido y se solicitaba de parte de los fiscales aplicar el criterio de oportunidad éste obedecía centralmente a la corta edad de los jóvenes (14 o 15 años), a la escasa gravedad del delito (por ejemplo hurtos falta) y a que se trababa de "una primera pasada por el sistema". ${ }^{182}$ En buena medida estos criterios muestran una preocupación por el impacto de la persecución penal en el joven que sería consistente que el criterio especial incluido en el inciso primero del artículo 35.

No obstante estos resultados, existe una crítica desde la doctrina nacional acerca de la poca amplitud o timidez que habría tenido el legislador al regular el principio de oportunidad ${ }^{183}$ $\mathrm{y}$, en general, frente a la falta de otros mecanismos de desestimación temprana del caso. ${ }^{184}$ En buena medida estos comentarios se fundan en que varios anteproyectos de la LRPA y posteriormente en el proyecto original, se contemplaban mecanismos más amplios de desestimación temprana de los casos que luego desaparecieron durante la tramitación legislativa de la ley. En efecto, en este último se contemplaba una norma más amplia de principio de oportunidad que no contenía los límites del artículo 170 del CPP y que permitía al fiscal considerar también como un criterio no sólo el impacto para la vida futura

\footnotetext{
${ }^{179}$ En este mismo sentido CERDA / CERDA, cit. nota $\mathrm{n}^{\mathrm{o}}$ 12, p. 177.

${ }^{180}$ Véase Ministerio Público, Boletín estadístico año 2008, pp. 138 y 12 respectivamente.

${ }^{181}$ Véase Ministerio Público, Boletín estadístico año 2009, pp. 48 y 19 respectivamente

${ }^{182}$ Véase por ejemplo Audiencia en caso RIT 342-09 del $7^{\circ}$ Juzgado de Garantía de Santiago de 16 de enero de 2009; Audiencia en caso RIT 1049-09 del $2^{\circ}$ Juzgado de Garantía de Santiago (2º de 23 de enero de 2009; y, Audiencia causa RUC 0900072965-2 ${ }^{\circ}$ del $9^{\circ}$ Juzgado de Garantía de Santiago de 23 de enero de 2009.

${ }_{183}$ En este sentido BUSTOS, Derecho Penal, cit. nota ${ }^{\circ} 11$, p. 78.

${ }^{184}$ En este sentido CERDA / CERDA, cit. nota $n^{\circ} 12$, pp. 176-177.
} 


\section{DUCE, MAURICIO. "El Derecho a un Juzgamiento Especializado de los} Jóvenes Infractores en el Nuevo Proceso Penal Juvenil Chileno".

sino que la mejor resolución del conflicto. ${ }^{185}$ Además de esto, en los anteproyectos se establecía que en caso que el fiscal decidiera llevar adelante la persecución penal, el juez podía constituir un filtro adicional en la primera audiencia ya que podía denegar la continuación del procedimiento en varias hipótesis: (a) si consideraba que los antecedentes del fiscal eran insuficientes para la continuación del procedimiento; (b) si consideraba que el procedimiento no era conveniente debido a la escasa relevancia del hecho; (c) si evaluaba que concurrían circunstancias de extinción de la responsabilidad penal; y, (d) si es que había una reparación o promesa de reparación satisfactoria para la víctima. ${ }^{186}$

Como se puede apreciar, se trataba de propuestas que iban bastante más allá de lo que en definitiva recogió la LRPA y que contemplaban mecanismos diversos a los establecidos en la legislación procesal penal de adultos. Con todo, esta limitación de mecanismos pareciera no haber constituido un obstáculo insalvable para un ejercicio intenso de la desestimación temprana por vía de la aplicación del principio de oportunidad.

\subsection{Remisión o desestimación condicionadas (antes o después de la intervención judicial).}

Una segunda hipótesis en la que resulta posible identificar normas especiales en nuestra legislación procesal se refiere a lo que propiamente se denomina "remisión" de casos. Es decir, los casos en que se decide, aún antes de iniciar un procedimiento formal, no llevar el caso adelante pero enviándolo algún tipo de servicio sustitutorio o a alguna medida para el tratamiento del joven infractor. En esta segunda hipótesis las autoridades encargadas de decidir si se lleva adelante la persecución formal de la infracción prefieren un sistema alternativo de resolución del conflicto al sistema judicial formal que podría implicar algún tipo de restricción de derechos del joven imputado.

En nuestro ordenamiento jurídico las dos instituciones principales en la materia son la suspensión condicional del procedimiento y los acuerdos reparatorios. En ambos casos se trata de figuras reguladas en el CPP y en las que la LRPA no contiene disposiciones específicas $^{187}$ y que se hacen operativas una vez producida la intervención de un juez de garantía. En consecuencia, en principio su aplicación al sistema procesal juvenil queda sujeto a las mismas regulaciones que para adultos. A pesar de esto, al insertarse estas salidas alternativas en el sistema juvenil se presentan algunos cambios en relación al uso que se da de las mismas respecto al sistema de adultos que a continuación revisaré. ${ }^{188}$

\footnotetext{
${ }^{185}$ Esto estaba regulado en el artículo 56 que señala en su inciso primero lo siguiente: “Artículo 56.- Principio de oportunidad. Los fiscales del ministerio público podrán no iniciar la persecución de la responsabilidad penal de un adolescente o abandonar la ya iniciada, cuando consideren que ello resulta conveniente para la mejor solución del conflicto jurídico-penal o para la vida futura del imputado." Véase Historia de la Ley ${ }^{\circ}$ 20.084 , p. 28.

${ }^{186}$ Véase DUCE, “El Proceso", cit. nota n 12, p. 107.

${ }^{187}$ Como veré un poco más adelante, en el proyecto de ley original sí existían reglas específicas en materia de acuerdos reparatorios que luego desaparecieron en el texto finalmente aprobado en el Congreso.

${ }^{188}$ Un análisis general de la justificación dogmática de estas instituciones y sus principales efectos en relación al sistema de responsabilidad juvenil en nuestro país puede verse en MORALES, Ana María, "Las Salidas Alternativas y las Sanciones no Privativas de Libertad de Reparación del Daño y Servicios en Beneficio de la Comunidad en el Subsistema de Responsabilidad Penal de Adolescentes Infractores de la Ley Penal", Santiago: Revista de Estudios de la Justicia, n 7 (2006), pp. 159-182. En dicho trabajo la autora presenta reservas respecto a la utilización de estas instituciones que podrían cumplir funciones sancionatorias sin que
} 


\subsubsection{La suspensión condicional del procedimiento en el sistema de la LRPA.}

Respecto a la suspensión condicional del procedimiento me parece se han presentado tres debates específicos respecto de su aplicación en el ámbito de la nueva justicia juvenil. El primero de ellos, el más simple de resolver en mi opinión, se refiere a los casos en que podría proceder la suspensión condicional. De acuerdo al artículo 237 a) del CPP se exige que para que proceda esta salida alternativa es necesario que en el caso de condenarse la pena a imponer no supere los tres años de privación de libertad. Llevado esto al ámbito juvenil una primera cuestión a resolver es si se debe considerar para los jóvenes la norma de rebaja de penas establecida en el artículo 21 de la LRPA. Al exigir el artículo 237 a) una pena en concreto me parece claro que eso incluye obviamente la aplicación del artículo 21 de la LRPA. ${ }^{189}$ El efecto de esto es que la suspensión condicional del procedimiento se amplía a casos en que normalmente, por las penas en juego, sería difícil que un adulto pudiera beneficiarse (esto sin considerar la conveniencia político criminal de utilizar esta medida en dichos casos). ${ }^{190}$

Vinculado con este punto, podrían existir dudas acerca de la aplicación de la suspensión condicional en casos en que los jóvenes imputados arriesguen penas superiores a tres años pero que no sean privativas de libertad (por ejemplo una libertad vigilada especial). La lógica indicaría que el límite del CPP no concurre en este tipo de situaciones. En esta misma dirección se ha pronunciado la escasa doctrina en la materia ${ }^{191}$ y ello me parece es la interpretación correcta en el punto.

Esta mayor amplitud de la suspensión condicional del procedimiento en su aplicación al sistema de responsabilidad penal adolescente se refleja en el funcionamiento empírico del sistema. Así, los datos del Ministerio Público muestran que el uso de esta institución en el sistema de la LRPA casi duplica el porcentaje de uso del sistema de adultos. Así, el año 2008, el 8,7\% del total de términos del sistema de adultos fue por uso de esta institución, allí donde en el sistema juvenil representó el 17\%. ${ }^{192}$ Durante el 2009 esta cifra subió a un $12,3 \%$ de los términos del sistema de adultos y a un $21 \%$ en el sistema de la LRPA. ${ }^{193}$ Estas cifras dan cuenta claramente de la relevancia de esta salida alternativa en el funcionamiento del sistema.

se haya determinado la culpabilidad de los responsables. En detalle sobre los fundamentos y regulación legal contenida en el CPP véase, en DUCE / RIEGO, Proceso, cit. nota 17, pp. 283-354.

${ }^{189}$ No parece haber discrepancia en la doctrina nacional sobre este punto. Así, véase MORALES, cit. nota $\mathrm{n}^{\circ}$ 188, p. 172 y Véase CERDA / CERDA, cit. nota ${ }^{\circ} 12$, p. 180.

${ }^{190}$ Un ejemplo de esto son los casos de robo con violencia o intimidación simples contenidos en el artículo 436 del Código Penal. La pena en abstracto en estos delitos se inicia en presidio mayor en su grado mínimo, es decir cinco años y un día de privación de libertad. La aplicación del artículo 21 de la LRPA hace que la pena de inicio sea presidio menor en su grado máximo, es decir tres años y un día. Con esto la posibilidad en concreto de llegar al máximo de tres es más frecuente que en los adultos. Así, en la observación de audiencias se pudo constatar dos casos en que dicha situación ocurrió. Véase Audiencia RIT 102-2009 del 7 de enero de 2009 del $13^{\circ}$ Juzgado de Garantía de Santiago en una causa por robo con intimidación y Audiencia RIT 180009 del 27 de enero de 2009 del $7^{\circ}$ Juzgado de Garantía de Santiago en causa por robo con intimidación.

${ }^{191}$ Véase CERDA / CERDA, cit. nota ${ }^{\circ} 12$, p. 180.

${ }^{192}$ Ministerio Público, Boletín Estadístico Anual año 2008, pp. 12 y 138 respectivamente.

${ }^{193}$ Ministerio Público, Boletín Estadístico Anual año 2009, pp. 19 y 48 respectivamente. 
DUCE, MAURICIO. "El Derecho a un Juzgamiento Especializado de los Jóvenes Infractores en el Nuevo Proceso Penal Juvenil Chileno".

En la observación de audiencias se pudo constatar que la suspensión condicional es frecuentemente utilizada en la primera audiencia del caso (se pudo ver 47 audiencias en que esto ocurrió así). Respecto al contenido de las condiciones impuestas, en la gran mayoría de los casos éstas incluyeron aspectos más bien formales de control como la fijación de domicilio, la prohibición de ingreso al local o tienda donde se había producido el delito (en delitos contra la propiedad) y la obligación de firmar con cierta periodicidad ante alguna autoridad. Sólo en casos excepcionales se pudo constatar la imposición de condiciones más sustantivas tales como invertir una cantidad de horas en trabajo en beneficios de la comunidad. ${ }^{194}$

Un segundo debate que ha existido respecto a la aplicabilidad de la suspensión condicional del procedimiento al sistema de la LRPA dice relación con la extensión del período de suspensión. De acuerdo al artículo 237 inciso sexto del CPP establece que el plazo de suspensión no debe ser inferior a un año ni superior a tres. La crítica en este punto se ha dirigido a la excesiva duración de estos plazos, especialmente considerando la duración de las sanciones que arriesgan los jóvenes en el contexto de la LRPA tratándose de delitos de mediana o baja gravedad. ${ }^{195}$ A ello habría que agregar el significado de un plazo tan amplio como el máximo de tres años para un joven de 14 o 15. Es decir, el hecho que claramente este sistema de plazos no está pensado para la realidad de la delincuencia juvenil. En este sentido, la Corte Suprema ha propuesto modificar el mínimo del plazo de suspensión de un año a seis meses para hacer más coherente la LRPA con el sistema. ${ }^{196}$ Me parece se trata de una propuesta acertada. El hecho que la LRPA no recoja una norma especial en este punto limita el uso de la suspensión condicional en casos en que el plazo mínimo resulta claramente poco proporcional con la sanción que la misma infracción tendría en el evento que se dictara una condena. Por otra parte, fuerza a acordar suspensiones con muy poco contenido sustantivo respecto a las condiciones que se acuerdan debido precisamente al problema anterior de proporcionalidad.

En la observación de audiencias se pudo constatar que el plazo de suspensión que se utilizó prácticamente en todos los casos fue el del mínimo establecido en el CPP, es decir de un año. Sólo en un caso excepcional este plazo fue de 24 meses. ${ }^{197}$

Finalmente, un tercer aspecto de funcionamiento de la suspensión condicional del procedimiento en el ámbito juvenil en nuestro país en donde se ha producido algún debate vinculado al "principio de especialidad" tiene que ver con las exigencias para asegurar la voluntariedad en el sentido que ya he discutido previamente a propósito de la sección destinada a la renuncia de derechos por parte de los adolescentes imputados. ${ }^{198}$ En esta materia específica, se ha señalado la necesidad de intensificar los controles del juez de la renuncia del joven de su derecho al juicio oral y demás garantías y fortalecer el rol de la

\footnotetext{
${ }^{194}$ Por ejemplo en las audiencias RIT 492-2009 del 4 Juzgado de Garantía de Santiago, RIT 303-2009 del $13^{\circ}$ Juzgado de Garantía de Santiago y RIT 351-2009 del 14 Juzgado de Garantía de Santiago, todas del 13 de enero de 2009.

${ }^{195}$ En este sentido véase CERDA / CERDA, cit. nota $\mathrm{n}^{\circ} 12$, p. 181.

${ }^{196}$ Véase Corte Suprema, AD-6001-2009, pp. 5 y 6, punto 7.

${ }^{197}$ Se trata de la audiencia RIT 102-2009 del $13^{\circ}$ Juzgado de Garantía de Santiago de 7 de enero de 2009. Se trataba eso si de un caso de robo con intimidación que fue recalificado como robo por sorpresa por el fiscal.

${ }^{198}$ Véase supra 1.4.
} 
Polit. crim. Vol. 5, № 10 (Diciembre 2010), Art. 1, pp. 280-340.

[http://www.politicacriminal.cl/Vol_05/n_10/Vol5N10A1.pdf]

defensoría en la entrega de información para la toma de decisiones del adolescente, tratando de evitar de esta forma que se llegue a decisiones de este tipo por consideraciones puramente eficientistas. ${ }^{199}$

En la observación de audiencias se pudo apreciar que en todos los casos en que se decreto una suspensión los jóvenes comparecieron con asistencia de un abogado y en muchas ocasiones acompañados de un adulto responsable. Además, se pudo percibir una preocupación especial de los jueces por explicar a los jóvenes imputados los alcances y consecuencias de las suspensiones condicionales del procedimiento, lo que permite concluir que aparentemente hay una mayor conciencia sobre la necesidad de hacer esfuerzos adicionales de información tratándose de jóvenes imputados que respecto a los adultos. ${ }^{200}$

\subsubsection{Los acuerdos reparatorios en el sistema de la LRPA.}

Los acuerdos reparatorios representan otra de las salidas alternativas que por aplicación del sistema de adultos se hace extensible también al sistema de la LRPA. A diferencia de lo que ocurre con la suspensión condicional del procedimiento, se trata de un tema en el que sí existía una propuesta especial en el proyecto de LRPA presentado por el Poder Ejecutivo al Congreso. En dicha propuesta se hacía un ampliación muy significativa de los casos en que los acuerdos eran procedentes ya que no se establecían límites, allí donde en virtud del artículo 241 del CPP estos son sólo procedentes en el sistema de adultos cuando los casos se refieran a hechos que afecten bienes jurídicos disponible de carácter patrimonial, fueren lesiones menos graves o constituyeren delitos culposos. ${ }^{201}$

Ya durante la tramitación en la Cámara de Diputados (Cámara de origen) se produjo un debate intenso acerca de la amplitud de esta norma y de los riesgos representaba en términos de potencial impunidad para delitos graves. ${ }^{202}$ De esta forma, el proyecto aprobado por la Cámara restringió su aplicación a varias categorías de hechos. ${ }^{203}$

\footnotetext{
${ }^{199}$ Véase MORALES, cit. nota ${ }^{\circ} 188$, p. 174.

${ }^{200}$ Ejemplo paradigmáticos de este mayor esfuerzo pudieron ser percibidos en las siguientes audiencias: RIT 209-2009 del $9^{\circ}$ Juzgado de Garantía de Santiago de 8 de enero de 2009;RIT 492-2009 del $4^{\circ}$ Juzgado de Garantía de Santiago de 13 de enero de 2009; RIT 303-2009 del 13 Juzgado de Garantía de Santiago de 13 de enero de 2009; y, RIT 496-2009 del 15 de enero de 2009.

${ }^{201}$ El artículo 58 del proyecto de ley establecía: "Artículo 58.- Acuerdo reparatorio. En los procesos de que trata la presente ley regirán los acuerdos reparatorios establecidos en el artículo 241 del Código Procesal Penal. En todo caso, no tendrá lugar la limitación establecida en el inciso segundo de dicha disposición, como tampoco su inciso tercero en lo que dice relación con aquél" Véase, Historia de la Ley n ${ }^{\circ}$ 20.084, p. 28.

${ }^{202}$ Los debates comenzaron a partir del Primer Informe de la Cámara de Diputados. Véase Historia de Historia de la Ley $\mathrm{n}^{\circ} 20.084$, p. 145 a 151

${ }^{203}$ De esta forma el artículo 58 pasó a ser artículo 57 con el siguiente contenido: "Artículo 57- Acuerdos reparatorios. El imputado y la víctima podrán llegar a acuerdos reparatorios, los que el juez de garantía conocerá en audiencia a la que citará a los intervinientes para escuchar sus planteamientos. Siempre que fuere posible, el imputado comparecerá con sus padres o, en su defecto, con quien lo tuviere a su cuidado, a objeto que éstos colaboren con la generación del acuerdo y posibiliten su posterior cumplimiento.

En la audiencia, el juez podrá aprobar o rechazar el acuerdo reparatorio, para lo que deberá considerar las siguientes circunstancias:

a) Si los interesados han concurrido a prestar su consentimiento en forma libre y con pleno conocimiento de sus derechos;

b) Que el delito no sea de aquéllos a que se refieren las letras a), b), c),d), e),f) y g) del artículo $7^{\circ}$, y
} 
DUCE, MAURICIO. "El Derecho a un Juzgamiento Especializado de los Jóvenes Infractores en el Nuevo Proceso Penal Juvenil Chileno".

Finalmente, en la tramitación en el Senado la norma desaparece debido a consideraciones en la misma línea de aquellas que habían llevado a restringir la propuesta inicial. Así en el segundo Informe de la Comisión de Constitución del Senado se señaló que:

"Hubo coincidencia entre los miembros de la Comisión en cuanto a la conveniencia de aplicar, en materia de acuerdos reparatorios relativos a los adolescentes, los mismos criterios que los posibilitan en relación a los adultos. Con este propósito, resolvió desechar esta disposición." 204

No obstante la limitación que tuvo la regulación originalmente propuesta en la materia que se tradujo en mantener el acuerdo reparatorio con un diseño idéntico al establecido para los adultos en el CPP, las estadísticas del Ministerio Público dan cuenta que se trata de una salida alternativa que se utiliza con mucha más frecuencia tratándose de jóvenes imputados que de adultos. En efecto, en el año 2008 los acuerdos reparatorios representaron el 1,4\% del total de términos aplicados en el sistema de adultos, cifra que se eleva a un $2 \%$ en el sistema juvenil, es decir un uso mayor cercano al 50\%. ${ }^{205}$ En el año 2009 esta cifra se incrementa. Así, esta salida representó un 1,41\% del total de términos aplicados para adultos y un 2,22\% para los jóvenes (uso un poco superior al 50\%). ${ }^{206}$ En consecuencia, pareciera que más allá de los límites legales establecidos en el CPP, se tiende a consolidar una práctica que favorece la utilización de este mecanismo en el sistema juvenil. Desafortunadamente, no hay mayor información acerca de cómo se desarrolla esta práctica que me permita profundizar este hallazgo.

\subsubsection{Remisión al momento de aplicar penas.}

Junto con las salidas alternativas, nuestro legislador optó por establecer también un sistema de remisión de casos una vez que ha sido establecida la responsabilidad del joven en el hecho imputado. En estricto rigor, se trata de instituciones que nos sacan del análisis procesal que hago en este trabajo y que, por lo mismo, no voy a desarrollar en detalle. Con todo, me interesa mencionarlas de forma que el lector pueda tener un panorama completo de nuestra legislación en la materia.

Se trata básicamente de dos instituciones. La primera de ellas está contenida en el artículo 41 de la LRPA y se refiere a la posibilidad de suspender la ejecución de la pena y sus efectos por un plazo de seis meses cuando un joven hubiera sido condenado por un delito cuya pena privativa o restrictiva de libertad no excediere de 540 días. Para ello se requiere que el juez considere que concurren antecedentes favorables en favor del condenado que

\footnotetext{
c) Que las obligaciones que haya contraído el imputado en el acuerdo satisfagan el interés de la víctima y conlleven un efecto educativo en el infractor. Asimismo, verificará el compromiso manifestado por los padres del imputado o de quienes lo tengan bajo su cuidado.

El Ministerio Público y la Defensoría Penal Pública procurarán disponer de equipos especializados destinados a mediar entre la víctima y el imputado para favorecer estos acuerdos." Véase de Historia de la Ley n ${ }^{\circ} 20.084$, p. 393.

${ }^{204}$ Véase Segundo Informe de la Comisión de Constitución del Senado en Historia de la Ley $\mathrm{n}^{\mathrm{o}} 20.084$, p. 746.

${ }^{205}$ Ministerio Público, Boletín Estadístico Anual año 2008, p. 12 y 138 respectivamente.

${ }^{206}$ Ministerio Público, Boletín Estadístico Anual año 2009, p. 19 y 48 respectivamente.
} 
hacen desaconsejable la imposición de la pena. El efecto de esta media es que transcurrido los seis meses de suspensión sin que el joven sea objeto de persecución penal en un nuevo caso, el tribunal debe dejar sin efecto la sentencia condenatoria y dictar en su reemplazo el sobreseimiento definitivo del caso. ${ }^{207}$

Se puede observar la similitud con la suspensión condicional del procedimiento. Incluso se podría sostener que ofrece un tratamiento mas beneficioso para el condenado que la salida alternativa debido al período de condicionalidad inferior (seis meses versus un año mínimo). La principal diferencia es el momento procesal en que opera, el cual supone en principio una condena. Por otra parte, cabe señalar que no se trata de una institución que sea una completa novedad de la LRPA ya que en el sistema de adultos se encuentra contemplada una facultad muy similar para los jueces en el artículo 398 del CPP. La principal diferencia es que en adultos sólo se aplica tratándose de condenas por faltas. En consecuencia, la novedad de la LRPA en la materia es la ampliación significativa que se hace del ámbito de aplicación de la misma.

Un segundo mecanismo, aún cuando un poco más alejado de la lógica que reviso en esta sección, está constituido por la sustitución de la condena en virtud del artículo 53 de la LRPA. De acuerdo a esta disposición, el tribunal encargado de la ejecución de la pena podría en cualquier momento, de oficio o a petición del adolescente, sustituirla por una menos gravosa en la medida en que esto parezca favorable para la reintegración del joven. Si bien se puede observar un cierto efecto de remisión, este se produce una vez iniciada la ejecución de la pena y no reemplaza del todo a la misma, sino busca utilizar una más idónea para el caso concreto.

Frente a la nula regulación de instituciones procesales de remisión de casos específicas para el sistema juvenil, me parece que nuestro legislador compensó dicha situación con estas dos instituciones. Esto da cuenta de una cierta desconfianza de contar con una política de "remisión" de casos muy agresiva a nivel legislativo durante el desarrollo del proceso y una cierta voluntad de compensar esta situación una vez establecida la condena del joven infractor.

\section{Conclusiones.}

La introducción de la LRPA en nuestro país ha significado un cambio profundo en el tratamiento de los jóvenes infractores. Con todo, como he podido revisar a lo largo de este trabajo, todavía se está bastante lejos de contener un sistema que reconozca y haya desarrollado en profundidad los elementos de especialidad procesal que requeriría un sistema de responsabilidad juvenil de acuerdo a los estándares desarrollados por el derecho internacional de los derechos humanos (y en algunos casos en el derecho comparado).

\footnotetext{
207 En las audiencias observadas se pudo constatar un uso relativamente frecuente de esta facultad de suspensión de casos. Véase como ejemplo audiencias RIT 82-2009 de 5 de enero de 2009 en donde se suspende la aplicación de la pena de amonestación y audiencia RIT 253-2009 de 13 de enero de 2009 en donde se suspende la ejecución de la pena de trabajo en beneficio de la comunidad.
} 
DUCE, MAURICIO. "El Derecho a un Juzgamiento Especializado de los Jóvenes Infractores en el Nuevo Proceso Penal Juvenil Chileno".

Un primer aspecto que es necesario mencionar se refiere al reconocimiento normativo de estos estándares de especialidad. Como se ha visto, nuestra LRPA contiene una regulación bastante escueta de los temas procesales lo que constituye un primer problema. Debe destacarse eso sí que en algunas las materias en donde la LRPA contempla una regulación específica, ello ha significado la introducción de reglas bastante potentes incluso considerando el contexto comparado (como por ejemplo en materia de limitaciones al uso de la internación provisional y de protección del derecho a no autoincriminarse). Con todo, los problemas de falta de reconocimiento de la especialidad del sistema juvenil en el área normativa no es el aspecto que me parece más problemático. Esto debido a que las potenciales carencias de normas y estándares especiales en nuestra legislación se debieran compensar con la existencia de un conjunto de reglas desarrolladas en tratados internacionales de derechos humanos suscritos por nuestro país y que son directamente aplicables.

El área identificada en este trabajo que sí me parece más problemática se refiere más bien a las prácticas a nivel jurisprudencial. Durante el trabajo se ha podido apreciar como los tribunales superiores han ido haciéndose cargo de algunos elementos de especialidad procesal, pero todavía de una manera relativamente incipiente. En general, los principales fallos que invocan elementos de especialidad del sistema juvenil lo hacen basándose en reglas bastante explícitas de la LRPA de forma tal que las decisiones judiciales tienden a ser aplicación relativamente formalista de las mismas sin una reflexión más profunda de los valores que se pretenden recoger con dichas reglas, lo que deja un vacío importante respecto a las orientaciones que debieran guiar la solución de casos futuros más complejos. Por otra parte, en varios casos en donde hay compromiso de garantías del debido proceso, nuestros tribunales superiores no son capaces de identificar con precisión las garantías específicas comprometidas y, por lo mismo, razonar de conformidad a la lógica que imponen las mismas (esto sin perjuicio que en muchos casos las decisiones parecen resolver adecuadamente el problema). Finalmente, en este escenario tampoco existe un uso intenso de la normativa y jurisprudencia internacional en la materia, sino sólo para hacer referencias muchas veces extremadamente genéricas. Todo lo anterior impide que se haya desarrollado un cuerpo de razonamientos claros que permitan ir profundizando el significado y alcances de las reglas especiales contenidas en la LRPA en materia procesal.

Algo similar ocurre con la observación de audiencias realizadas en juzgados de garantía. Si bien -como he sostenido con anterioridad- la investigación no ha pretendido tener una visión representativa de la práctica de todos los jueces de garantía debido al foco de lo observado, sí me parece haber detectado una heterogeneidad muy importante en la aplicación de criterios por parte de los mismos. Esto se traduce nuevamente en falta de claridad acerca del significado y alcances de los estándares especiales que se deben aplicar.

Me parece que las causas que explican la situación descrita son diversas y complejas. Por de pronto, no me parece que todas ellas sean de responsabilidad de los jueces, sino que en una medida importante también emanan de la poca colaboración (básicamente por defectos de argumentación) que tienen de los propios litigantes (fiscales y defensores) en el desarrollo de estándares más especializados y de una doctrina nacional que es francamente pobre en la materia. Esto me lleva a preguntar si en el fondo de este problema no hay 
Polit. crim. Vol. 5, № 10 (Diciembre 2010), Art. 1, pp. 280-340.

[http://www.politicacriminal.cl/Vol_05/n_10/Vol5N10A1.pdf]

defectos a nivel de diseño institucional en el sistema. El primero de ellos tiene que ver con la falta de una especialización mayor del mismo. Como es sabido, el legislador optó por un sistema de especialización funcional que en la práctica es muy morigerado por la forma en que las distintas instituciones del sistema gestionan sus recursos humanos. Esto impide asegurar que se contará con actores efectivamente especializados en cada audiencia y llevando cada caso (me refiere tanto a jueces, defensores y fiscales). En este sentido, me parece que la falta de especialización del sistema debiera tener un poder explicativo muy poderoso de buena parte de las prácticas detectadas en este trabajo.

En segundo término, me parece que otro problema de fondo se refiere a la falta de un modelo claro respecto a la orientación que debiera tener el sistema entre los distintos actores. Por ejemplo, no me parece esté suficientemente asentado ni menos consensuado cuánto el sistema debiera reproducir la dinámica adversarial del sistema de adultos o debiera más bien estructurarse de una lógica distinta de colaboración entre los distintos intervinientes. Esta cierta ambigüedad se paga con prácticas que son muy heterogéneas y en algunos casos producen consecuencias negativas para los jóvenes. Se trata de un tema en donde más que poner el acento solamente en la práctica jurisprudencial, nuestra sociedad debiera tener una propuesta de diseño institucional un tanto más sofisticada.

Como se puede apreciar, los desafíos para nuestro país en el asentamiento de un sistema especializado en el procesamiento de casos para determinar la responsabilidad de jóvenes infractores son todavía enormes. Estos pasan no sólo por un desarrollo más sofisticado a nivel jurídico sino que también en la necesidad de pensar con cuidado varios aspectos del diseño y el modelo que subyacen a nuestra LRPA. En este contexto, el trabajo ha pretendido ser un primer aporte desde el punto de vista de mejoramiento de nuestro conocimiento jurídico en la materia.

\section{BIBLIOGRAFÍA}

Libros, Capítulos de Libros y Artículos Académicos:

BERRÍOS, Gonzalo, "Derecho de los Adolescentes y Actividad Persecutoria Previa al Control Judicial de la Detención”, Santiago: Revista de Estudios de la Justicia, no 7 (2006), pp. 121-157.

BUSTOS, Juan, Derecho Penal del Niño-Adolescente, Santiago: Ediciones Jurídicas de Santiago, 2007.

CERDA, Rodrigo, Manual del Nuevo Sistema de Justicia Criminal, Santiago: Librotecnia, 2005.

CERDA, Mónica; CERDA, Rodrigo, Sistema de Responsabilidad Penal para Adolescentes, Santiago: Librotecnia, 2007.

CHAHUÁN, Sabas, Manual del Nuevo Procedimiento Penal, Santiago: Lexis Nexis, 2007, pp. 220-221; CASTRO, Javier, Introducción al Derecho Procesal Penal Chileno, Santiago, Legal Publishing, 2008. 
DUCE, MAURICIO. "El Derecho a un Juzgamiento Especializado de los Jóvenes Infractores en el Nuevo Proceso Penal Juvenil Chileno".

CILLERO, Miguel; ESPEJO, Nicolás, "Derechos de los Adolescentes Privados de Libertad en Chile: En Busca de la Tutela Judicial Efectiva", en Revista General de Derecho Penal Iustel, $\mathrm{n}^{\mathrm{o}} 9$ (2008), 12 pp.

CRUZ, Beatriz, Educación y Prevención General en el Derecho Penal de Menores, Barcelona: Marcial Pons, 2006.

DUCE, Mauricio, "El Derecho a un Juzgamiento Especializado de los Jóvenes Infractores en el Derecho Internacional de los Derechos Humanos y su Impacto en el Diseño del Proceso Penal Juvenil", Ius et Praxis, no 1 (2009), pp. 73-120.

DUCE, Mauricio, "El Proceso Establecido en el Proyecto de Ley que Crea un Sistema de Responsabilidad de los Adolescentes por Infracciones a la Ley Penal: Avances y Problemas", Revista de Derechos del Niño, Santiago: nº 2 (2004), pp. 99-113.

DUCE, Mauricio; COUSO SALAS, Jaime, El Derecho a un Juzgamiento Especializado de los Jóvenes Infractores en el Derecho Comparado, Documento no Publicado, disponible en formato electrónico en los archivos del autor.

DUCE, Mauricio; RIEGO, Cristián, Proceso Penal, Santiago: Editorial Jurídica, 2007.

DUCE, Mauricio; RIEGO, Cristián, "La Prisión Preventiva en Chile: El Impacto de la Reforma Procesal Penal y Sus Cambios Posteriores", Prisión Preventiva y Reforma Procesal Penal en América Latina: Evaluación y Perspectivas, Santiago: Centro de Estudios de Justicia de las Américas, pp. 151-212.

ESTRADA, Francisco "La Renuncia al Derecho a Guardar Silencio por un Adolescente en Nuestro Ordenamiento y en el Estadounidense: Comentario a Propósito del Fallo In re E.T.C”, Revista de Derechos del Niño números 3 y 4 (2006), pp. 181-196.

FUENZALIDA, Iván, "Regulación y Efectos de las Anotaciones Prontuariales de los adolescentes”, Santiago: Revista jurídica del Ministerio Público, nº 35, julio (2008), pp. $321-335$.

GARCÍA-MÉNDEZ, Emilio; BELOFF, Mary (compiladores), Infancia Ley y Democracia en América Latina Tomo I, Bogotá: Temis, 2004.

HORVITZ, María Inés; LÓPEZ, Julián, Derecho Procesal Penal Chileno, Tomo I, Santiago: Editorial Jurídica de Chile, 2002.

MAIER, Derecho Procesal Penal Tomo I, Buenos aires: Editores del Puerto, 1996.

MARÍN, Felipe, ¿Puede Condenarse a un Adolescente a Penas Privativas de Libertad en un Procedimiento Abreviado?, 5 pp., documento no publicado en poder del autor.

MERINO, Guillermo Felipe, "Comentario a la Resolución que no Decreta Cautelares del art. 155 del Código Procesal Penal, por Hechos Ocurridos al Interior del Centro Semicerrado de Limache", Revista Jurídica del Ministerio Público, Santiago: no 39, Junio (2009), pp. 244-246.

MONTERO, Jorge, La Prisión Preventiva ¿Es una Medida Cautelar de Carácter Excepcional?, Santiago: Trabajo de Seminario I, Facultad de Derecho Universidad Diego Portales, 2010, Marzo (disponible en la biblioteca de la misma Facultad).

MORALES, Ana María, "Las Salidas Alternativas y las Sanciones no Privativas de Libertad de Reparación del Daño y Servicios en Beneficio de la Comunidad en el Subsistema de Responsabilidad Penal de Adolescentes Infractores de la Ley Penal", Santiago: Revista de Estudios de la Justicia, no 7 (2006), pp. 159-182.

OBERG, Héctor, "Ley de Responsabilidad Penal Juvenil”, Revista Actualidad Jurídica, no 15 (2007, Enero), Universidad del Desarrollo, pp. 181 -189. 
Polit. crim. Vol. 5, № 10 (Diciembre 2010), Art. 1, pp. 280-340.

[http://www.politicacriminal.cl/Vol_05/n_10/Vol5N10A1.pdf]

SALAS ASTRAIN, Jaime, Problemas del Proceso Penal, Santiago: Librotecnia, 2009.

SOTO, Elizabeth; NAREA, Juan Andrés, Responsabilidad Penal Adolescente y su Nuevo Ordenamiento Jurídico, Santiago: Editorial Jurídica Congreso, 2007.

Otros Documentos:

AHUMADA, Alejandra; FARREN, Diego; WILLIAMSON, Bernardita, Encuesta de Opinión de Jueces: Evaluación de las Medidas Cautelares y Otros Temas Relacionados, Santiago: Fundación Paz Ciudadana, 2009, en: http://www.pazciudadana.cl/docs/pub_20100310181248.pdf [visitado el 05.04.2010]

BERRÍOS, Gonzalo, Jóvenes Presos: La Otra "Cota Mil”, Santiago: La Tercera, Miércoles 25 de Febrero de 2009, p 2.

Centro de Derechos Humanos, Informe Anual sobre Derechos Humanos en Chile 2008, Santiago: Facultad de Derecho Universidad Diego Portales, 2009.

Centro de Derechos Humanos, Informe Anual sobre Derechos Humanos en Chile 2009, Santiago: Facultad de Derecho Universidad Diego Portales, 2010.

Comité de Derechos del Niño Observación General n ${ }^{\circ} 10$ (2007).

Corte Suprema, AD-601-2009, de 21 de Octubre de 2009.

CORTÉS, Julio; ESTRADA, Francisco, Sobre la Inaplicabilidad de la Ley que crea el Sistema Nacional de Registros de ADN en el Sistema Penal de Adolescentes, Diciembre de 2008, 3 pp., documento en formato electrónico disponible en el archivo del autor.

Defensoría Penal Pública, Memoria Anual 2008, Santiago: 2009.

Defensoría Penal Pública, Informe Estadístico de Primer año de Vigencia Ley de Responsabilidad Penal Adolescente (8 de junio 2007 a 7 junio de 2008), pp.1-123, p. 8, en: http://www.defensoriapenal.cl/Documentos/estadisticas/2009/INFORMEPRIMER-ANO-RPA.pdf [visitado el 06.06.2010].

Fiscalía Nacional, Oficio $n^{0} 511$ Instructivo ${ }^{\circ} 7$ de la Ley 20.084, de 23 de abril de 2007.

Fiscalía Nacional Oficio $n^{0} 714$ Instructivo $n^{\circ} 14$ de la ley $n^{\circ} 20.084$ de 29 de mayo de 2007.

Historia de la Ley $\mathrm{n}^{\mathrm{o}} 20.084$ en www.ben.cl.

Ministerio Público, Boletín Estadístico Anual año 2008.

Ministerio Público, Boletín Estadístico Anual año 2009. 